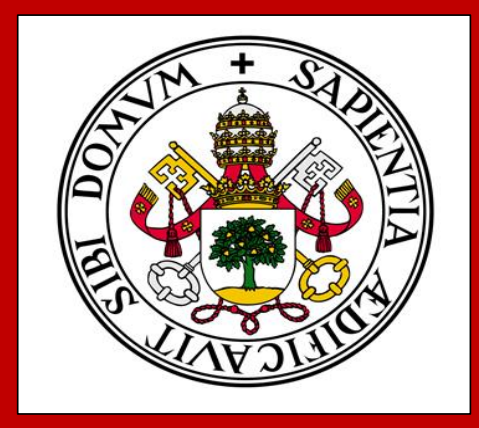

Universidad de Valladolid

Facultad de Medicina

\title{
ESTUDIO DEL PERFIL GINECOLÓGICO DE PACIENTES PORTADORAS DE VARICES ESENCIALES
}

MEMORIA PARA OPTAR AL GRADO DE DOCTORA Doctoranda

María Azpeitia Rodríguez

Director

Prof. Carlos Vaquero Puerta 

Universidad deValladolid

PROGRAMA DE DOCTORADO EN INVESTIGACIÓN EN CIENCIAS DE LA SALUD

TESIS DOCTORAL:

\title{
ESTUDIO DEL PERFIL GINECOLÓGICO DE PACIENTES PORTADORAS DE VARICES ESENCIALES
}

\author{
Presentada por \\ María Azpeitia Rodríguez \\ para optar al grado de \\ Doctora por la Universidad de Valladolid
}

Dirigida por:

Prof. Carlos Vaquero Puerta

Catedrático de Angiología y Cirugía Vascular 

"El sentido de la vida está en vivir cada día tal como se presenta."

\section{Anthony Hopkins}

"El hombre no sabe de lo que es capaz hasta que lo intenta"

\section{Charles Dickens}

"Sabemos lo que somos pero no lo que podemos llegar a ser" William Shakespeare 



\section{DEDICATORIA}

A Pablo y a Elisa 



\section{AGRADECIMIENTOS}

A Pablo, por ayúdame siempre de forma incondicional y creer en mí.

Al Prof. Carlos Vaquero Puerta, por su paciencia, dedicación y apoyo no solo durante el desarrollo la tesis sino durante toda mi carrera profesional.

A la Dra. Lourdes del Río Solá, por su ayuda y dedicación durante la realización de la tesis.

A mis padres, por quererme tal y como soy.

A Cristina, Charly, Carlitos y Ginebra por hacerme ver la vida siempre desde el lado más optimista.

A Elpidio y Yolanda por su disposición siempre a ayudarnos. 

Esta tesis doctoral es el resultado de un trabajo conjunto y colaboración entre el Servicio de Angiología y Cirugía Vascular del Hospital Clínico Universitario de Valladolid y el Servicio de Ginecología y Obstetricia del Hospital Universitario Río Hortega, bajo la dirección del Dr. Carlos Vaquero Puerta.

Valladolid, Marzo 2018.

El presente trabajo forma parte de una línea de investigación sobre Insuficiencia Venosa Crónica y patología Varicosa que se desarrolla en el Servicio de Angiología y Cirugía Vascular del Hospital Clínico Universitario de Valladolid. 

ÍNDICE 

1. RESUMEN 15

$\begin{array}{ll}1.1 \text { Resumen } & 17\end{array}$

$\begin{array}{ll}1.2 \text { Abstract } & 20\end{array}$

2. INTRODUCCIÓN 23

2.1 Concepto de insuficiencia venosa crónica 25

2.2 Anatomía del sistema venoso 26

2.3 Fisiología del sistema venoso 33

2.4 Etiopatogenia de las varices 36

$\begin{array}{ll}2.5 \text { Clínica de la insuficiencia venosa crónica } & 37\end{array}$

2.6 Epidemiologia de la insuficiencia venosa crónica 42

2.7 Diagnóstico de enfermedad venosa crónica $\quad 55$

2.8 Tratamiento de las varices 58

3. HIPÓTESIS 63

3.1 Justificación del trabajo $\quad 65$

3.2 Hipótesis 66

4. OBJETIVOS 67

4.1 Objetivo principal $\quad 69$

4.2 Objetivos secundarios $\quad 69$

5. MATERIAL Y METODOS 71

5.1 Ámbito de estudio 73

$\begin{array}{ll}5.2 \text { Pacientes } & 73\end{array}$

5.3 Criterios de inclusión y exclusión $\quad 75$

5.4 Variables analizadas $\quad 75$

5.5 Definición de términos $\quad 77$

5.6 Análisis estadístico 83 
6. RESULTADOS

6.1 Características generales de las pacientes con insuficiencia venosa crónica

6.2 Características analíticas y hormonales de las pacientes con insuficiencia venosa crónica

6.3 Perfil ginecológico de las pacientes con insuficiencia venosa crónica 96

6.4 Descripción de las características principales de la insuficiencia venosa crónica

98

6.5 Factores de riesgo para el desarrollo de insuficiencia venosa crónica

7. DISCUSIÓN

7.1 Perfil general de las pacientes con insuficiencia venosa crónica

7.2 Perfil analítico y hormonal de las pacientes con insuficiencia venosa crónica

7.3 Perfil ginecológico de las pacientes con insuficiencia venosa crónica

7.4 Perfil clínico de la insuficiencia venosa crónica

7.5 Fortalezas del estudio

8. CONCLUSIONES

9. BIBLIOGRAFÍA

10. ANEXO

10.1 Listado de acrónimos 


\section{RESUMEN}





\section{Resumen}

\subsection{RESUMEN}

\section{INTODUCCIÓN}

Las varices son dilataciones permanentes del sistema venoso superficial, afectando predominantemente a los miembros inferiores, que conllevan alteraciones estructurales de la pared del vaso, destrucción valvular y cambios de la hemodinámica del sistema venoso. La incidencia y prevalencia de la insuficiencia venosa crónica en España se puede considerar muy alta, sin embargo, no es fácil conocer los datos exactos puesto que hay pocos estudios al respecto.

La encuesta epidemiológica DETECT-IVC (2000) concluyó que el 68,6\% de los pacientes que acude a la consulta del Médico de Familia presenta algún síntoma y/o signo de insuficiencia venosa crónica; no obstante, algunos problemas metodológicos nos hacen ser cautelosos ante tales resultados pues es probable que estén magnificados. El DETECT-IVC (2006) encuentra un $71 \%$ de pacientes con algún dato clínico de insuficiencia venosa crónica, fundamentalmente varículas (53\%) y varices (35\%), y hasta un $2 \%$ úlceras cutáneas. La enfermedad es más frecuente en mujeres (64\%) que en hombres (36\%) y la edad media es de 52,3 años. Entre los factores de riesgo clásicos, presentes en un $82 \%$ de los casos en el sexo femenino, destacan los embarazos, el sedentarismo, los antecedentes familiares y el sobrepeso, mientras que en el sexo masculino, el factor de riesgo más relevante es la obesidad.

La diferencia de prevalencia entre hombres y mujeres se justifica en base a factores hormonales, situaciones ginecológicas, hábitos de la mujer, obesidad y otras características ligadas a este sexo

No obstante no existen estudios concluyentes ni datos concretos que oferten una información fiable y exacta que relacione la aparición y desarrollo de las varices y la historia ginecológica de la mujer. Parece muy interesante el desarrollo de un estudio prospectivo que aporte información sobre esta patología y la relación con la historia ginecológica de la mujer y otros datos relativos a las características de las pacientes.

El objetivo es analizar la historia ginecológica de las pacientes con insuficiencia venosa crónica. 


\section{Resumen}

\section{MATERIAL Y MÉTODOS}

Se diseña un estudio prospectivo en el cual se recogieron datos de pacientes del sexo femenino que se remitieron a la consulta externa del Servicio de Angiología y Cirugía Vascular (ACV) del Hospital Clínico Universitario de Valladolid para valoración del síndrome varicoso de extremidades inferiores, las cuales constituyeron el grupo caso $(n=503)$. El grupo control, estuvo constituido por pacientes mujeres que acudieron a la Consulta de ACV por un motivo diferente al de patología venosa.

Para ello por cada paciente evaluada se rellenó un cuestionario en el que recogieron datos descriptivos en relación con antecedentes personales (edad, situación laboral, antecedentes personales, antecedentes familiares), antecedentes ginecológicos (edad de la menarquia, menopausia, número de embarazos e hijos, tratamiento hormonal sustitutivo) y características de la enfermedad venosa crónica (flebitis previa, estadio de la CEAP, sintomatología, localización, tratamiento profiláctico con terapia compresiva y antecedentes quirúrgicos de cirugía del síndrome varicosos). Por otra parte se valoraron datos analíticos en aspectos bioquímicos, citológícos, de coagulación y parámetros hormonales, para detectar posibles diferencias entre ambos grupos.

Para realizar el análisis de los datos, primero se efectuó un análisis descriptivo de las principales variables en ambos grupos para estudiar la homogeneidad de los mismos. Y a continuación se realizó un análisis univariante, para estudiar las diferencias estadísticamente significativas que existen en ambos grupos en relación con los antecedentes personales y los antecedentes ginecológicos.

\section{RESULTADOS}

Las principales características de la insuficiencia venosa crónica fueron la presencia de varices tronculares (75.9\%) sobre venas reticulares y teleangiectasias, los estadios C1-C2 de la clasificación CEAP (97.4\%) y la localización bilateral en un 88.9\%.

La localización más frecuente fue la vena safena interna (30.8\%) y la forma clínica más frecuentemente presentada fue la pesadez de piernas (72.2\%), si bien hasta un $14.7 \%$ de las pacientes se encontraban asintomáticas y el motivo de consulta fue puramente estético. Solamente un 33.4\% utilizaban terapia compresiva con medias elásticas, y la tasa antecedentes de cirugía varicosa previa en el momento de la consulta fue de un $20.3 \%$. 


\section{Resumen}

Las pacientes con insuficiencia venosa crónica presentaron una edad media de $47.7 \pm 13.1$ años, sin diferencias significativas con el grupo control (44.7 \pm 12.2 años, $\mathrm{p}=0.082$ ).

Tampoco se objetivaron diferencias estadísticamente significativas en relación con el tipo de situación laboral asociada a bipedestación (19.2\% vs $16.8 \%, p=0.542)$ ni a la sedestación ( $11.6 \%$ vs $13.9 \%, p=0.41)$, ni en la prevalencia de obesidad $(8.7 \%$ vs $7.5 \%$, $p=0.67)$.

Sin embargo la situación fue distinta respecto a los antecedentes familiares, donde un $32 \%$ de las pacientes refirieron la presencia de esta patología en algún miembro de la familia frente a un $18.6 \%$ en el grupo control $(p<0.001)$.

Respecto a los factores ginecológicos analizados, las pacientes con patología varicosa presentaron mayor prevalencia de menopausia ( $43.5 \%$ vs $16.5 \%, p<0.001$ ), sin embargo en la edad de presentación no encontramos diferencias ( $49.2 \pm 3.1$ vs $49.26 \pm$ 3 años, $p=0.84$ ). Tampoco se observaron diferencias en la edad de la menarquia.

Si hemos encontrado diferencias tanto en el número de pacientes que refieren alguna gestación en algún momento de su vida ( $82 \%$ vs $59 \%, p<0.001$ ) como en el número de gestaciones por paciente $(2.01 \pm 1.03$ vs $1.63 \pm 0.89, p<0.001)$.

Por último destacamos que en nuestros resultados obtenemos una diferencia estadísticamente significativa $(p<0.001)$ respecto al uso de terapia hormonal. Encontrando un $49.1 \%$ en el grupo de varices frente a un $25.3 \%$ en grupo control.

\section{CONCLUSIONES}

Las mujeres con patología varicosa de extremidades inferiores atendidas en nuestro medio se caracterizan por la presencia de mayor tasa de varices en etapa menopaúsica, y haber presentado un mayor número de embarazos e hijos durante su vida. Los principales predictores de desarrollo de síndrome varicoso son la presencia de menopausia, el número de embarazos a término y la terapia hormonal. 


\section{Resumen}

\subsection{ABSTRACT}

\section{INTRODUCTION}

Varicose veins are permanent dilations of the superficial venous system, affecting predominantly the lower limbs, which drive to structural alterations of the vessel wall, valvular destruction and changes in the hemodynamics of the venous system. The incidence and prevalence of chronic venous insufficiency in Spain can be considered very high, however, it is not easy to know the exact data, since there are a few studies regarding this topic

The epidemiological survey DETECT-IVC (2000) concluded that $68.6 \%$ of the patients attending the Family Physician visit have not any symptoms and / or signs of chronic venous insufficiency; However, some methodological problems make us cautious about such results, as they are probably to be magnified.

DETECT-IVC (2006) found $71 \%$ of patients with clinical signs of chronic venous insufficiency, mainly varicose veins (53\%) and varicose veins (35\%), and up to $2 \%$ of cutaneous ulcers. The disease is more frequent in women (64\%) than in men (36\%) and the mean age is 52.3 years. Among the classic risk factors present in $82 \%$ of the cases, in the female sex, pregnancies, sedentarism, family history and overweight are highlighted, whereas in the male sex, the most relevant risk factor is obesity.

The difference in prevalence between men and women is justified on the basis of hormonal factors, gynecological situations, women's habits, obesity and other characteristics related to this sex

However, there are no conclusive studies or specific data that offer reliable and accurate information that relates the appearance and development of varicose veins and gynecological history of women. It seems very interesting the development of a prospective study that provides information about this pathology and the relationship with the gynecological history of the woman and other data related to the characteristics of the patients.

The objective is to analyze the gynecological history of patients with chronic venous insufficiency. 


\section{Resumen}

\section{MATERIAL AND METHODS}

A prospective study was designed in which, data were collected from female patients who were referred to the Outpatient Department of the Angiology and Vascular Surgery Service of the Hospital Clínico Universitario de Valladolid for the evaluation of varicose lower limb syndrome, which Were the case group $(n=503)$. The control group consisted of female patients who came to the ACV consultation for another reason than venous pathology.

For each patient evaluated, a form was filled out in which they collected descriptive data regarding personal history (age, work status, personal history, family history), gynecological history (age of menarche, menopause, number of pregnancies and children, Previous phlebitis, stage of CPAP, symptomatology, localization, prophylactic treatment with compressive therapy and surgical history of surgery of the varicose syndrome). Subsequently to expand the study, analytical data (biochemistry, blood cytology, coagulation and hormonal parameters) were collected to assess the differences between both groups.

To perform the analysis of the data, a descriptive analysis of the main variables in both groups was carried out to study the homogeneity of the data. And a univariate analysis was then performed to study the statistically significant differences that exist in both groups in relation to personal history and gynecological history.

\section{RESULTS}

The main characteristics of chronic venous insufficiency were the presence of truncal varices $(75.9 \%)$ on reticular veins and teleangiectasia, C1-C2 stages of the CEAP classification (97.4\%) and bilateral location in $88.9 \%$. The most frequent location was the internal saphenous vein $(30.8 \%)$ and the most frequently presented clinical form was leg heaviness (72.2\%), although up to $14.7 \%$ of the patients were asymptomatic and the reason for consultation was purely aesthetic. Only $33.4 \%$ used compressive therapy with elastic stockings, and the previous rate of prior varicose surgery at the time of the consultation was $20.3 \%$.

Patients with chronic venous insufficiency had a mean age of $47.7 \pm 13.1$ years, with no significant difference in the control group $(44.7 \pm 12.2$ years, $p=0.082)$. 


\section{Resumen}

There were also statistically significant differences in relation to the type of work situation associated with bipedestation (19.2\% vs $26.5 \%, p=0.027)$ or to sit $(11.6 \%$ vs $13.9 \%, p=0.41)$, nor in the prevalence of obesity ( $8.7 \%$ vs. $7.5 \%, p=0.67)$.

However, the situation was different with respect to the family history, where $32 \%$ of the patients reported the presence of this pathology in some family member compared to $18.6 \%$ in the control group $(p<0.001)$.

Regarding the gynecological factors analyzed, the patients with varicose pathology had a higher prevalence of menopause (43.5\% vs $16.5 \%, p<0.001$ ), however in the age of presentation we did not find differences ( $49.2 \pm 3.1$ vs $49.26 \pm 3$ years, $p=$ $0.84)$. No differences in the age of menarche were observed either.

If we have found differences both in the number of patients who report some pregnancy at some point in their lives $(82 \%$ vs $59 \%, p<0.001)$ and in the number of pregnancies per patient $(2.01 \pm 1.03$ vs $1.63 \pm 0.89, p<0.001)$.

Finally, we emphasize that in our results we obtain a statistically significant difference $(p<0.001)$ regarding the use of hormonal therapy. Finding $49.1 \%$ in the varicose group versus $25.3 \%$ in the control group.

\section{CONCLUSIONS}

Women with varicose pathology of the lower extremities treated in our country are characterized by the presence of a higher rate of varicose veins in the menopausal stage and having presented a higher number of pregnancies and children during their lifetime. The main predictors of development of varicose syndrome are the presence of menopause, number of term pregnancies and hormone replacement therapy. 
2. INTRODUCCIÓN 



\section{Introducción}

\subsection{CONCEPTO DE INSUFICIENCIA VENOSA CRÓNICA}

Las enfermedades varicosas son conocidas desde la antigüedad. En 1550 AC, Ebers ya menciona esta patología como dilataciones en forma de serpiente de las venas. En la tabla Acrópolis del siglo IV AC, podemos visualizar un miembro inferior que muestra una variz. Son múltiples los estudios realizados por Leonardo de Vinci sobre las venas, y aún hoy en día se conservan muchos de sus dibujos que muestran las diferentes estructuras venosas. En 1585, Fabrice d'Acquapendente describió las válvulas venosas. Las diferentes medidas preventivas y de tratamiento también se comenzaron a describir hace siglos con Hipocrates que valora las punciones o compresiones externas como posible medida terapéutica. En 1525, Ambroise Paré describió el vendaje de la pierna para el tratamiento de las úlceras, más adelante en 1854 Unna describirá otro sistema de vendaje que en la actualidad lleva su nombre. En 1676, Wiseman inventó las primeras medias de apoyo de cuero. Respecto a las medidas terapéuticas de tipo quirúrgico, Pravaz en 1860, inventó una jeringa para el tratamiento de las varices y el inicio de la escleroterapia. Frederic von Trendelenburg hace ya un siglo, que descubrió los reflujos en las venas varicosas y realizó las primeras ligaduras de las venas safenas mayores. En 1905 y 1906, Keller y Mayo realizaron la primera ablación de la vena safena mayor. ${ }^{1}$

La insuficiencia venosa crónica (IVC) es un síndrome clínico que agrupa un amplio espectro de manifestaciones con un mecanismo fisiopatológico común; la hipertensión venosa (HTV). En este espectro tenemos tanto las formas más benignas, varices, como los estadios más avanzados de la enfermedad en forma de alteraciones cutáneas y ulceración. 


\section{Introducción}

La forma inicial de presentación de la insuficiencia venosa crónica incluye síntomas y signos más leves, como pueden ser el edema o el desarrollo de varices. Sin embargo, pueden evolucionar a formas graves como pueden ser la celulitis y la pigmentación por estasis y finalmente complicaciones como la lipodermatoesclerosis y la ulceración. ${ }^{2}$

La OMS ha definido a las várices como venas superficiales, cilíndricas o saculares, dilatadas anormalmente, que pueden ser circunscriptas o segmentarias, e incluye a las telangiectasias diminutas así como a las dilataciones amplias de los troncos venosos principales del sistema venoso superficial, safeno interno y externo. ${ }^{3}$

Las venas varicosas pueden aparecer en cualquier parte del cuerpo donde el retorno venoso es débil, pero a menudo la localización más frecuente es en extremidades inferiores.

\subsection{ANATOMÍA DEL SISTEMA VENOSO}

El aparato circulatorio forma parte del sistema cardiovascular, junto o con el sistema linfático. El sistema cardiovascular constituido por el corazón y los vasos sanguíneos es el encargado de transportar nutrientes y oxígeno a los diferentes órganos y de la recogida de las sustancias de desecho de dichos órganos.

Los vasos sanguíneos se dividen en grandes rasgos en arterias, venas y capilares. 


\section{Introducción}

La sangre sale del corazón a través de las arterias de mayor calibre de ahí pasara a otras de menor calibre hasta llegar a las arteriolas (arterias de pequeño tamaño) y de ahí a los capilares, localización donde se producirá el intercambio de gases y nutrientes, para transportar posteriormente a través de vénulas y venas desde los diferentes órganos y tejidos las sustancias de desecho de nuevo al corazón para dirigirse posteriormente a la circulación pulmonar. (Figura 1)

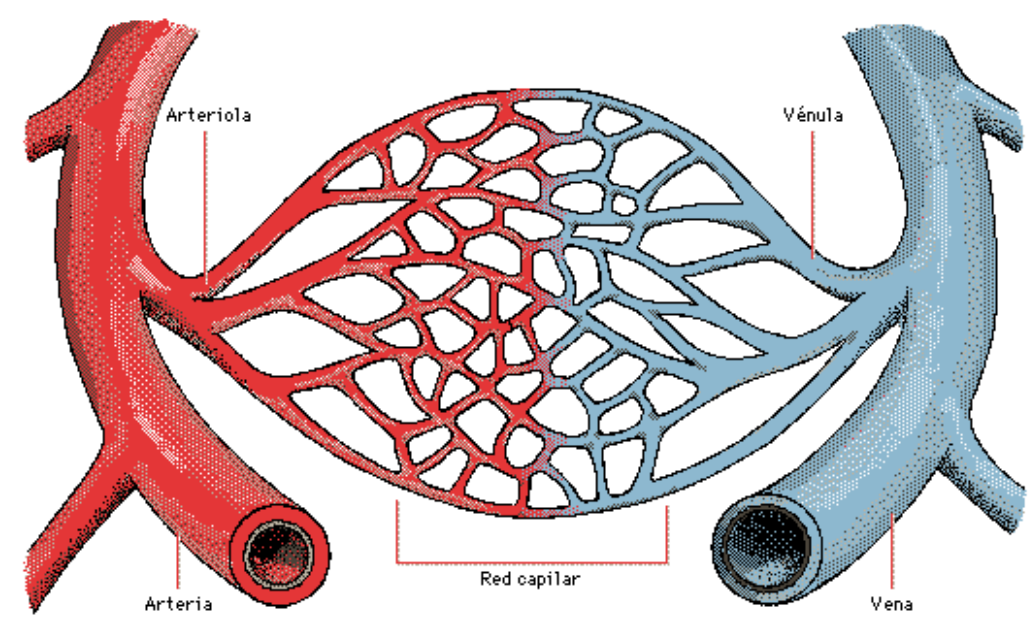

Figura 1: Esquema de la microcirculación

Histológicamente, los vasos sanguíneos están constituidos por tres capas: (Figura 2)

- Túnica íntima: es la capa más interna y está formada por células endoteliales. Los capilares están constituidos tan solo por esta túnica.

- Túnica media: como su propio nombre indica, es la capa media, y se encuentra formada por músculo liso.

- Túnica adventicia: es la capa más externa (túnica externa) y está formada por tejido conectivo, siendo la capa más gruesa de las tres. 


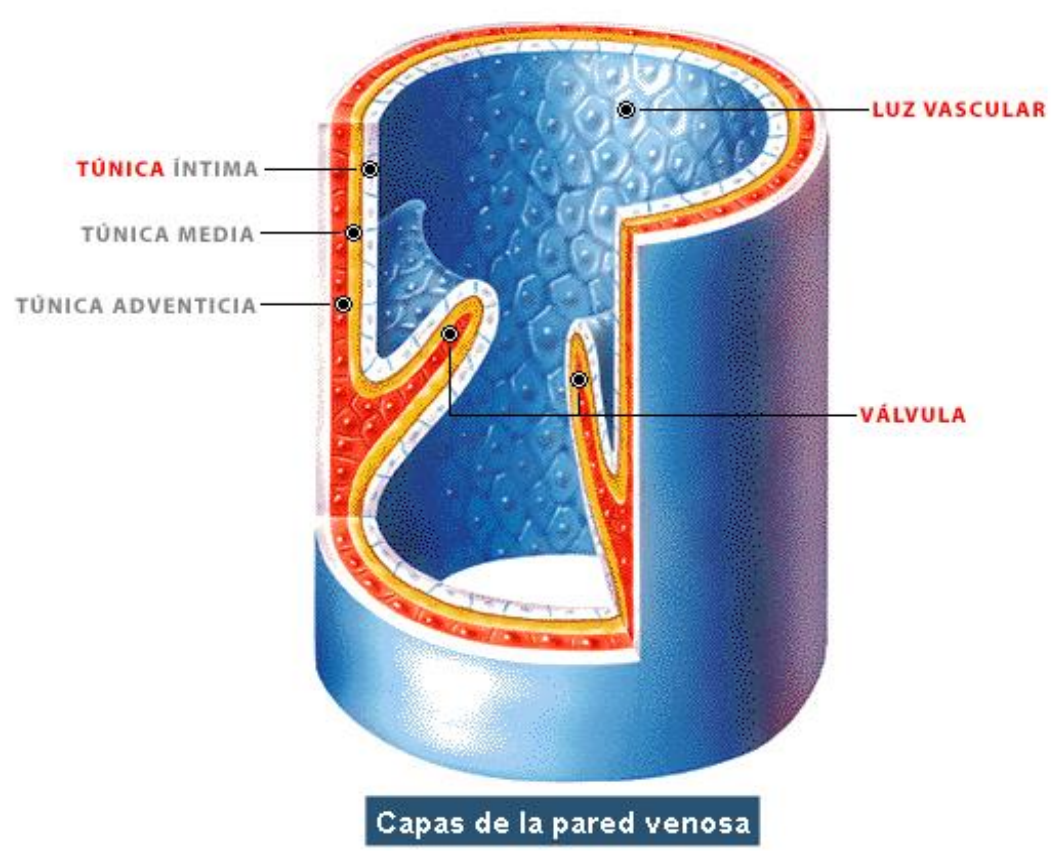

Figura 2: Capas de la pared venosa

Las arterias son los vasos sanguíneos encargados de transportar la sangre desde el corazón a los diferentes tejidos. Esta sangre pasara a arterias cada vez de menor calibre hasta alcanzar los capilares. Los diferentes tipos de arterias se van a distinguir entre sí, no solo por el tamaño de las mismas, sino también por la composición a nivel de la túnica media (cantidad de tejido elástico y de músculo), la relación entre el grosor de la pared y la luz y por su función: (Figura 3)

- Grandes arterias elásticas: Entre las que se encuentra la aorta. Y cuya función principal es la conducción.

- Arterias musculares medias: El componente fundamental son las fibras musculares y se encargan de la distribución sanguínea.

- Arterias pequeñas y arteriolas: El tono del músculo liso de la pared de estas arterias determina en gran medida la hipertensión arterial. 


\section{Introducción}

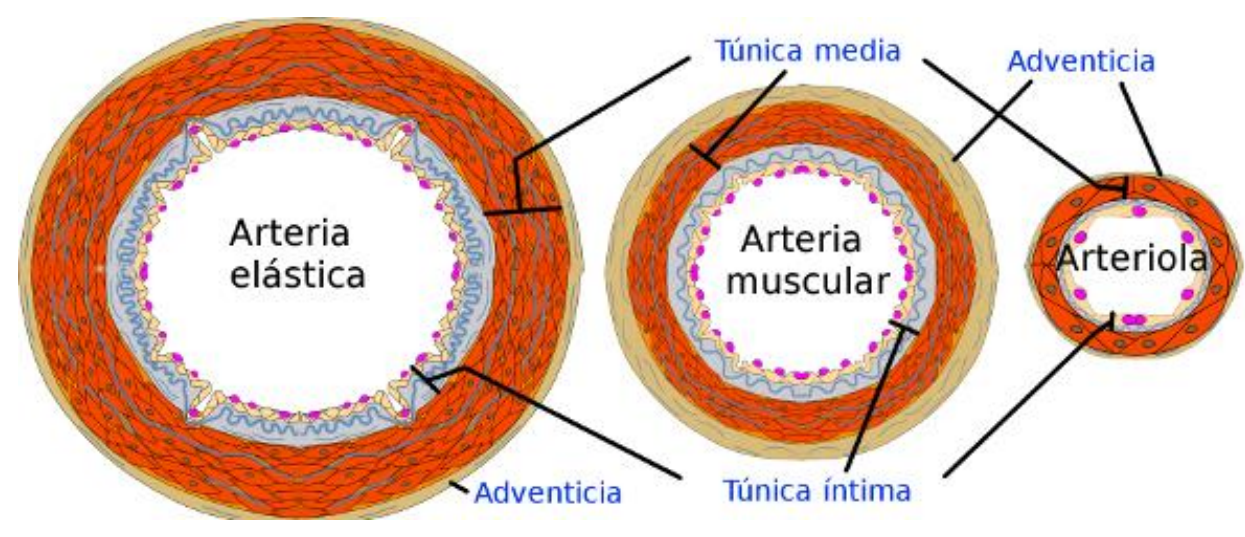

Figura 3: Estructura vascular arterial

Las venas son vasos sanguíneos cuya función fundamental es el transporte de la sangre desoxigenada (sangre venosa) al corazón. Lo que les da un aspecto azul oscuro. Tan solo las grandes venas pulmonares transportan sangre oxigenada.

Existen diferentes tipos de venas según su tamaño:

- Venas grandes: Como la cava. Presentan mayor cantidad de musculo liso y mayor desarrollo de túnica adventicia.

- Venas medias: Drenan los plexos venosos, citados anteriormente y acompañan a las arterias medias. Este tipo de venas en algunas localizaciones como las piernas presentas valvas antirreflujo.

- Vénulas: Son las venas de menor tamaño. Desde estos vasos comienza a retornar la sangre al corazón desde los capilares. Se unen varias entre sí para formar plexos. (Figura 4) 


\section{Introducción}

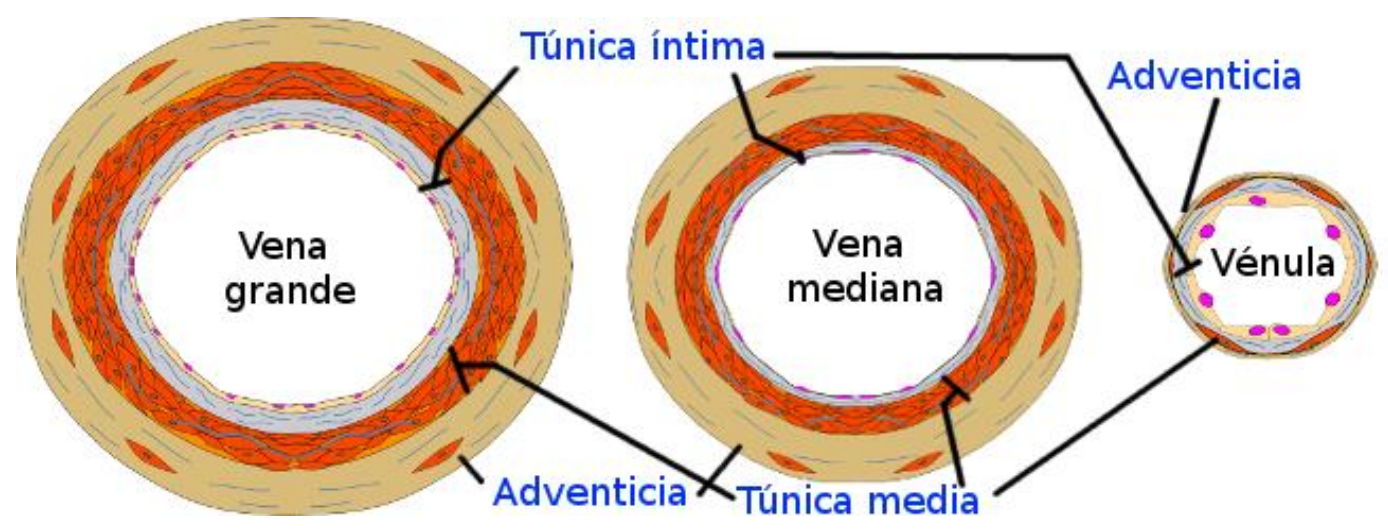

Figura 4: Tipos de venas

Las venas son más numerosas que las arterias y además presentan mayor número de anastomosis. Debido a la baja presión del sistema venoso, a diferencia de las arterias, las venas presentan una pared fina y sin fibras elásticas en su túnica media, lo que les permite una gran capacidad de expansión. Otra diferencia será que las venas no tienen pulso, por lo que ante su lesión no se produce sangre a chorro. ${ }^{4}$

La mayor parte de las venas de nuestro cuerpo, en concreto las de tamaño superior a $1 \mathrm{~mm}$, contienen en su interior unas estructuras denominadas válvulas. Estas válvulas no son más que pliegues de la túnica íntima hacia el interior del vaso, suelen ser bicúspides y su función principal es permitir el flujo unidireccional de sangre, de distal a proximal y de sistema venoso superficial hacia sistema venoso profundo excepto a nivel del pie. De esta forma, la sangre avanza solamente en sentido anterógrado hacia el corazón. Encontraremos mayor número de válvulas en aquellas zonas sometidas a una mayor presión hidrostática. ${ }^{5}$ 


\section{Introducción}

Es remarcable, el hecho de que estas válvulas no existen en "el sistema venoso cerebroespinal", por lo que en esta localización es característico el flujo retrogrado y bidireccional. Probablemente esto sea debido a que el retorno venoso desde esta localización se ve favorecido por el efecto positivo de la gravedad. La sangre pude moverse en una dirección o en otra según las variaciones de postura y presión dentro de la caja torácica y el abdomen regulando así la presión intracraneal. El CSVS proporciona

una ruta directa vascular para la propagación de los tumores, las infecciones o las embolias. ${ }^{6}$

La fisiología del sistema venoso se explicará con más detalle en el apartado correspondiente (2.3 Fisiología).

Las venas están distribuidas por compartimentos de acuerdo a su posición con respecto a la piel y al sistema muscular. Tres son los sistemas vasculares venosos reconocidos:

- Sistema venoso superficial: lo componen las venas situadas entre la piel y la aponeurosis muscular. Su principal misión es transportar la sangre poco oxigenada de la piel y el tejido subcutáneo hacia el sistema venoso profundo.

- Sistema venoso profundo: constituido por las venas de localización subaponeurótica, que circulan entre los músculos estriados, generalmente acompañando a la arteria correspondiente. Es el responsable principal del retorno sanguíneo al corazón, de ahí que se caracterice por un mayor diámetro en sus venas, y una mayor capacidad de distensión que el sistema venoso superficial. El $90 \%$ de la sangre discurre por el sistema venoso profundo y solamente un $10 \%$ por el sistema superficial. ${ }^{7}$ (Figura 5 ) 


\section{Introducción}

- Sistema de perforantes: formado por una red de venas que conectan los dos compartimentos descritos previamente. Su función es permitir la redistribución de flujo de acuerdo a un sistema de presiones. Dentro de las venas perforante encontramos un grupo de mayor importancia respecto al resto, son "las venas perforantes de Cockett" que comunican las venas tibiales posteriores con la vena safena mayor accesoria posterior, drenando indirectamente el sistema venoso profundo.

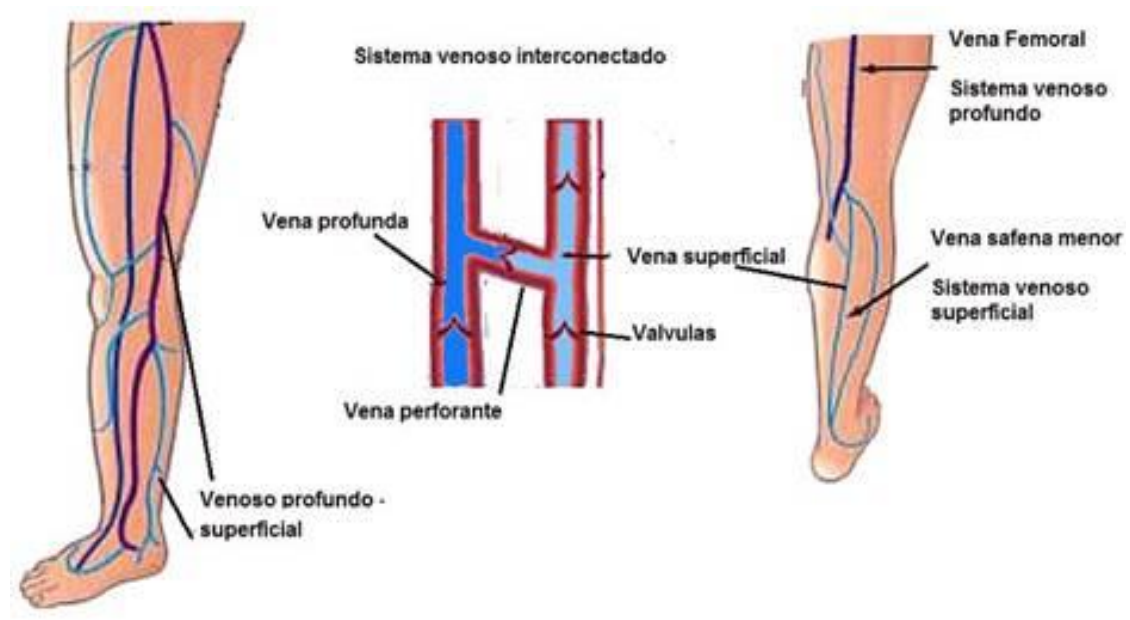

\section{Figura 5: Sistemas venosos Superficial y Profundo}

Como ya hemos comentado anteriormente, las venas varicosas pueden aparecer en cualquier parte del cuerpo donde el retorno venoso es débil, pero a menudo la localización más frecuente es en extremidades inferiores.

El sistema venoso superficial también se conoce como "sistema venoso safeno". Presenta una distribución reticular en las que las pequeñas venas superficiales del pie se van reuniendo hasta finalmente agruparse en única vena: la vena safena mayor. 


\section{Introducción}

- La vena safena mayor o vena safena magna es la vena más larga del cuerpo. Comienza en la vena marginal medial del dorso del pie, asciende por la cara interna de la pierna, continua su ascenso por el muslo hasta el triángulo de Scarpa donde atraviesa la fascia cribiforme y termina desembocando en la vena femoral a nivel de la ingle. En su trayecto recibe sangre de un gran número de venas cutáneas y también se anastomosa con la vena safena menor. Las válvulas en la vena safena magna varían de número entre personas. Aproximadamente existen entre diez y veinte en cada extremidad, siendo más numerosas a nivel de la pierna que en el muslo. ${ }^{8,9}$

- La vena safena menor comienza como continuación de la vena marginal lateral del pie. En su ascenso perforará la fascia profunda para terminar a nivel de la vena poplítea, sin embargo, primero desprende una rama para unirse a la vena safena mayor. El número de válvulas de la vena safena menor también es variable, y aproximadamente presenta entre nueve y doce válvulas, encontrándose la última de ellas en la desembocadura en la vena poplítea. ${ }^{8,9}$

\subsection{FISIOLOGÍA DEL SISTEMA VENOSO}

El sistema venoso es el sistema encargado de trasportar la sangre desde los capilares al corazón. Además, actúa como reservorio de la sangre, ya que almacena la mayor parte del volumen sanguíneo circulatorio. Solo un $20 \%$ de la sangre se encuentra en las arterias, mientras que el $80 \%$ estará distribuido por las venas. De esta forma, puede aumentar o disminuir su capacidad para adaptarse a las necesidades corporales, y regular funciones tan importantes como la temperatura corporal. 


\section{Introducción}

La regulación del flujo sanguíneo depende tanto de factores vasculares como extravasculares.

Por un lado, existen mecanismos generales que controlan la circulación global de sangre a través de la regulación de la función cardiaca y del músculo liso de los vasos sanguíneos. El sistema nervioso y el sistema endocrino son los responsables de esta regulación, actuando de forma sinérgica y complementándose el uno al otro.

Por otro lado, existen mecanismos de carácter local, que se encargan de regular el flujo sanguíneo en cada territorio, adaptándolo a las necesidades propias. ${ }^{10}$

A diferencia del sistema arterial, el sistema venoso es un sistema de bajas presiones (5-10 $\mathrm{mmHg}$ ), por lo que el retorno de la sangre desde los capilares hasta el corazón se ve influenciado por varios factores. ${ }^{11}$

Factores que favorecen el retorno venoso:

- El sistema de válvulas venosas, que impide el flujo retrógado de sangre.

- La presión negativa intratorácica generada en cada ciclo respiratorio durante la respiración.

- El "Vis a tergo" o presión residual traspasada desde el sistema arterial al sistema venoso a través de los capilares.

- La contracción de los sistemas musculares que rodean a las venas. De hecho, la presión venosa a nivel del sistema profundo es mayor que en el sistema superficial debido a la presión que ejerce la contracción muscular (fundamentalmente los músculos gastrocnemius y sóleo a nivel de las extremidades inferiores). La contracción muscular produce el avance de la 


\section{Introducción}

sangre por un fenómeno de "ordeño". El cierre de las válvulas venosas asociado a la contracción muscular impide el flujo retrógrado de sangre, y permite un acúmulo de presión que será transmitido al sistema venoso superficial a través del sistema de venas perforantes. La relajación muscular invierte la relación de presiones y permite el drenaje venoso del sistema superficial en el profundo. ${ }^{12}$

- Generalmente las arterias profundas son acompañadas por dos o más venas denominadas venas satélites. Cuando la arteria se expande durante la contracción del corazón presionará a las venas satélites adyacentes favoreciendo el retorno venoso. ${ }^{13}$

Factores en contra del retorno venoso, y que por tanto, pueden favorecer el desarrollo de síndrome varicoso:

- La gravedad es el principal factor que dificulta el retorno sanguíneo general al corazón. Sin embargo, hay que recordar que a nivel de cabeza y cuello sería un factor favorable al retorno venoso.

- La viscosidad sanguínea dificulta el desplazamiento de la sangre.

- El aumento de la presión torácica o abdominal.

- El "Vis a fronte" que consiste en la resistencia al flujo que opone el circuito corazón - venas. ${ }^{11}$ 


\section{Introducción}

\subsection{ETIOPATOGENIA DE LAS VARICES}

Las varices son el resultado de una alteración del funcionamiento del sistema venoso, ya sea superficial o profundo, con el consiguiente aumento de presión intraluminal y la dilatación de la pared del vaso.

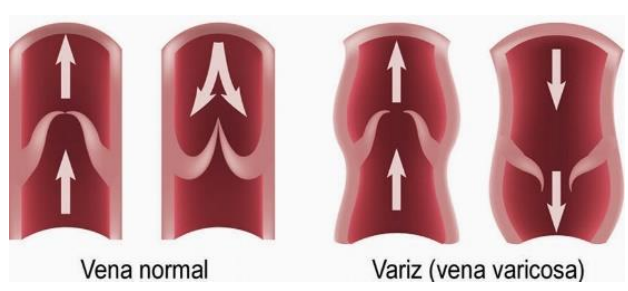

Figura 6: Alteración funcionamiento sistema venoso

Existen varices primarias o secundarias. Las varices primarias están relacionadas con el riesgo potencial del individuo según su historia familiar, edad o sexo y por factores desencadenantes como obesidad, gestaciones, posturales, factores hormonales. Las varices secundarias serán aquellas que se originan como complicación de una trombosis venosa profunda (TVP). ${ }^{14}$ Por lo que será importante preguntar a los pacientes sobre sus antecedentes personales y familiares, en concreto, por la existencia de episodios de TVP para diferenciar las primarias de las secundarias.

El origen de la disfunción a nivel del sistema venoso es controvertido. Por un lado, existe lesión a nivel de la pared venosa, y por otro, también existe lesión a nivel valvular. Sin bien no disponemos de suficiente evidencia científica y existen diferentes teorías para determinar cuál de los dos es el mecanismo inicial, aunque parece lógico pensar que la lesión inicial se produzca a nivel de la pared venosa. 


\section{Introducción}

A nivel parietal, estudios histológicos han mostrado las siguientes alteraciones:

- Aumento desproporcionado del espesor de las túnicas íntima y media en venas varicosas. Esto se produce fundamentalmente a expensas de un incremento del contenido en colágeno, que se acompaña de una disminución del contenido en elastina. Ambos eventos sería independientes de la presencia de insuficiencia valvular. ${ }^{15}$

- Desestructuración de la matriz extracelular.

- Desestructuración de la arquitectura del musculo liso.

- Infiltración por células de tipo inflamatorio como macrófagos.

- Liberación de ciroqueratina. ${ }^{16}$

Parece lógico concluir que, en respuesta a una agresión inicial, se producen una serie de alteraciones a nivel histológico en las tres capas que componen la pared venosa (endotelio, fibras musculares lisas y tejido conectivo).

Estos cambios estructurales provocarán un fallo secundario del funcionamiento con el consiguiente incremento de presión intraluminal, que sería el responsable de la disfunción a nivel valvular. El reflujo venoso perpetuará el incremento de presión venosa, en un círculo vicioso que finalmente condiciona la dilatación, la elongación y la tortuosidad de los vasos venosos que conocemos con el nombre de varices. ${ }^{17}$

\subsection{CLÍNICA DE LA INSUFICIENCIA VENOSA CRÓNICA}

Como ya hemos explicado previamente, la enfermedad venosa crónica es un síndrome clínico caracterizado por un amplio espectro de manifestaciones que incluyen: el edema a nivel de las extremidades, la dilatación venosa y las lesiones cutáneas como la hiperpigmentación, la dermatitis o la úlcera. ${ }^{2}$ 
El edema crónico de las extremidades inferiores debido al linfedema, además de una deformidad estética también supone una situación invalidante. Puede presentar complicaciones graves como infecciones bacterianas y fúngicas, inflamación crónica, y ocasionalmente degeneración maligna. ${ }^{18}$

La clasificación CEAP permite utilizar unos criterios uniformes para la clasificación, el estudio y el tratamiento de cualquier grado de enfermedad venosa crónica. Sus siglas hacen referencia a cada uno de los elementos de la clasificación ${ }^{19,20,}$ 21, 22, 23:

- C: Grado Clínico (CO - C6).

- Clase 0: sin signos visibles o palpables de insuficiencia venosa.

○ Clase 1: telangiectasias, venas reticulares y corona maleolar.

○ Clase 2: venas varicosas.

- Clase 3: edema sin cambios cutáneos.

- Clase 4: cambios cutáneos como la dermatitis ocre, el eccema venoso o la lipodermatoesclerosis.

- Clase 5: cambios cutáneos con úlcera cicatrizada.

○ Clase 6: úlcera activa.

- E: Etiología.

○ Congénita.

- Primaria.

- Secundaria.

- Sin causa identificada. 
- A: Extensión Anatómica.

- Sistema venoso superficial.

- Sistema venoso perforante.

- Sistema venoso profundo.

- Sin identificar.

- P: Patofisiología.

○ Reflujo.

○ Obstrucción.

- Ambos.

○ Sin Identificar.

Como es evidente, estas manifestaciones clínicas no son exclusivas de la enfermedad venosa crónica, y a menudo es preciso realizar un diagnóstico diferencial con otras enfermedades. En este sentido, un aspecto relevante es la localización de las lesiones. Por su fisiopatología es lógico entender que la enfermedad venosa crónica aparezca fundamentalmente en zonas declives, sobre todo en las extremidades inferiores, y más aún en la región perimaleolar.

Las varices son la forma más frecuente de presentación de la EVC superficial, sin embargo, lo más habitual es que se detecten de forma casual y se mantengan silentes durante largos períodos de tiempo.

Los síntomas más frecuentes son el dolor y la quemazón, aunque pueden presentar complicaciones como la varicorragia o la trombosis venosa superficial, e incluso pueden evolucionar a formas más severas del espectro de la insuficiencia venosa crónica. 
En función del tamaño, podemos clasificar las varices ${ }^{24,25}$ :

- Telangiectasias: pequeñas dilataciones a nivel cutáneo menores de $1 \mathrm{~mm}$, también llamadas arañas vasculares. Se vacían a la presión.

- Varículas: De tamaño algo mayor a las anteriores y no se vacían a la presión.

- Dilataciones venosas reticulares: inferiores a $3 \mathrm{~mm}$. Generalmente aparecen en cara externa del muslo, pierna y en hueco poplíteo.

- Varices tronculares: venas dilatadas de diámetro superior a $3 \mathrm{~mm}$. Generalmente producidas por la insuficiencia en alguna de las venas safenas.

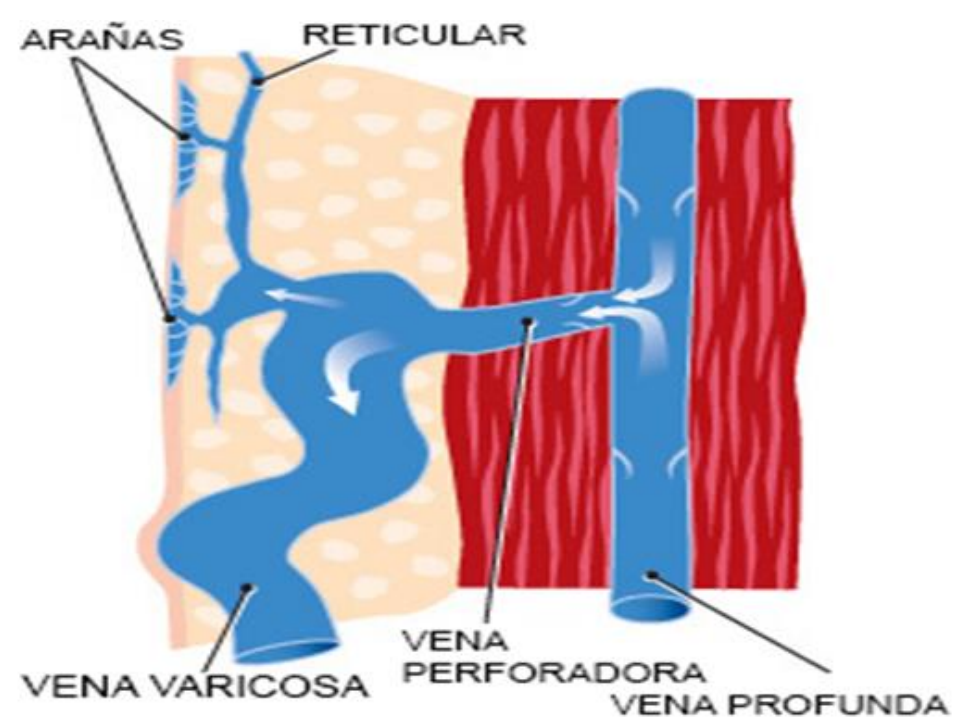

Figura 7: Clasificación de varices según su forma 

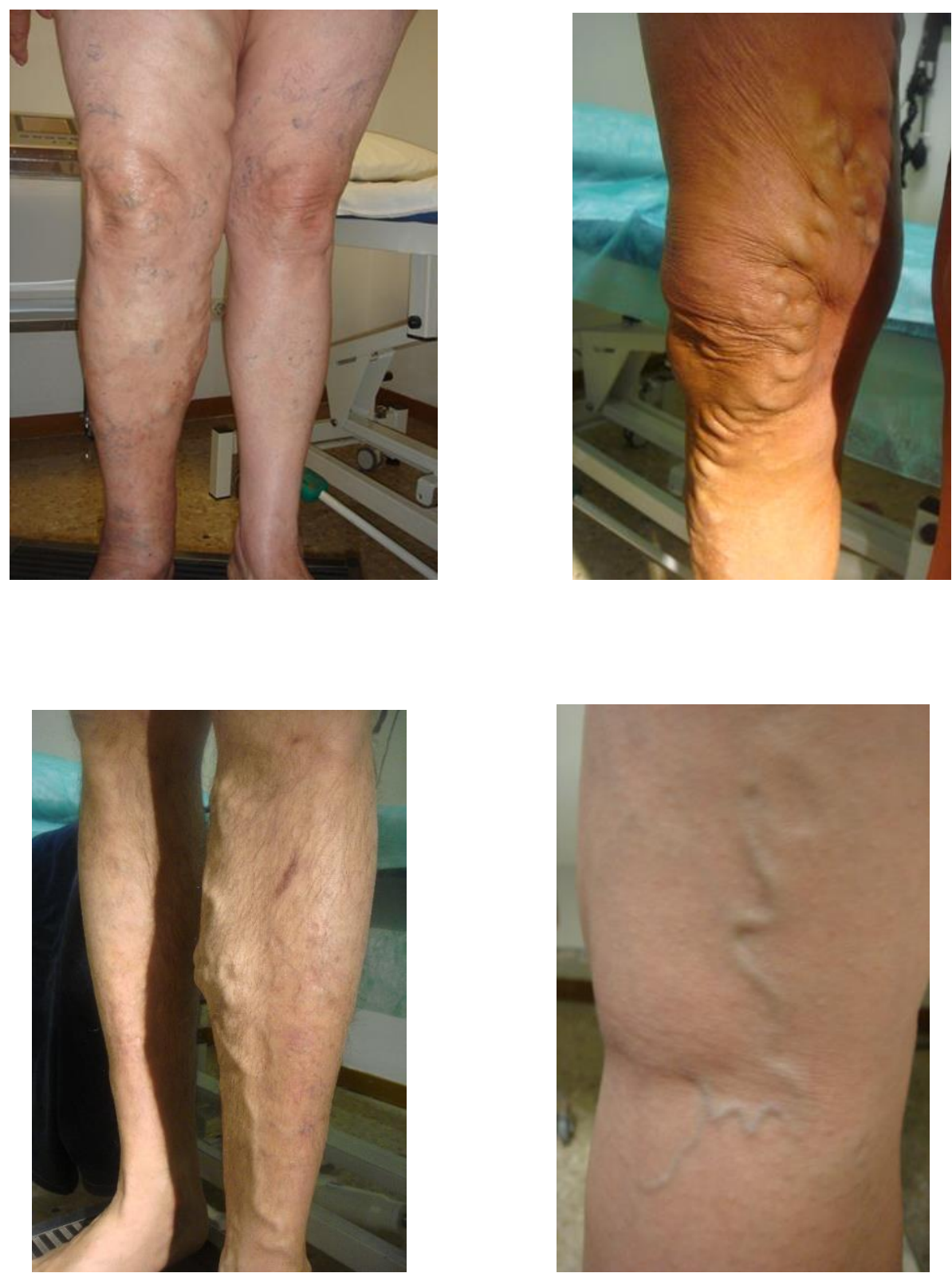

Figura 8: Diferentes grados de varices 


\section{Introducción}

Las varices pueden no solo producir una sintomatología clínica, sino también suponer un impacto emocional tanto por las alteraciones estéticas como por las limitaciones funcionales. Por lo que será necesario conocer al detalle cuales son los factores de riesgo que influirán en su aparición y desarrollo para evitar los factores de riesgo y prevenir las complicaciones. ${ }^{26}$

\subsection{EPIDEMIOLOGÍA DE LA INSUFICIENCIA VENOSA CRÓNICA}

La incidencia de enfermedad vascular está aumentando de forma progresiva y supone la primera causa de muerte y hospitalización en España. ${ }^{27}$ Las varices forman parte de dicho problema no tanto por la gravedad como por la gran cantidad de casos. Su prevalencia y sus complicaciones son un problema emergente ya desde inicios de siglo, tanto por el aumento de la discapacidad que produce en los pacientes, como por el coste del tratamiento. ${ }^{28}$

En las últimas décadas han sido publicados diferentes estudios sobre la epidemiología de la insuficiencia venosa crónica. Se observan variaciones importantes en la cifra de prevalencia de enfermedad venosa crónica que varía entre $<1 \%$ a un $40 \%$ en mujeres y de un $<1 \%$ a un $17 \%$ en varones. Existen diferentes factores que pueden justificar estas diferencias. Por un lado, el propio diseño de los estudios, con diferentes criterios de inclusión que pueden no abarcar todo el espectro de la EVC, teniendo en cuenta tan sólo estadios más avanzados de la enfermedad C3, C4, C5 y C6. ${ }^{2,29}$ 


\section{Introducción}

Por otro lado, las diferentes áreas geográficas y población de estudio también influyen, ya que se sabe que la prevalencia de EVC es mayor en países industrializados y desarrollados que en países subdesarrollados. ${ }^{29}$

En cualquier caso, tanto la incidencia como la prevalencia de EVC en la población se puede considerar muy alta. ${ }^{30,31}$ Concretamente en España, no es fácil conocer los datos exactos. Por un lado, existen pocos estudios realizados con este propósito en nuestra población nacional. Por otro lado, el carácter benigno y asintomático que, a menudo caracteriza a esta enfermedad, justifica tanto un posible número elevado de pacientes sin atención sanitaria, como un manejo íntegro en Centros de Salud por los equipos de Atención Primaria. De ahí que los estudios realizados en Atención Especializada estén sesgados por un tipo de paciente con patología en estados más avanzados. Estos son varios de los motivos por los que la mayoría de los procedimientos tanto quirúrgicos como endovasculares registrados en los centros de Angiología y Cirugía Vascular de nuestro país son por patología arterial. ${ }^{32}$

Los principales estudios realizados en España han sido impulsados desde la Sociedad Española de Angiología y Cirugía Vascular (SEACV) en colaboración con la Sociedad Española de Medicina Familiar Y Comunitaria (SEMFYC) y los Centros de Salud nacionales. En el año 2000 se realizó una encuesta epidemiológica (DETECT-IVC 2000) sobre la prevalencia de la EVC en los servicios de Atención Primaria del territorio nacional. Se incluyó a todos los pacientes que acudían a la consulta, independientemente de que el motivo de consulta fuera vascular o de otro tipo.

Se concluyó que el $68,6 \%$ de los pacientes que acude a la consulta del Médico de Atención Primaria presenta algún síntoma y/o signo de insuficiencia venosa crónica. ${ }^{30}$ 


\section{Introducción}

Sin embargo, los sesgos epidemiológicos son evidentes a la hora de intentar extrapolar estos resultados a la población general.

Más adelante, en el año 2006, se decidió repetir de nuevo esta encuesta poblacional con el fin de comparar los resultados con los del año 2000. EI DETECT-IVC 2006 mostró una prevalencia de EVC del 71\%, ligeramente superior a la encuesta del año 2000. Un 62\% de los pacientes presentaba signos evidentes de la enfermedad; fundamentalmente varículas (53\%) y varices (35\%), y hasta un $2 \%$ úlceras cutáneas. Si bien la edad media de global de los pacientes fue ligeramente superior (52,3 años vs 51,4), no hubo diferencias en la distribución entre sexos, pero sí una marcada mayor prevalencia de la enfermedad en mujeres que en hombres (64\% vs $36 \%$ ). ${ }^{31}$

Estos y otros estudios han permitido identificar una serie de factores que de una forma u otra se asocian con el desarrollo de EVC. Entre estos factores de riesgo destacan la edad, el sexo, la historia familiar, el peso y la actividad física. Según su relación etiopatogénica, estos factores se clasifican de la siguiente manera ${ }^{33}$ :

- Factores primarios: influyen en la aparición y desarrollo de la insuficiencia venosa crónica.

- Factores secundarios: actúan como agravantes del proceso.

\subsubsection{La edad}

La edad es un factor bien conocido asociado a la EVC. Existen estudios que demuestran una asociación significativa entre la edad y un aumento del número de segmentos venosos insuficientes. Sin embargo, esta asociación estadística es incluso más importante entre la edad y el grado de reflujo venoso o la gravedad de la enfermedad evaluada mediante la clasificación CEAP. ${ }^{34}$ 


\section{Introducción}

Todo ello sugiere que si bien la edad puede actuar como factor de riesgo primario y secundario, su principal valor radica en la aceleración del desarrollo de la enfermedad, favoreciendo la aparición de complicaciones. ${ }^{35}$

La relación de la edad con la patología del sistema venoso en concreto, y del sistema cardiovascular en general, no se limita a un mero valor numérico, si no que depende de los cambios fisiológicos que se producen asociados a la senectud. Estos cambios afectan al cuerpo humano en todos sus niveles, pero algunos de ellos son especialmente relevantes a nivel del sistema venoso, influyendo de forma directa en el desarrollo o la progresión de insuficiencia venosa crónica. ${ }^{36}$

Existen una serie de cambios asociados al envejecimiento:

- Pérdida de masa y tono muscular. Supone la pérdida de uno de los principales determinantes del retorno de sangre venosa fundamentalmente desde las extremidades inferiores.

- Disminución de actividad física. Condiciona por un lado la pérdida de masa y tono muscular y por otro lado favorece el éxtasis sanguíneo a nivel de las zonas declives.

- Aumento del tejido conectivo en la pared vascular, lo que implica una mayor rigidez vascular y una menor amortiguación de los cambios de presión intraluminal. 


\section{Introducción}

\subsubsection{El sexo}

En general más hombres que mujeres sufrirán un ingreso a lo largo de su vida por una enfermedad de tipo cardiovascular. ${ }^{37}$ Esto es así para la afectación arterial y cardiaca en concreto, sin embargo, ocurrirá lo contrario en el caso de la EVC, siendo además esta relación independiente de la edad. ${ }^{38,39}$

Las mujeres suelen presentar una afectación funcional más superficial, mientras que los hombres presentas un afectación más profunda, quizá esto también este influido porque solicitan asistencia médica más tarde. ${ }^{40}$

En este sentido, ocurre algo similar al efecto de la edad en la patología venosa. No es una relación directa con el sexo lo que determina el desarrollo de la EVC, sino una serie de factores asociados al sexo que comentaremos de forma individual.

\subsubsection{Factores hormonales}

Diversos estudios han demostrado que a nivel de las venas existen receptores de estrógenos y progesterona, lo que involucra de forma directa a las hormonas sexuales en el desarrollo de varices.

Si bien el mecanismo exacto aún no se conoce, estudios realizados en mujeres nulíparas han demostrado que los cambios hormonales sucedidos a lo largo del ciclo menstrual asocian cambios en el diámetro de las venas y el cierre de las válvulas que a largo plazo podrían conducir a una disfunción venosa que favoreciera el desarrollo de varices. ${ }^{41,}, 42$ 


\section{Introducción}

Los estrógenos se relacionan con una mayor elasticidad a nivel de las paredes venosas, y la progesterona disminuye el tono de las fibras musculares que componen la túnica media de la pared venosa. ${ }^{43}$ El resultado, una vasodilatación venosa que favorecerá la insuficiencia valvular y por tanto la regurgitación. Estos cambios serán más o menos evidentes asociados al nivel hormonal en cada momento, que como sabemos es cíclico en las mujeres y varía con estados fisiológicos (embarazo o menopausia) y en respuesta a estímulos externos (anticonceptivos orales, terapia hormonal sustitutiva...).

\subsubsection{El embarazo.}

Por otro lado, otros estudios afirman que no se observa diferencia en la prevalencia de insuficiencia venosa entre mujeres nulíparas y hombres, pero sí entre hombres y mujeres multíparas, lo que nos hace pensar que el número de gestaciones actúa como un factor de riesgo importante, sin embargo aún no está claro cuál es el mecanismo causante. ${ }^{44}$ Esto nos hace pensar que la gestación actúa como un factor de riesgo exponencial, favoreciendo el desarrollo de varices de forma progresiva a medida que avanza la gestación. ${ }^{45}$

A los factores hormonales, ya explicados con anterioridad, habría que incluir una serie de factores mecánicos y cambios cardiovasculares que siendo fisiológicos, podrían influir en el agravamiento del proceso.

- El aumento del tamaño uterino ocasiona un obstáculo al retorno venoso por compresión de la vena cava inferior. El aumento de presión hidrostática se transmitirá de forma retrógrada afectando tanto a la función valvular como parietal. 


\section{Introducción}

- El incremento ponderal durante la gestación. Se ha estudiado que el promedio de peso ganado durante el embarazo es de $12,5 \mathrm{Kg}$, fundamentalmente a expensas del tamaño del feto, pero también en depósito de grasa y aumento del volumen sanguíneo circulante y líquido extracelular. ${ }^{46} \mathrm{Sin}$ embargo, no

está del todo claro que la relación entre peso y varices sea independiente del grado de ganancia ponderal.

En cualquier caso, el aumento de peso condiciona una menor movilidad y con ello una menor eficiencia de la contribución del sistema muscular al retorno venoso.

- El incremento del volumen sanguíneo circulante. Durante la gestación se producen cambios a nivel del sistema cardiovascular (aumento de la frecuencia cardiaca, aumento del volumen latido y disminución de la resistencia vascular periférica); que generan un incremento del gasto cardiaco hasta en un $50 \% .{ }^{47}$ Este incremento de volemia favorece por un lado el estasis sanguíneo a nivel de un sistema venoso ya de por sí menos competente, y además genera una disminución de la presión coloidoosmótica que favorece el aumento del espacio extracelular provocando edema y dificultando el retorno sanguíneo también por el sistema linfático. ${ }^{46}$

El embarazo no solo actúa como factor primario favoreciendo la aparición de EVC, sino también como factor secundario, permitiendo la evolución de la enfermedad hacia estadios más avanzados. ${ }^{48}$ 


\section{Introducción}

Existen estudios sobre los cambios producidos a nivel de las varices en pacientes gestantes y en puérperas, que demuestran que los cambios producidos retornan a la normalidad a los tres meses del parto. Sin embargo, también se ha demostrado que se produce un debilitamiento progresivo de la pared vascular venosa que favorece a largo plazo el desarrollo de la enfermedad y un curso más insidioso. ${ }^{49}$

\subsubsection{Los anticonceptivos orales y la terapia hormonal sustitutiva}

Tanto los anticonceptivos orales como la terapia hormonal sustitutiva se caracterizan por influir más en el desarrollo de complicaciones vasculares que en ser factores primarios de la aparición de varices. Si bien la influencia de la dosis de estrógenos es difícil de evaluar, tiene sentido tratar de utilizar la menor dosis eficaz. ${ }^{50,51}$

Pacientes que tienen varices y se encuentran bajo tratamiento con anticonceptivos orales tienen un riesgo aumentado de sufrir una trombosis venosa, ya sea a nivel del sistema superficial o profundo.

Lo mismo que ocurre con la terapia hormonal sustitutiva en pacientes postmenopáusicas. ${ }^{51}$

\subsubsection{La Menopausia}

En las mujeres postmenopáusicas es mayor la incidencia de varices.

Además de los cambios fisiológicos, existen otra serie de factores que dificultan la valoración independiente de la influencia de la menopausia en el desarrollo de insuficiencia venosa. No es infrecuente el uso de terapia hormonal sustitutiva durante 


\section{Introducción}

este proceso, algo que ocurre hasta en un $4,7 \%$ de las mujeres, y que como hemos señalado con anterioridad, actúa como factor secundario favoreciendo el desarrollo de complicaciones vasculares..$^{52}$

Lo mismo ocurre con la edad, la menopausia se produce a una edad media de 51,4 años en mujeres normales, por lo que no se puede despreciar su influencia concomitante en el proceso.

\subsubsection{La historia familiar}

La historia familiar de insuficiencia venosa crónica ha sido identificada como un importante factor de riesgo, sin embargo se trata de un tema controvertido y los datos en este sentido deben interpretarse con cautela.

Por un lado, aquellos pacientes que presentan enfermedad venosa serán más conscientes de la presencia de esta afectación entre otros miembros de su familia, que aquellos individuos sin enfermedad. Además, la mayoría de los estudios se basan en datos obtenidos a partir de encuestas, en las que la presencia de afectación familiar no es constatada clínicamente, lo que puede suponer un elevado número de falsos positivos..$^{53}$

Por otro lado, varios estudios epidemiológicos han demostrado que, además de los factores ambientales, los mecanismos genéticos pueden desempeñar un papel en la determinación de la susceptibilidad a la enfermedad vascular. ${ }^{14,} 29,54$

Si bien debemos considerar que esta agrupación genética podría deberse no solo en exclusiva a factores genéticos sino también a factores ambientales, un estudio realizado en familias con hijos adoptados demostró una mayor prevalencia de EVC en hijos biológicos. ${ }^{55,56}$ 


\section{Introducción}

Estos factores genéticos no son del todo conocidos, si bien mutaciones en diversos genes han sido relacionados con el desarrollo de varices:

- Alteración del enzima MTHFR regulador del metabolismo de la homocisteina. La homocisteína es un aminoácido que se sintetiza como producto intermedio del metabolismo de la metionina, y que en a altas dosis puede provocar lesión vascular.

Alteraciones genéticas que influyan en el funcionamiento del enzima MTHFR provocan un incremento de los niveles de homocisteina lo que ocasionará un aumento del número de radicales libres con el consiguiente daño endotelial. Sin embargo este mecanismo más que en el desarrollo de varices participa en eventos trombóticos a nivel tanto de arterias como de venas. ${ }^{57,58}$

- Mutaciones en el gen VEGFA (Factor de crecimiento del endotelio vascular). La expresión de este gen es imprescindible durante la embriogénesis para formación del endotelio vascular. ${ }^{59,60}$

- Mutaciones en el gen de la hemocromatosis (HFE). Éstas podrían actuar tanto como factor secundario, favoreciendo la formación de procesos ulcerativos, como factor primario, aumentando la susceptibilidad al desarrollo de varices. 61 


\section{Introducción}

\subsubsection{El peso}

El sobrepeso y la obesidad son patologías en claro incremento, fundamentalmente en los países desarrollados, y además se espera que su frecuencia continúe creciendo en los próximos años. ${ }^{62}$

La obesidad actúa como factor de riesgo para una gran variedad de enfermedades principalmente afectando al sistema cardiovascular. ${ }^{63}$ Focalizándonos en la patología vascular venosa, los pacientes obesos no sólo presentan un riesgo adicional de desarrollo de varices, sino que además tienden a presentar síntomas y complicaciones con mayor frecuencia. ${ }^{64}$

Aunque en algunos estudios se excluye a pacientes obesos, existen otros directamente dirigidos a estudiar la influencia del peso en el desarrollo de EVC. Se ha determinado un mayor diámetro de la vena femoral en pacientes obesos.

El mecanismo podría ser similar al efecto del embarazo en las mujeres; la obesidad generaría un incremento de presión intraabdominal, que dificultaría el retorno venoso desde las extremidades inferiores por compresión de la vena cava inferior. La transmisión retrógrada de la tensión parietal disminuiría la elasticidad de la pared del vaso produciendo disfunción valvular y una menor adaptabilidad del sistema venoso a los cambios fisiológicos. Sin embargo, en contra de esta teoría hay que tener en cuenta que los estudios se realizan teniendo en cuenta el índice de masa corporal, pero no la distribución corporal de grasa. ${ }^{65}$ 


\section{Introducción}

Además, al comparar pacientes con patrones anatómicos similares de EVC según el índice de masa corporal, encontramos que los pacientes obesos presentan estadios clínicos más avanzados de la enfermedad, y presentan con más frecuencia complicaciones a nivel cutáneo, en forma de úlceras, y a nivel vascular, en forma de trombosis. ${ }^{53,66,67}$

Al efecto físico de la obesidad sobre la presión abdominal, hay que añadir otros efectos secundarios que favorecen el desarrollo de complicaciones asociadas a la EVC. Por un lado, los cambios hormonales secundarios al aumento del tejido adiposo, junto con las alteraciones a nivel de la microvascularización provocan una alteración de los procesos de cicatrización y regeneración celular que favorecerían el desarrollo de las úlceras cutáneas. Por otro lado, los pacientes con un índice de masa corporal elevado presentan alteraciones de la coagulación que favorecen el desarrollo de fenómenos trombóticos; niveles más elevados de fibrinógeno, dímero-D y factores de la coagulación. ${ }^{68}$

\subsubsection{El ejercicio físico}

La prescripción de ejercicio físico para el tratamiento de la EVC es una buena práctica médica, que además es habitual. Por un lado previene de la obesidad, cuyo efecto deletéreo ya ha sido explicado, pero además el propio ejercicio físico en sí mismo, acarrea una serie de efectos beneficiosos que deben ser comentados.

La deambulación como ejercicio tiene un efecto positivo a nivel de los músculos de la pantorrilla que actúan como bomba, incluso en los estadios más evolucionados de la enfermedad varicosa, como la ulceración. ${ }^{69}$ 
El ejercicio estructurado para mejorar la fuerza de la pantorrilla y la movilidad del tobillo mejora la hemodinámica venosa al mejorar la función de la bomba del músculo de la pantorrilla. ${ }^{70,71}$

Sin embargo, hay que tener en cuenta que existe una gran variedad de actividades deportivas, que pueden clasificarse según su grado de componente de fuerza, valorado por la intensidad de las contracciones del músculo y según su componente de resistencia, valorado por la intensidad relativa del ejercicio. ${ }^{72} \mathrm{Se}$ recomiendan deportes dinámicos y con poco impacto. ${ }^{73}$ Deportes con un alto componente de carga estática, por ejemplo el levantamiento de pesas, podrían tener un impacto negativo en la enfermedad venosa al asociar incrementos importantes de la presión intraabdominal e intratorácica. ${ }^{74}$

Dentro de la actividad física merece un comentario especial la influencia de la postura en el desarrollo de EVC. La posición erecta en bipedestación durante largos períodos de tiempo favorece el desarrollo de varices fundamentalmente por un aumento directo de la presión intrabdominal. En este sentido, factores socioeconómicos y laborales tienen un peso importante; diversos estudios han relacionado de forma directa la ocupación laboral, el tiempo en bipedestación y el desarrollo de varices. ${ }^{75}$ Así, entre profesiones sanitarias o en hostelería por ejemplo, la prevalencia de EVC es elevada, lo que se justifica, al menos en parte, por el número de horas seguidas en bipedestación prolongada se pasan a lo largo del día. ${ }^{76}$ 


\section{Introducción}

\subsection{DIAGNÓSTICO DE ENFERMEDAD VENOSA CRÓNICA}

A menudo en los casos de estadios avanzados de EVC, las manifestaciones clínicas suelen ser suficiente para su diagnóstico, sin embargo en los estadios iniciales, además de los síntomas que nos refiere el paciente debemos de complementar el estudio con pruebas objetivas para confirmar nuestro diagnóstico de sospecha.

Estas pruebas diagnósticas pueden ser eficaces en el diagnóstico y tratamiento precoz, lo que puede evitar la progresión a formas más graves de la enfermedad.

Tanto en las formas graves como en las leves debemos realizar una historia clínica correcta, preguntando a los paciente sobre los principales factores de riesgo para el desarrollo de esta patología (ver sección 2.4 Etiopatogenia) y los síntomas clínicos que presenta (ver sección 2.5 Clínica)

Ahora, con la existencia de nuevas técnicas terapéuticas aplicadas a la patología varicosa mediante técnicas endovenosas, es aún más importante aumentar nuestro conocimiento de CVI desde el punto de vista morfológico y hemodinámico.

Respecto a la realización de pruebas objetivas para la confirmación del diagnóstico tenemos:

\subsubsection{Ecodoppler "Color"}

Los estudios anatómicos y hemodinámicos mediante Ultrasonidos son una herramienta diagnostica útil para la identificación del patrón de reflujo venoso de la patología varicosa y para caracterizar la probable asociación con la gravedad clínica de CVI. ${ }^{77}$ 


\section{Introducción}

En ocasiones se pueden confundir los términos Doppler y Ecodoppler. Sin embargo cuando hablamos de:

- Doppler: Nos referimos a una técnica de ultrasonidos mediante la que detectamos el flujo sanguíneo. Puede ser con análisis espectral de onda o no. El censado y expresión del espectro de ondas que proceden de un vaso nos da información sobre la velocidad y dirección del flujo.

- Ecodoppler: En esta técnica de ultrasonidos no sólo captamos el espectro de ondas de flujo sanguíneo sino que somos capaces de visualizar la imagen bidimensional en tiempo real de la estructura anatómica que analiza además de esta forma será posible visualizar variantes anatómicas. Será útil para identificar los diferentes y diversos orígenes del reflujo venoso y su frecuencia.

Se ha visto que muchas de las recurrencias producidas en los años posteriores a la cirugía se deben a una inadecuada intervención por falta de una adecuada evaluación anatómica y hemodinámica previa a la cirugía. ${ }^{78}$

La ecografía diagnóstica es la técnica más utilizada en la actualidad y que ha sustituido por completo las técnicas existentes previamente para la evaluación de los trastornos venosos. Como hemos mencionado anteriormente, es una técnica de ultrasonidos que combina imágenes ecográficas modo B en tiempo real de las venas con el doppler pulsado del flujo sanguíneo, al que se añade el análisis espectral de onda. ${ }^{79}$ 


\section{Introducción}

Nos ofrecerá información sobre lesiones a nivel valvular y reflujo del sistema venoso superficial. Además de aportarnos información en otras muchas situaciones como cambios crónicos en las venas profundas y superficiales tales como obstrucción y/o reflujo. ${ }^{80}$

Actualmente ese admite que es imperativo realizar un estudio ecodoppler a todos los pacientes con patología varicosa. La utilización de esta técnica es de gran utilidad en aquellas situaciones en las que no encontremos beneficios con el tratamiento conservador o decidamos realizar tratamiento quirúrgico (abierto o endovascular). En los pacientes con ulceración cutánea tendrá utilidad en primer lugar para realizar un diagnóstico diferencial con otras patologías, y una vez establecido el diagnóstico, para someter a estos pacientes a una ablación venosa, ya que disminuye el riesgo de recurrencias. ${ }^{81}$

El ecodoppler es más sensible y específica que la flebografía descendente para predecir gravedad clínica de insuficiencia venosa. ${ }^{82}$

\subsubsection{La Flebografía}

La flebografía ascendente era el "gold standard" previo a la aparición del ecodoppler para el diagnóstico de la trombosis venosa profunda y alteraciones anatómicas a nivel venoso. Sin embargo fue sustituido por este último ya que se trata de una técnica invasiva, costosa, incómoda para los pacientes y con mayor riesgo de complicaciones. Tan solo se usa en contextos clínicos complejos. ${ }^{83,84}$ 


\section{Introducción}

\subsubsection{La Pletismografía aérea}

Se trata de un examen fisiológico no invasivo que mide los cambios de volumen relativo en la extremidad (mediante un manguito de presión arterial) que se producen en respuesta a cambios posturales y en la actividad muscular. Aunque no es capaz de localizar con exactitud el sitio donde se produce el reflujo sanguíneo, los cambios en la pletismografía se correlacionan con la gravedad clínica de la enfermedad. En la actualidad esta prueba apenas se utiliza ya que disponemos de técnicas más avanzadas.

\subsubsection{La Fotopletismografía}

La fotopletismografia al igual al igual que la platismografía aérea evalúa la hemodinámica venosa en general sin conocer el punto exacto en el que se produce el reflujo. También se encuentra en desuso en la actualidad por la disponibilidad del dúplex venoso.

\subsection{TRATAMIENTO DE LAS VARICES}

Las varices no tratadas a tiempo pueden evolucionar a estadios más graves provocando alteraciones cutáneas o ulceración, situaciones que serán mucho más complejas de manejar. 
La intervención farmacéutica o quirúrgica puede retrasar la progresión de la enfermedad, pero desafortunadamente, muchas personas con EVC consultan demasiado tarde, en estadios avanzados de la enfermedad. En tales casos, la intervención es difícil y con frecuencia fracasada. ${ }^{85}$

Existen terapias que mejoran el flujo venoso y por lo tanto favorecen que la enfermedad no evolucione a estadios más avanzados:

- Medidas generales como elevación de extremidades inferiores o ejercicio. La elevación de las piernas durante 30 minutos en tres o cuatro ocasiones al día mejora la velocidad del flujo microcirculatorio y ha demostrado ser beneficioso en la curación de las ulceras cutáneas. La elevación debe ser por encima del nivel de la aurícula para ser efectivo. ${ }^{86,87}$ Los ejercicios a nivel de los músculos de la pantorrilla y el tobillo para tonificar, mejoran la función de bomba y por tanto la hemodinámica venosa. Todo esto dará lugar a una disminución de la hipertensión venosa en las extremidades inferiores. ${ }^{70,88}$

- Vendajes compresivos o medias de compresión: Son eficaces por diferentes efectos: actúan aumentando la velocidad del flujo sanguíneo y el retorno sanguíneo. Reducen el reflujo ya que la compresión a nivel de músculos de la pierna actúan como bomba. ${ }^{89,90} \mathrm{El}$ vendaje compresivo también tendrá eficacia en el postoperatorio de varices, tal es así que existen estudios que no muestran diferencias en la evolución y complicaciones del posoperatorio de varices entre el uso de medias de compresión, deambulación precoz y HBPM y el uso de las primeras medidas sin HBPM adyuvante. Lo cual demuestra la importancia de las medidas conservadoras. ${ }^{91,} 92$ 


\section{Introducción}

Si con las medidas más conservadoras no es suficiente, el siguiente paso será el tratamiento farmacológico constituido por sustancias venoactivas (flebotónicos). ${ }^{93} \mathrm{El}$ escalón más alto en la escala de tratamientos estaría reservado para la cirugia abierta endovascular.

Frente a la cirugía convencional para el tratamiento de las varices basada en la realización de una safenectomía (exéresis completa de las venas safenas), se han desarrollado nuevas técnicas de cirugía endovenosa para la oclusión de vasos patológicos generalmente mediante la aplicación de radiofrecuencia o energía láser que serían las técnicas de: ablación endovenosa con láser (EVLA) y ablación con radiofrecuencia (RFA).

También es posible el cierre del vaso mediante técnicas mecánicas o inyección de sustancias químicas mediante la escleroterapia con espuma guiada por ultrasonido (UGFS). Estas técnicas son más sencillas, con menor tasa de complicaciones y menor dolor postoperatorio, lo que favorece una rápida recuperación.

La cirugía endovascular es una forma de cirugía mínimamente invasiva diseñada para acceder al interior de un vaso y posteriormente movilizarnos en el interior del vaso mediante un sistema alámbrico denominado guía hasta alcanzar la zona del vaso que precisa la aplicación del tratamiento. ${ }^{94}$

La ablación endovenosa con láser (EVLA) o con radiofrecuencia (RFA) son técnicas para sellar y coagular la pared de la vena mediante calor. En ambas, a diferencia de la cirugía convencional, en la que será necesaria una anestesia locorregional, será suficiente en la mayoría de los casos con un anestésico local. La terapia mediante Láser utiliza una fuente de energía localizada en la punta del catéter, este una vez que discurre a través del vaso va cerrando el mismo logrando solucionar el problema que se está 


\section{Introducción}

tratando. La radiofrecuencia desde el punto de vista fisiológico es similar a la técnica anterior pero usando fuente enérgica de radiofrecuencia. ${ }^{95,96}$

La escleroterapia con espuma guiada por ultrasonido (UGFS) consiste en la inyección de un líquido esclerosante en forma de espuma. Se administra en de esta forma porque incrementa la potencia y efectividad del esclerosante consiguiendo el engrosamiento de la pared venosa lo que producirá una reacción flebítica. Es eficaz y tampoco precisa anestesia general. ${ }^{97}$

Como hemos mencionado anteriormente el tratamiento fundamental a nivel de las varices es la ablación de las mismas mediante cirugía convencional o mediante nuevas técnicas. Los fines de dicho tratamiento son tanto a nivel estético como hemodinámico para la mejora de los síntomas y la prevención de complicaciones. Además disminuye los efectos que puede producir la hipertensión venosa en los tejidos adyacentes. ${ }^{98}$

Existen estudios que han demostrado que el uso de Bemiparina podría estar indicado en cirugía de varices, sin embargo no es una práctica clínica que se esté realizando en el momento actual. ${ }^{99}$ 
3. HIPÓTESIS 



\subsection{JUSTIFICACIÓN DEL TRABAJO}

La enfermedad venosa crónica de las extremidades inferiores es el trastorno vascular más frecuente, y su incidencia está aumentando de forma progresiva. ${ }^{40}$ Desde principios de siglo, la insuficiencia venosa crónica constituye un problema de salud, no tanto por su gravedad clínica, como por la discapacidad que genera en el paciente, el absentismo laboral que ésta ocasiona y el gasto sanitario derivado de su morbilidad. ${ }^{21}$,

${ }^{67}$ Se trata además de un problema sanitario emergente, diferentes estudios, sitúan su prevalencia en torno al $70 \%$ de la población adulta atendida en los Centros de Salud nacionales, con un claro predominio en mujeres. ${ }^{24}$ Este predominio de la enfermedad en el sexo femenino implica la participación de factores de riesgo específicos de esta subpoblación. Durante la introducción, varios de estos factores han sido mencionados, sin embargo, en numerosas ocasiones la relación causal no ha sido claramente establecida, y su asociación se basa únicamente en hipótesis.

Nuestro estudio analiza el perfil ginecológico de pacientes con enfermedad venosa crónica superficial o síndrome varicoso, con el objetivo de determinar la influencia de éste en la génesis y desarrollo de la enfermedad. La identificación de los factores de riesgo ginecológicos en el desarrollo de varices, puede permitir implementar medidas de prevención en pacientes de riesgo, y de forma secundaria reducir la incidencia de la enfermedad, frenar la progresión de la misma con la consiguiente mejoría de la sintomatología, y, finalmente, disminuir los costes sanitarios asociados. 


\subsection{HIPOTESIS}

Tras una revisión de la literatura médica, en base a la información recogida y resumida en la introducción, establecemos la hipótesis de trabajo de que las pacientes portadoras de síndrome varicoso primario presentan un perfil ginecológico diferente.

La identificación de los principales factores de riesgo ginecológicos para el desarrollo y progresión de la EVC superficial, permitiría implementar medidas de prevención, con el objetivo último de mejorar la calidad de vida de los pacientes. Además, un mayor conocimiento de la interrelación entre patología varicosa y antecedentes ginecológicos puede aumentar la conciencia sobre la enfermedad y facilitar su reconocimiento por parte de los cirujanos vasculares y médicos de atención primaria, implementándose medidas de prevención o de tratamiento para evitar el desarrollo y progresión de la enfermedad. 
4. OBJETIVOS 



\section{Objetivos}

\subsection{OBJETIVO PRINCIPAL}

El objetivo principal del trabajo ha sido determinar el perfil ginecológico de las pacientes con síndrome varicoso primario.

\subsection{OBJETIVOS SECUNDARIOS}

Los objetivos secundarios del trabajo han sido los siguientes:

- Estudiar el impacto de factores de riesgo clásicamente aceptados en el desarrollo de síndrome varicoso primario.

- Estudiar el impacto de diversas variables bioquímicas, hormonales y hematológicas en el desarrollo de varices.

- Describir las características clínicas de la insuficiencia venosa crónica en mujeres de nuestro medio.

- Contrastar los datos obtenidos en una amplia población de estudio, con los existentes en la bibliografía

- Comparar los resultados obtenidos con otros perfiles de pacientes ofertados a través de la bibliografía, procedentes de otras áreas geográficas. 


\section{MATERIAL Y MÉTODOS}





\section{Material y métodos}

\section{1 ÁMBITO DE ESTUDIO}

El estudio se ha llevado a cabo en un Hospital del Sistema Nacional de Salud; el Hospital Clínico Universitario de Valladolid. Se trata de un centro hospitalario de tercer nivel, centro de referencia en Angiología y Cirugía Vascular para la comunidad autónoma de Castilla y León. En colaboración ha participado también el Servicio de Obstetricia y Ginecología del Hospital Universitario Río Hortega de Valladolid.

\subsection{PACIENTES}

Desde Septiembre de 2013 hasta Septiembre de 2016, se valoran todas las pacientes mujeres atendidas en una consulta de las disponibles en el Servicio de Angiología y Cirugía Vascular del Hospital Clínico Universitario de Valladolid, con diagnóstico final de síndrome varicoso primario, que cumplían los criterios de inclusión, y ninguno de los criterios de exclusión, que han sido consecutivamente reclutadas en una base de datos multipropósito. Disponemos de una población de estudio con 503 pacientes con síndrome varicoso primario. La población control está constituida por 237 pacientes, también mujeres que fueron atendidas en esa misma consulta externa del Servicio de Angiología y Cirugía Vascular y canalizadas con el diagnostico por parte de Atención Primaria de "actividades preventivas", incluidas en el grupo una vez descartado en ellas patología vascular significativa tras el estudio angiológico correspondiente. La distribución de las pacientes en las diferentes consultas, incluida donde se realizó el estudio fue aleatoria con lo que se evitaba cualquier sesgo de perfil patológico. 


\section{Material y métodos}

Tras el estudio inicial, basado principalmente en las características generales y ginecológicas de las pacientes con insuficiencia venosa crónica, se ha realizado una ampliación retrospectiva con diferentes variables analíticas y hormonales. Se pudo disponer de información analítica completa en 147 pacientes con síndrome varicoso primario y 143 pacientes del grupo control, incluyendo bioquímica sanguínea, hemograma y estudio de coagulación con las variables posteriormente expuestas. Para el estudio hormonal se dispuso de los datos en 41 pacientes del grupo de insuficiencia venosa crónica y en 41 controles, sin embargo, debido al estudio retrospectivo de los mismos, no conocemos el momento exacto del ciclo menstrual en el que las muestras fueron obtenidas. La obtención de los datos analíticos se ha ceñido estrictamente a criterios éticos, sin que en las pacientes se hayan realizado ningún tipo de actuación no conveniente, improcedente o no justificada para la atención de las enfermas de su proceso patológico. Estando en todos los casos que se ha realizado justificada la extracción analítica.

El estudio se ha aprobado tanto a nivel de la Comisión de Investigación del Hospital Clínico Universitario de Valladolid, desde el punto de vista científico, como del Comité Ético de Investigación Clínica CEIC/CEIm del Area de Salud Valladolid-Este (CINV 13-74). 


\subsection{CRITERIOS DE INCLUSION Y EXCLUSIÓN}

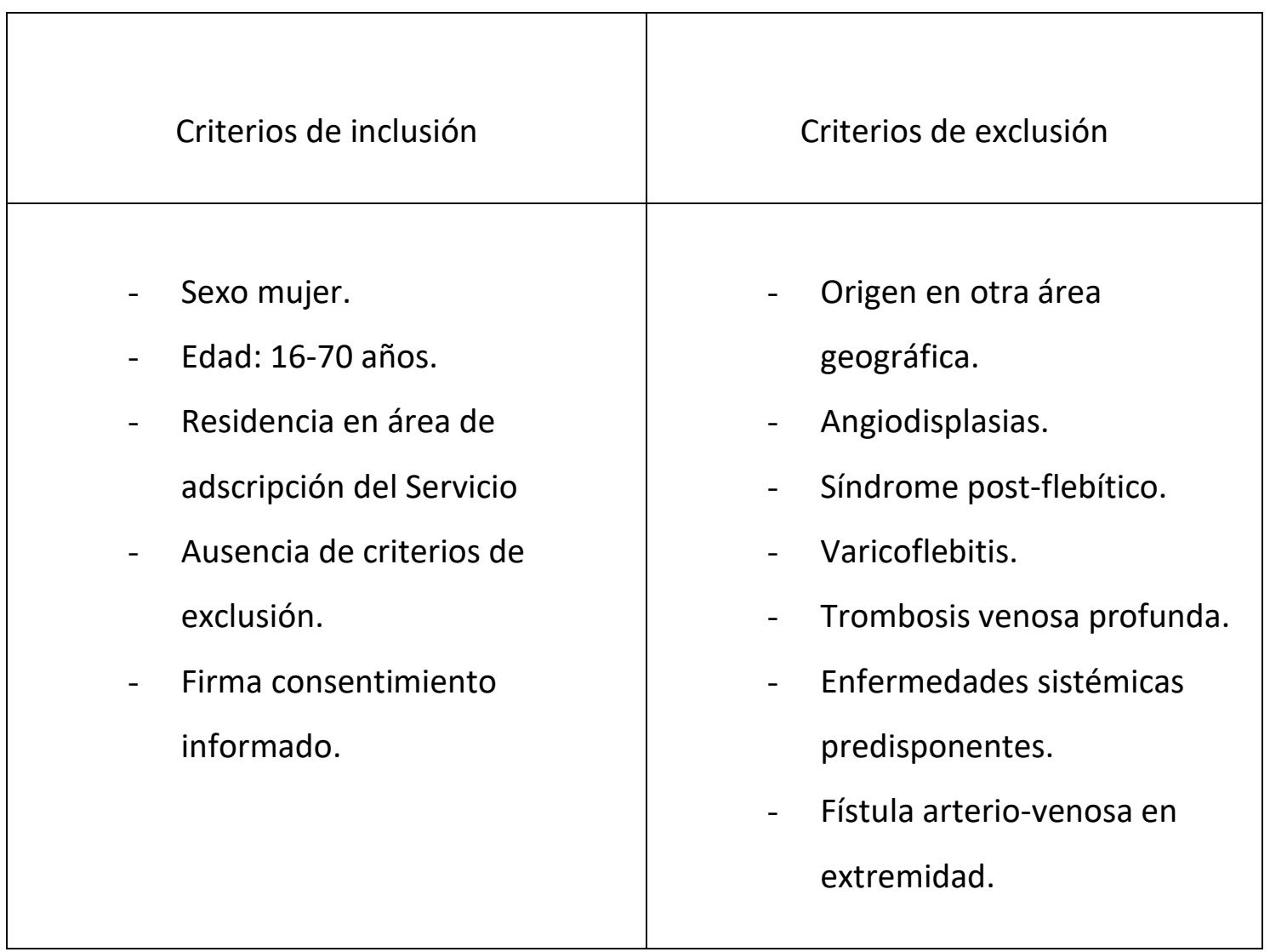




\section{Material y métodos}

\subsection{VARIABLES ANALIZADAS}

Para nuestro trabajo hemos realizado un estudio descriptivo que muestra las características generales de la población estudiada, tanto en el grupo caso como en el grupo control:

- Datos demográficos: edad, profesión, antecedentes familiares de primer grado (padres, hermanos, abuelos), estado nutricional (sobrepeso), enfermedades generales de la paciente (diabetes mellitus, hipertensión arterial, enfermedades de origen endocrino), menarquia, menopausia, número de embarazos e hijos, toma anovulatorios, hábito tabáquico.

- Estadio clínico: telangectasias, variculas, reticulares, tronculares

- Sintomatología: (pesadez, tirantez, hinchazón, prurito) analizando si está presente alguna sintomatología o las pacientes son asintomáticas.

- Estadio clínico de la paciente

- Medidas prevención: Si la paciente ha realizado medidas de prevención tanto primaria como secundaria.

- Tratamiento: uso de medias elásticas y antecedente de tratamiento quirúrgico de las varices.

- Variables analíticas: Bioquímica (urea, glucosa, creatinina, proteínas totales, albumina, calcio, fosforo, magnesio y hierro), citología sanguínea (Hematíes, leucocitos, plaquetas, linfocitos, monocitos, neutrófilos, eosinófilos y hemoglobina) y estudios de coagulación (Tiempo de Protrombina, Índice de Protrombina, Ratio Internacional Normalizada (INR), Tiempo Parcial de Tromoplastina Activada (TTPA)). 


\section{Material y métodos}

- Variables hormonales: Hormona Foliculoestimulante (FSH), Hormona Luteinizante (LH), Hormona estimulante del tiroides (TSH), Estradiol, Progesterona, Prolactina (PRL) y Hormona Antimüleriana $(\mathrm{AMH})$.

\subsection{DEFINICIÓN DE TÉRMINOS}

- Edad: Años de la paciente en el momento en el que ha sido incluido en el estudio.

- Profesión: Actividad habitual a la que se dedica una persona, generalmente para la que se ha preparado, que, al ejercerla, tiene derecho a recibir una remuneración o salario. En base a las características de la profesión, hemos clasificado a las pacientes según el tiempo que se encuentran en situación de sedestación o bipedestación, de tal forma que establecemos 3 categorías: bipedestación (si más del 50\% del tiempo de trabajo se encuentra en dicha posición), sedestación (si más del $50 \%$ del tiempo de trabajo se encuentra sentado) y ninguna de las anteriores.

- Antecedentes familiares: Información que nos han aportado los pacientes sobre familiares de primer grado (padres, hermanos, abuelos) para obtener información que se asocia al potencial de vida que trae la persona como herencia y puede influir en el desarrollo de la enfermedad. Debido a la imposibilidad de asumir la evaluación de todos los familiares de primer grado de las pacientes atendidas, nos hemos limitado a recoger la información mediante anamnesis indirecta a través del sujeto a estudio.

- Estado nutricional: hemos definido obesidad para valores de índice de masa corporal superiores a $30 \mathrm{~kg} / \mathrm{m}^{2}$. 


\section{Material y métodos}

- Diabetes: Siguiendo las guías de práctica clínica actuales, establecemos tres categorías según el resultado de la determinación de glucemia basal en ayunas: resultado normal para pacientes con glucosa sanguínea inferior a 100 $\mathrm{mg} / \mathrm{dL}$, glucemia basal alterada para valores de glucosa sanguínea entre 100 y $126 \mathrm{mg} / \mathrm{dL}$, y diabetes mellitus para niveles de glucemia basal mayores o iguales a $126 \mathrm{mg} / \mathrm{dL}$. De forma práctica, no hemos considerado la repetición de la prueba necesaria para confirmar el diagnóstico al no ser este un objetivo del estudio. Además, para los antecedentes personales asumimos el diagnóstico de diabetes mellitus en pacientes bajo tratamiento con insulina o antidiabéticos orales. ${ }^{100}$

- Hipertensión Arterial: definida por la determinación de cifras de presión arterial superiores a valores de $140 \mathrm{mmHg}$ de presión sistólica o $90 \mathrm{mmHg}$ de presión diastólica. ${ }^{101} \mathrm{~A}$ efectos prácticos hemos asumido el diagnóstico en aquellas pacientes que lo refieren en anamnesis indirecta o que se encontraban bajo tratamiento antihipertensivo.

- Alteraciones Tiroideas: a efectos de antecedentes personales hemos considerado alteraciones tiroideas, hipotiroidismo o hipertiroidismo, aquellas referidas por la paciente durante la anamnesis o en casos de tratamiento sustitutivo ${ }^{102}$. Además, al haber recogido el valor de TSH como parte del estudio hormonal, y de acuerdo con los valores de referencia del laboratorio consideramos alteración tiroidea valores de TSH por debajo de $0.2 \mathrm{mUl} / \mathrm{mL}$ o por encima de $4.7 \mathrm{mUl} / \mathrm{ml}$.

- Cáncer de mama: definido como una proliferación maligna de células que constituyen las glándulas mamarias. En nuestro estudio hemos incluido en esta variable aquellas pacientes que referían dicho antecedente o reflejaban una intervención quirúrgica en su historia clínica por dicho motivo. 


\section{Material y métodos}

- Síndrome depresivo: Trastorno psiquiátrico caracterizado por una disminución persistente del estado de ánimo, presencia de pensamientos negativos y, en algunos casos, síntomas somáticos. ${ }^{103}$ Se ha considerado que presentaban este antecedente aquellas pacientes que referían tratamiento antidepresivo o presentaban informe de psiquiatría con el consiguiente diagnóstico.

- Menarquia: Se denomina menarquia a la primera menstruación. ${ }^{104}$ Hemos considerado la edad que las pacientes han referido como el momento de su primera regla durante la anamnesis.

- Menopausia: Se denomina menopausia a la última menstruación de una mujer, si bien debe haber transcurrido al menos un año desde la última menstruación para utilizar este término. ${ }^{104} \mathrm{El}$ dato se ha obtenido mediante anamnesis directa de los casos y controles, teniéndose en cuenta tanto la presencia o ausencia del evento, así como la edad a la que se produjo.

- Número de embarazos: Se han considerado el número de gestaciones que ha tenido la paciente hasta el momento de la consulta, incluyendo tanto las gestaciones a término como las que han finalizado en aborto.

- Número de hijos: se ha considerado el número de gestaciones a término, o hijos nacidos vivos.

- Terapia hormonal: dentro de este apartado hemos considerado el uso de anticonceptivos hormonales combinados y el uso de terapia hormonal sustitutiva (THS).

- Telangiectasias: pequeñas dilataciones a nivel cutáneo menores de $1 \mathrm{~mm}$, también llamadas arañas vasculares. Se vacían a la presión. ${ }^{24,25}$

- Varículas: De tamaño algo mayor a las anteriores y no se vacían a la presión. 24,25 


\section{Material y métodos}

- Dilataciones venosas reticulares: inferiores a $3 \mathrm{~mm}$. Generalmente aparecen en cara externa del muslo, pierna y en hueco poplíteo. ${ }^{24,25}$

- Varices Tronculares: venas dilatadas de diámetro superior a $3 \mathrm{~mm}$. Generalmente producidas por la insuficiencia en alguna de las venas safenas. 24,25

- Pesadez: sensación de cansancio en extremidades inferiores que compromete la realización de actividades de la vida diaria.

- Edema: Aumento transitorio del volumen de una parte del cuerpo por una acumulación excesiva de sangre o de otro líquido orgánico. Se ha considerado a las pacientes que presentaban dicho signo en la exploración física.

- Prurito: Picor que se siente en una parte del cuerpo o en todo él y que provoca la necesidad o el deseo de rascarse. Hemos incluido en este grupo a las pacientes que refieren dicho síntoma a diario, excluyendo aquellas que lo refieren de una forma ocasional.

- Medidas prevención: La prevención designa al conjunto de actos y medidas que se ponen en marcha para reducir las situaciones de riesgo ligadas a la aparición de enfermedades o a ciertos comportamientos nocivos para la salud. En este sentido hemos considerado el empleo de medias de compresión elástica como medida preventiva de la insuficiencia venosa crónica. 


\section{Material y métodos}

- Variables analíticas: se han considerado los valores de referencia del laboratorio del Hospital Clínico Universitario de Valladolid.

- Valores normales de parámetros bioquímicos:

- Urea: $10-40 \mathrm{mg} / 100 \mathrm{~mL}$

- Glucosa: 60-110mg/100mL. Hemos considerado como glucosa basal alterada: $100-126 \mathrm{mg} / \mathrm{dL}$ tras 8 horas de ayuno.

- Creatinina: 0.6-1.4 mg/100mL. Hemos considerado valor de creatinina alterado para nuestras pacientes un valor mayor o igual a $1.2 \mathrm{mg} / \mathrm{dL}$, que corresponde con una tasa de índice de filtración glomerular de $60 \mathrm{~mL} / \mathrm{min} / 1.73 \mathrm{~m} 2$ para mujeres de raza blanca y 48 años de edad de acuerdo con la fórmula CKDEPI.

- Proteínas totales: $6.0-8.0 \mathrm{~g} / 100 \mathrm{~mL}$.

- Albumina: 3.4-5.4 g/dL

- Calcio: $8.5-10.5 \mathrm{mg} / 100 \mathrm{~mL}$

- Fosforo: $2.2-4.4 \mathrm{mg} / 100 \mathrm{~mL}$

- Magnesio: 1.5-2.0 mEq/L

- Hierro: 60-160 $\mu \mathrm{g} / \mathrm{dl}$

- Valores normales de la citología sanguínea:

- Hematíes: $4.8 \pm 1.0\left(\times 10^{12} / \mathrm{L}\right)$

- Leucocitos: 4.5-11-5 (x10\%/L)

- Plaquetas: $150-450$ (x109/L)

- Linfocitos: $17-45$ (\%) 


\section{Material y métodos}

- Monocitos: 2.0-8.0 (\%)

- Neutrófilos: 55-70 (\%)

- Hemoglobina: los valores normales de hemoglobina varía para hombres y mujeres. Teniendo en cuenta que nuestro estudio se centra en mujeres hemos considerado como valor normal de hemoglobina: $14 \pm 2 \mathrm{~g} / \mathrm{dL}$

- Valores normales de los parámetros de coagulación:

- Tiempo de protrombina (Quick): 12-14 segundos

- Índice de protrombina: $80-125 \%$

- INR: 0.79-1.2

- TTPA: 35-43 segundos

- Valores normales de los parámetros hormonales:

- TSH: 0.2-5.0 mU/L

- PRL: 3-24 ng/MI

- FSH, LH, Progesterona y Estradiol: los valores normales van a variar según el momento del ciclo.

- $\quad \mathrm{AMH}: 1.5-5 \mathrm{ng} / \mathrm{mL}$ 


\section{Material y métodos}

\subsection{ANALISIS ESTADISTICO}

Las variables categóricas se han expresado como valor absoluto y porcentaje, y las variables continuas como media [ $[ \pm$ ] desviación estándar, y/o mediana y rango intercuartílico. La asunción de normalidad en las variables cuantitativas se ha comprobado mediante el análisis de la curtosis y asimetría y el test de Shapiro-Wilk's.

Se ha considerado como evento la presencia de síndrome varicoso primario. La presencia o ausencia del evento divide nuestros pacientes en dos grupos, los cuales hemos comparado en el caso de variables cualitativas con el test Chi-cuadrado o el test exacto de Fisher cuando las frecuencias esperadas eran inferior a 5. Las variables continuas las hemos comparado utilizando el test $t$ de Student o su homólogo no paramétrico, el test U de Mann-Whitney si no cumplía la hipótesis de normalidad.

Todos los datos han sido analizados en el paquete estadístico IBM SPSS Statistics Versión 23.0. Los $p$ valores son bilaterales y se ha considerado estadísticamente significativo un valor de $p<0.05$. 
6. RESULTADOS 



\section{Resultados}

\subsection{CARACTERÍSTICAS GENERALES DE LAS PACIENTES CON INSUFICIENCIA VENOSA CRÓNICA.}

Presentamos un análisis descriptivo sobre las características generales de las 503 pacientes con insuficiencia venosa crónica (Tabla 1).

- Edad media: la edad media de las pacientes estudiadas fue de 47.7 años (DE 13.1), con un rango entre 19 y 78 años.

- Situación laboral: de las 503 pacientes estudiadas se obtuvo información en relación a su profesión en 501 pacientes. La situación laboral fue relacionada con una situación de bipedestación prolongada en 96 pacientes $(19,2 \%)$, con sedestación prolongada en 58 pacientes $(11,6 \%)$ mientras que en las 347 pacientes restantes $(69,0 \%)$ la situación laboral no estaba relacionada ni con sedestación ni bipedestación prolongada.

- Antecedentes personales: un total de 436 pacientes $(86.7 \%)$ no tuvieron antecedentes personales de interés. 13 pacientes de las estudiadas (2.6\%) había presentado un cáncer de mama, 7 pacientes (1.4\%) presentaban alteraciones tiroideas, 20 pacientes (4\%) eran hipertensas, 19 (3.8\%) presentaban diabetes mellitus y 9 pacientes $(1.8 \%)$ refirieron antecedentes de síndrome depresivo.

- Antecedentes familiares: 161 (32\%) refirieron tener antecedentes familiares de síndrome varicoso bien paterno, materno o en ambos progenitores.

- Estado nutricional: 44 (8.7\%) de las pacientes presentaron un índice de masa corporal superior a $30 \mathrm{~kg} / \mathrm{m}^{2}$. 
Tabla 1. Características generales de las pacientes con insuficiencia venosa crónica.

\begin{tabular}{|c|c|}
\hline & $\begin{array}{c}\text { Pacientes con insuficiencia venosa } \\
\text { crónica }(n=503)\end{array}$ \\
\hline Edad, media $\pm \mathrm{DE}$ & $47.7 \pm 13.1$ \\
\hline \multicolumn{2}{|l|}{ Situación laboral, n (\%) } \\
\hline Bipedestación & $96(19.2)$ \\
\hline Sedestación & $58(11.6)$ \\
\hline Antecedentes personales, $\mathrm{n}(\%)$ & $68(13.5)$ \\
\hline Hipertensión arterial & $20(4)$ \\
\hline Diabetes Mellitus & $19(3.8)$ \\
\hline Cáncer de Mama & $13(2.6)$ \\
\hline Enfermedad del tiroides & $7(1.4)$ \\
\hline Síndrome Depresivo & $9(1.8)$ \\
\hline
\end{tabular}




\section{Resultados}

\begin{tabular}{|l|c|}
\hline Antecedente de flebitis, $\mathbf{n}(\%)$ & $47(9.3)$ \\
\hline $\begin{array}{l}\text { Antecedentes familiares de } \\
\text { insuficiencia venosa crónica, } \mathbf{n}(\%)\end{array}$ & $161(32)$ \\
\hline Obesidad, $\mathbf{n}(\%)$ & $44(8.7)$ \\
\hline
\end{tabular}

\subsection{CARACTERISTICAS ANALITICAS Y HORMONALES DE LAS PACIENTES CON INSUFICIENCIA VENOSA CRÓNICA}

Hemos realizado un estudio retrospectivo de las analíticas sanguíneas disponibles en el momento de la atención sanitaria en la consulta de Angiología y Cirugía Vascular. Del total de 503 pacientes con insuficiencia venosa crónica, se disponía de analítica sanguínea completa de 147 pacientes (29,2\%).

Se recogieron valores de diferentes parámetros bioquímicos, de citología sanguínea y de coagulación. Los resultados se exponen en la tabla 2.

Respecto a la bioquímica sanguínea se obtuvieron los siguientes resultados:

- Urea: el valor medio de urea de las pacientes con insuficiencia venosa crónica fue de $29.76 \mathrm{mg} / 100 \mathrm{~mL}$ (DE 8.11), con un valor mínimo de 12 y un máximo de $50 \mathrm{mg} / \mathrm{dL}$. Del total de pacientes, 16 (10.9\%) presentaban valores por encima del límite de laboratorio (40 mg/dL). 


\section{Resultados}

- Glucosa: el rango de valores de glucemia basal es $56-109 \mathrm{mg} / 100 \mathrm{~mL}$, con un valor medio de $83.81 \mathrm{mg} / 100 \mathrm{~mL}$ (De 11.63). Desatacamos que 13 pacientes (8.8\%) presentaban glucemia basal alterada, pero ninguna cumplía diagnóstico de diabetes mellitus, ni tampoco valores en rango de hipoglucemia.

- Creatinina: Los valores de creatinina se encontraban en un rango de 0.6-1.5 $\mathrm{mg} / 100 \mathrm{~mL}$, con un valor medio de $0.97 \pm 0.24 \mathrm{mg} / 100 \mathrm{~mL}$. Un total de 39 pacientes $(26.5 \%)$ presentaban valores de creatinina mayor o igual a 1,2 $\mathrm{mg} / \mathrm{dL}$, que como hemos comentado previamente, se corresponde con un índice de filtración glomerular menor de $60 \mathrm{~mL} / \mathrm{min} / 1.73 \mathrm{~m} 2$ para mujeres de raza blanca y 48 años de edad según la fórmula CKD-EPI.

- Proteínas totales: Los valores de proteínas totales se encontraban en un rango de $6.3-8.4 \mathrm{~g} / 100 \mathrm{~mL}$, con una media de $7.14 \pm 0.67 \mathrm{~g} / 100 \mathrm{~mL}$. Tan solo 3 de las 147 pacientes (2\%) han presentado un valor menor del corte establecido por el laboratorio $(6 \mathrm{~g} / 100 \mathrm{~mL})$.

- Albumina: Los valores de albumina se encuentran en un rango de 3.1-5 g/dl. La media ha sido $4.03 \pm 0.36 \mathrm{~g} / \mathrm{dL}$, sin ningún valor fuera de los límites de referencia del laboratorio.

- lones: los valores obtenidos de calcio, fosforo y magnesio se encuentran dentro del rango de la normalidad con unos valores medios de $9.16 \pm$ $0.67 \mathrm{mg} / 100 \mathrm{~mL}, 3.57 \pm 0.47 \mathrm{mg} / 100 \mathrm{~mL}$ y $1.94 \pm 0.25 \mathrm{mEq} / \mathrm{L}$ respectivamente. 


\section{Resultados}

- Hierro sérico: Los valores obtenidos de hierro sérico se encuentran en un rango de 57-150 $\mu \mathrm{g} / \mathrm{dl}$. Siendo la media de este parámetro entre todas las pacientes de $95.54 \pm 89.49 \mu \mathrm{g} / \mathrm{dl}$.

Los resultados de citología sanguínea son los siguientes:

- Hematíes: Los valores obtenidos de hematíes en sangre se encuentran en un rango de 4.12-5.2 (x1012/L). La media ha sido de $4.62 \pm 0.24$ (x1012/L). La hemoglobina se ha encontrado en un rango de $11-16 \mathrm{~g} / \mathrm{dL}$, con un valor medio de $12.85 \pm 1.07 \mathrm{~g} / \mathrm{dL}$. Del total de pacientes sólo 4 (2.7\%) presentan valores de hemoglobina por debajo del límite considerado para mujeres (12 $\mathrm{g} / \mathrm{dL})$.

- Leucocitos: Los valores obtenidos de leucocitos en sangre se encuentran todos dentro de la normalidad con un rango de 4.5- 9.5 (x109/L). La media ha sido de $6.74 \pm 1.09$ (x109/L). Los valores de linfocitos, monocitos y neutrófilos se han encontrado en todos los casos dentro de la normalidad..

- Plaquetas: Los valores obtenidos de plaquetas en sangre se encuentran en un rango de 146-456 (x109/L) con un valor medio de $269.16 \pm 58.18$ (x109/L). Tan solo 2 pacientes han presentado valores alterados una por debajo y otra por encima de los valores de la normalidad.

El estudio de coagulación todos los parámetros analizados se encontraron en rango de normalidad y se reflejan en la tabla 2. 


\section{Resultados}

Tabla 2. Analítica sanguínea de 147 pacientes con insuficiencia venosa crónica.

\begin{tabular}{|c|c|}
\hline Media \pm DE & $\begin{array}{c}\text { Pacientes con insuficiencia venosa } \\
\text { crónica }(n=147)\end{array}$ \\
\hline \multicolumn{2}{|l|}{ Bioquímica } \\
\hline Urea (mg/100mL) & $29.76 \pm 8.11$ \\
\hline Glucosa (mg/100mL) & $83.81 \pm 11.63$ \\
\hline Creatinina (mg/100mL) & $0.97 \pm 0.24$ \\
\hline Proteínas Totales (g/100mL) & $7.14 \pm 0.67$ \\
\hline Albumina (g/dL) & $4.03 \pm 0.36$ \\
\hline Calcio (mg/mL) & $9.16 \pm 0.67$ \\
\hline Fosforo (mg/100mL) & $3.57 \pm 0.47$ \\
\hline Magnesio (mEq/L) & $1.94 \pm 0.25$ \\
\hline Hierro ( $\mu \mathrm{g} / \mathrm{dl})$ & $95.54 \pm 89.49$ \\
\hline
\end{tabular}


6. Resultados

\begin{tabular}{|c|c|}
\hline \multicolumn{2}{|l|}{ Hematimetría } \\
\hline Hematíes (x1012/L) & $4.62 \pm 0.24$ \\
\hline Leucocitos (x109/L) & $6.74 \pm 1.09$ \\
\hline Plaquetas (x109/L) & $269.16 \pm 58.18$ \\
\hline Linfocitos (\%) & $34.70 \pm 7.49$ \\
\hline Monocitos (\%) & $6.44 \pm 7.37$ \\
\hline Neutrófilos (\%) & $59.29 \pm 7.48$ \\
\hline Hemoglobina (g/dL) & $12.85 \pm 1.07$ \\
\hline \multicolumn{2}{|l|}{ Coagulación } \\
\hline Tiempo de Protrombina (seg) & $14.02 \pm 1.52$ \\
\hline Índice de Protrombina (\%) & $97.22 \pm 11.03$ \\
\hline INR & $1.06 \pm 0.18$ \\
\hline TTPA (seg) & $34.79 \pm 3.2$ \\
\hline
\end{tabular}


Del total de 503 pacientes con insuficiencia venosa crónica, se disponía de estudio hormonal en 41 pacientes. Los resultados se exponen en la tabla 3.

- Hormonas sexuales: Todos los valores de las hormonas sexuales medidas se encuentran dentro del rango de normalidad para los límites de laboratorio. La media de todos los valores obtenidos para las diferentes hormonas ha sido de $6.12 \pm 2.19 \mathrm{mU} / \mathrm{mL}, 5.44 \pm 1.87 \mathrm{mU} / \mathrm{mL}, 88.50 \pm 34.94 \mathrm{pg} / \mathrm{mL}, 12.45 \pm$ $3.78 \mathrm{ng} / \mathrm{mL}, 10.78 \pm 4.81 \mathrm{ng} / \mathrm{mL}$ y $2.33 \pm 0.67 \mathrm{ng} / \mathrm{mL}$ para $\mathrm{FSH}$, LH, Estradiol, Progesterona, PRL y AMH respectivamente.

- TSH: Los valores de TSH se encuentran en un rango de 0.9-4.6 mU/L con un valor medio de $2.97 \pm 0.89 \mathrm{mU} / \mathrm{L}$. No existen valores fuera de los límites de referencia establecidos por el laboratorio. 


\section{Resultados}

Tabla 3. Estudio hormonal en 41 pacientes con insuficiencia venosa crónica.

\begin{tabular}{|c|c|}
\hline Media \pm DE & Pacientes con insuficiencia venosa \\
crónica ( $\mathbf{n}=\mathbf{4 1})$
\end{tabular}




\section{Resultados}

\subsection{PERFIL GINECOLÓGICO DE LAS PACIENTES CON INSUFICIENCIA VENOSA CRÓNICA.}

La tabla 4 recoge las principales características ginecológicas de las pacientes con insuficiencia venosa crónica que además se presentan a continuación:

- Menarquía: todas las pacientes habían presentado la menarquia ( $n=503$, 100\%). La edad media fue de 12.35 años con una desviación estándar de 0.99 años, rango 9-15 años.

- Menopausia: 219 pacientes habían alcanzado la menopausia (43.5\%). La edad media de la menopausia fue de 49.2 años, con una desviación estándar de 3.1 años, rango 40-59 años.

- Número de gestaciones: 412 pacientes (82\%) refieren gestación en algún momento de su vida. Incluimos tanto las gestaciones a terminó como los abortos. La media de gestación por paciente fue de 2.01 gestaciones con una desviación estándar de 1.03 (rango 0-8).

- Número de hijos: 405 pacientes (81\%) referían haber tenido al menos un hijo vivo a lo largo de su vida. La media de hijos por paciente del grupo de varices ha sido de 1.8, desviación estándar de 0.83 (rango 0-6).

- Tratamiento hormonal: un total de 247 pacientes (49.1\%) refería toma de anticonceptivos orales combinados o tratamiento hormonal sustitutivo en el momento de la consulta. 
Tabla 4. Perfil ginecológico de las pacientes con síndrome varicoso primario y su comparación con el grupo control.

\begin{tabular}{|c|c|}
\hline & $\begin{array}{l}\text { Pacientes con insuficiencia venosa crónica } \\
\text { ( } \mathbf{n}=\mathbf{5 0 3 )}\end{array}$ \\
\hline Menarquia, $\mathbf{n}$ (\%) & $503(100)$ \\
\hline Edad, media \pm DE & $12.35 \pm 0.99$ \\
\hline Menopausia, $\mathbf{n}$ (\%) & $219(43.5)$ \\
\hline Edad, media \pm DE & $49.2 \pm 3.1$ \\
\hline Gestación, $\mathbf{n}$ (\%) & $412(82)$ \\
\hline Número de gestaciones, media \pm DE & $2.01 \pm 1.03$ \\
\hline Hijos, $\mathbf{n}$ (\%) & $405(81)$ \\
\hline Número de hijos, media \pm DE & $1.8 \pm 0.83$ \\
\hline Terapia hormonal, $n$ (\%) & $247(49.1)$ \\
\hline
\end{tabular}




\section{Resultados}

\subsection{DESCRIPCIÓN DE LAS CARACTERÍSTICAS PRINCIPALES DE LA INSUFICIENCIA VENOSA CRÓNICA}

La tabla 5 recoge las principales características de la EVC de las pacientes incluidas en el estudio.

El estadio clínico más frecuente ha sido la variz troncular ( $n=382,75.9 \%)$, seguida de la varícula $(n=68,13.5 \%)$, las telangiectasias $(n=29,5.8 \%)$ y la reticular $(n=24,4.8 \%)$.

Respecto al grado evolutivo, hemos utilizado la clasificación de la CEAP para su estratificación. De acuerdo con ella, los grados evolutivos más frecuentes han sido los siguientes:

- Estadio C1: 116 pacientes (23\%)

- Estadio C2: 374 pacientes (74.4\%)

- Estadio C3: 13 pacientes (2.6\%)

En el 30.8\% de las pacientes (155) se observó una insuficiencia de la vena safena interna. El 88.9\% (447) de las pacientes presentaban síndrome varicoso bilateral, mientras que el $11.1 \%$ restante (56 pacientes) sólo presentaron varices en la extremidad inferior consultada.

Cuarenta y siete pacientes de las 503 estudiadas refirieron antecedentes de flebitis en la extremidad inferior afectada por el síndrome varicoso mientras que las 456 pacientes restantes (90.7\%) no refirieron antecedentes de esta complicación. Del total de las mujeres de nuestro estudio, 74 de ellas (14.7\%) consultaron por motivos estéticos siendo el síndrome varicoso asintomático. El resto de las pacientes, hasta un total de 487 mujeres presentaron clínica la cual consistió en un $72.2 \%$ en pesadez de 


\section{Resultados}

extremidades inferiores, $5.2 \%$ en prurito, $3.6 \%$ en edema y en $4.4 \%$ en dolor de miembros inferiores.

Solamente el 33.4\% de las pacientes (168) utilizaban compresión extrínseca mediante medias de compresión elástica gradual, y sólo el $20.3 \%$ había sido sometido a tratamiento quirúrgico frente al síndrome varicoso en el momento de la consulta. De estas últimas, 81 (89.4\%) había sido intervenida una vez, y 21 (20.6\%) dos o más veces en esa misma extremidad o en la contralateral

Tabla 5. Descripción de las características principales de la insuficiencia venosa crónica.

\begin{tabular}{|c|c|}
\hline & $\begin{array}{l}\text { Pacientes con insuficiencia venosa } \\
\text { crónica }(n=503)\end{array}$ \\
\hline \multicolumn{2}{|l|}{ Tipo de variz, n (\%) } \\
\hline Telangiectasias & $29(5.8)$ \\
\hline Varículas & $68(13.5)$ \\
\hline Reticular & $24(4.8)$ \\
\hline Troncular & $382(75.9)$ \\
\hline \multicolumn{2}{|c|}{ Grado evolutivo según CEAP, n (\%) } \\
\hline $\mathrm{C} 1$ & $116(23)$ \\
\hline $\mathrm{C} 2$ & $374(74.4)$ \\
\hline $\mathrm{C} 3$ & $13(2.6)$ \\
\hline
\end{tabular}




\section{Resultados}

\begin{tabular}{|c|c|}
\hline Localización, n (\%) & \\
\hline Vena safena interna & $155(30.8)$ \\
\hline Bilateral & 447 (88.9) \\
\hline Unilateral & $56(11.1)$ \\
\hline Clínica, n (\%) & \\
\hline Flebitis previa & $47(9.3)$ \\
\hline Asintomático & $74(14.7)$ \\
\hline Pesadez de piernas & $363(72.2)$ \\
\hline Prurito & $26(5.2)$ \\
\hline Edema & $18(3.6)$ \\
\hline Dolor & $22(4.4)$ \\
\hline Tratamiento, n (\%) & \\
\hline Medias de compresión & $168(33.4)$ \\
\hline Cirugía & $102(20.3)$ \\
\hline Una intervención & $81(79.4)$ \\
\hline Dos o más intervenciones & $21(20.6)$ \\
\hline
\end{tabular}




\section{Resultados}

\subsection{FACTORES DE RIESGO PARA EL DESARROLLO DE INSUFICIENCIA VENOSA CRÓNICA}

Hemos realizado un análisis univariante de las variables previamente expuestas agrupadas por categorías para evaluar su posible influencia en el desarrollo de insuficiencia venosa crónica.

\subsubsection{Características generales de la población.}

Los resultados se muestran en la tabla 6 y se resumen a continuación. Las pacientes con insuficiencia venosa crónica se caracterizan por tener más antecedente familiar de insuficiencia venosa crónica ( $32 \%$ vs $18.6 \%, p<0.001)$. No se encontraron diferencias estadísticamente significativas en la edad, la situación laboral, ni en antecedente de tromboflebitis u obesidad.

Tabla 6. Análisis univariado de insuficiencia venosa crónica teniendo en cuenta características generales de la población.

\begin{tabular}{|c|c|l|l|}
\hline & $\begin{array}{c}\text { Pacientes con } \\
\text { insuficiencia venosa } \\
\text { crónica (n=503) }\end{array}$ & $\begin{array}{l}\text { Grupo } \\
\text { control } \\
\text { (n=237) }\end{array}$ & P valor \\
\hline Edad, media \pm DE & $47.7 \pm 13.1$ & $44.7 \pm 12.2$ & 0.082 \\
\hline Situación laboral, $\mathbf{n}(\%)$ & $96(19.2)$ & $40(16.8)$ & 0.542 \\
\hline Bipedestación & $58(11.6)$ & $33(13.9)$ & 0.41 \\
\hline Sedestación & & & \\
\hline
\end{tabular}


6. Resultados

\begin{tabular}{|l|l|l|l|}
\hline Antecedente de flebitis, $\mathbf{n}(\%)$ & $47(9.3)$ & $12(5)$ & 0.058 \\
\hline $\begin{array}{l}\text { Antecedentes familiares de } \\
\text { insuficiencia venosa crónica, } \mathbf{n ~ ( \% ) ~}\end{array}$ & $161(32)$ & $44(18.6)$ & $<0.001$ \\
\hline Obesidad, $\mathbf{n ~ ( \% ) ~}$ & $44(8.7)$ & $18(7.5)$ & 0.67 \\
\hline
\end{tabular}

\subsubsection{Variables analíticas y hormonales.}

En la taba 7 se disponen los resultados del análisis univariado considerando las variables analíticas. Destacamos como resultados que las pacientes con insuficiencia venosa crónica presentan una glucemia basal ligeramente más elevada que las pacientes del grupo control (83.81 \pm 11.63 vs $77.27 \pm 11.22 \mathrm{mg} / 100 \mathrm{~mL}, \mathrm{p}<0.001)$, con un mayor porcentaje de pacientes con glucemia basal alterada ( $8.8 \%$ vs $3.4 \%$ ) no estadísticamente significativo ( $p=0.087)$. Además las pacientes con insuficiencia venosa crónica presentan un nivel de creatinina sanguínea más elevado que el grupo control $(0.97 \pm 0.24$ vs 0.86 $\pm 0.22 \mathrm{mg} / 100 \mathrm{~mL}, \mathrm{p}<0.001)$, y un mayor porcentaje de pacientes con cifra de creatinina sanguínea superior a $1.2 \mathrm{mg} / 100 \mathrm{~mL}(26.5 \%$ vs $13.3 \%, \mathrm{p}=0.005)$, sin diferencias significativas en el nivel de urea. Respecto a los niveles de proteínas plasmáticas y albúmina, las pacientes con insuficiencia venosa crónica presentaban niveles ligeramente inferiores que el grupo control $(7.14 \pm 0.67$ vs $7.52 \pm 0.35 \mathrm{~g} / 100 \mathrm{~mL}$ de proteínas plasmáticas, $p<0.001$ y $4.03 \pm 0.36$ vs $4.15 \pm 0.52 \mathrm{~g} / \mathrm{dL}$ de albúmina, $p=0.02$ ), sin embargo, sólo 3 pacientes presentaban niveles compatibles con hipoproteinemia ( $2 \%$ vs $0 \%, p=0.248)$. 


\section{Resultados}

El hemograma también muestra diferencias entre las pacientes con insuficiencia venosa crónica y los controles. Las primeras se caracterizan por un nivel más bajo de hemoglobina ( $12.85 \pm 1.07$ vs $13.09 \pm 1.01 \mathrm{~g} / \mathrm{dL}, \mathrm{p}=0.05$ ) y menor número de hematíes $\left(4.62 \pm 0.24\right.$ vs $\left.4.69 \pm 0.20 \times 10^{12} / L, p=0.01\right)$ y plaquetas $(269.16 \pm 58.18$ vs $289.72 \pm 75.23$ $x 10^{9} / L, p=0.001$ ).

Las diferencias más importantes en el estudio de la coagulación fueron un nivel más alto de tiempo de protrombina $(14.02 \pm 1.52$ vs $12.97 \pm 0.98 \mathrm{seg}, \mathrm{p}<0.001)$ con valores levemente más bajos de INR (1.06 \pm 0.18 vs $1.09 \pm 0.14, p=0.04)$ en el grupo de pacientes con varices.

Tabla 7. Análisis univariado de insuficiencia venosa crónica teniendo en cuenta variables analíticas de la población.

\begin{tabular}{|c|c|c|c|}
\hline \multicolumn{1}{|l|}{} & $\begin{array}{r}\text { Pacientes con } \\
\text { insuficiencia } \\
\text { Media } \pm \text { DE }\end{array}$ & $\begin{array}{r}\text { Grupo Control } \\
\text { (n=143) } \\
\text { (n=14) }\end{array}$ & P valor \\
\hline Bioquímica & $29.76 \pm 8.11$ & $29.76 \pm 8.53$ & 0.99 \\
\hline Urea $(\mathrm{mg} / 100 \mathrm{~mL})$ & & & \\
\hline Glucosa $(\mathrm{mg} / 100 \mathrm{~mL})$ & $83.81 \pm 11.63$ & $77.27 \pm 11.22$ & $<0.001$ \\
\hline
\end{tabular}




\section{Resultados}

\begin{tabular}{|c|c|c|c|}
\hline Creatinina $(\mathrm{mg} / 100 \mathrm{~mL})$ & $0.97 \pm 0.24$ & $0.86 \pm 0.22$ & $<0.001$ \\
\hline Proteínas Totales (g/100mL) & $7.14 \pm 0.67$ & $7.52 \pm 0.35$ & $<0.001$ \\
\hline Albumina (g/dL) & $4.03 \pm 0.36$ & $4.15 \pm 0.52$ & 0.02 \\
\hline Calcio (mg/mL) & $9.16 \pm 0.67$ & $9.23 \pm 0.63$ & 0.36 \\
\hline Fosforo (mg/100mL) & $3.57 \pm 0.47$ & $3.57 \pm 0.49$ & 0.93 \\
\hline Magnesio (mEq/L) & $1.94 \pm 0.25$ & $1.92 \pm 0.69$ & 0.5 \\
\hline Hierro ( $\mu \mathrm{g} / \mathrm{dl})$ & $95.54 \pm 89.49$ & $96.40 \pm 29.29$ & 0.91 \\
\hline \multicolumn{4}{|l|}{ Hematimetría } \\
\hline Hematíes (x10²/L) & $4.62 \pm 0.24$ & $4.69 \pm 0.20$ & 0.01 \\
\hline Leucocitos $\left(\times 10^{9} / \mathrm{L}\right)$ & $6.74 \pm 1.09$ & $6.64 \pm 1.31$ & 0.49 \\
\hline Plaquetas $\left(\times 10^{9} / \mathrm{L}\right)$ & $269.16 \pm 58.18$ & $289.72 \pm 75.23$ & 0.001 \\
\hline Linfocitos (\%) & $34.70 \pm 7.49$ & $35.94 \pm 7.03$ & 0.14 \\
\hline Monocitos (\%) & $6.44 \pm 7.37$ & $6.66 \pm 7.60$ & 0.81 \\
\hline
\end{tabular}


6. Resultados

\begin{tabular}{|c|c|c|c|}
\hline Neutrófilos (\%) & $59.29 \pm 7.48$ & $55.94 \pm 9.43$ & $<0.001$ \\
\hline Hemoglobina $(\mathrm{g} / \mathrm{dL})$ & $12.85 \pm 1.07$ & $13.09 \pm 1.01$ & 0.05 \\
\hline \multicolumn{4}{|l|}{ Coagulación } \\
\hline Tiempo de Protrombina (seg) & $14.02 \pm 1.52$ & $12.97 \pm 0.98$ & $<0.001$ \\
\hline Índice de Protrombina (\%) & $97.22 \pm 11.03$ & $98.20 \pm 11.72$ & 0.46 \\
\hline INR & $1.06 \pm 0.18$ & $1.09 \pm 0.14$ & 0.04 \\
\hline TTPA (seg) & $34.79 \pm 3.2$ & $35.48 \pm 4.46$ & 0.13 \\
\hline
\end{tabular}

Los resultados de la comparación del perfil hormonal de ambos grupos se exponen en la tabla 8 . Los resultados muestran que no existen diferencias estadísticamente significativas en los valores de hormonas sexuales, pero las pacientes con insuficiencia venosa crónica presentan valores de hormona estimulante del tiroides superiores al grupo control ( $2.97 \pm 0.89$ vs $2.43 \pm 0.91 \mathrm{mU} / \mathrm{L}, \mathrm{p}=0.009)$. 


\section{Resultados}

Tabla 8. Análisis univariado de insuficiencia venosa crónica teniendo en cuenta el perfil hormonal de la población.

\begin{tabular}{|c|c|c|c|}
\hline Media \pm DE & $\begin{array}{l}\text { Pacientes con } \\
\text { insuficiencia } \\
\text { venosa crónica } \\
\qquad(n=41)\end{array}$ & $\begin{array}{l}\text { Grupo Control } \\
\qquad(n=41)\end{array}$ & $P$ valor \\
\hline \multicolumn{4}{|l|}{ Hormonas } \\
\hline $\mathrm{FSH}(\mathrm{mU} / \mathrm{mL})$ & $6.12 \pm 2.19$ & $5.70 \pm 1.56$ & 0.32 \\
\hline $\mathrm{LH}(\mathrm{mU} / \mathrm{mL})$ & $5.44 \pm 1.87$ & $5.84 \pm 1.70$ & 0.31 \\
\hline TSH (mU/L) & $2.97 \pm 0.89$ & $2.43 \pm 0.91$ & 0.009 \\
\hline Estradiol (pg/mL) & $88.50 \pm 34.94$ & $88.31 \pm 31.45$ & 0.97 \\
\hline Progesterona (ng/mL) & $12.45 \pm 3.78$ & $11.73 \pm 3.52$ & 0.37 \\
\hline PRL (ng/mL) & $10.78 \pm 4.81$ & $10.07 \pm 4.23$ & 0.48 \\
\hline $\mathrm{AMH}(\mathrm{ng} / \mathrm{mL})$ & $2.33 \pm 0.67$ & $2.06 \pm 0.74$ & 0.09 \\
\hline
\end{tabular}




\subsubsection{Variables ginecológicas}

La tabla 9 y las figuras 1 a 4 recogen la comparación de las variables ginecológicas recogidas entre las pacientes con insuficiencia venosa crónica y el grupo control.

Destacamos que entre las pacientes con insuficiencia venosa crónica hay más pacientes menopaúsicas $(43.5 \%$ vs $16.5 \%, \mathrm{p}<0.001)$ y con uso de terapia hormonal (49.1\% vs $25.3 \%, p<0.001$ ). También es mayor el porcentaje de pacientes que refieren gestaciones ( $82 \%$ vs $59 \%, p<0.001$ ) e hijos a término ( $81 \%$ vs $57 \%, p<0.001)$, así como el número medio de los mismos $(2.01 \pm 1.03$ vs $1.63 \pm 0.89$ número de gestaciones, $p<0.001$, y $1.8 \pm 0.83$ vs $1.45 \pm 0.71$ número de hijos, $p<0.001)$. 


\section{Resultados}

Tabla 9. Análisis univariado de insuficiencia venosa crónica teniendo en cuenta los antecedentes ginecológicos de la población.

\begin{tabular}{|c|l|l|l|}
\hline & $\begin{array}{l}\text { Pacientes con } \\
\text { insuficiencia } \\
\text { venosa crónica } \\
\text { (n=503) }\end{array}$ & $\begin{array}{l}\text { Grupo } \\
\text { control } \\
\text { (n=237) }\end{array}$ & valor \\
\hline Menarquia, $\mathbf{n}$ (\%) & $503(100)$ & $237(100)$ & 0.999 \\
\hline Edad, media \pm DE & $12.35 \pm 0.99$ & $12.32 \pm 0.95$ & 0.743 \\
\hline Menopausia, $\mathbf{n}$ (\%) & $219(43.5)$ & $39(16.5)$ & $<0.001$ \\
\hline Edad, media \pm DE & $49.2 \pm 3.1$ & $49.26 \pm 3$ & 0.84 \\
\hline Gestación, $\mathbf{n}$ (\%) & $412(82)$ & $139(59)$ & $<0.001$ \\
\hline Número de gestaciones, media \pm & $2.01 \pm 1.03$ & $1.63 \pm 0.89$ & $<0.001$ \\
\hline DE & & $60(25.3)$ & $<0.001$ \\
\hline Hijos, $\mathbf{n}$ (\%) & $405(81)$ & $134(57)$ & $<0.001$ \\
\hline Número de hijos, media \pm DE & $1.8 \pm 0.83$ & $1.45 \pm 0.71$ & $<0.001$ \\
\hline Terapia hormonal, $\mathbf{n}(\%)$ & $247(49.1)$ & & \\
\hline
\end{tabular}




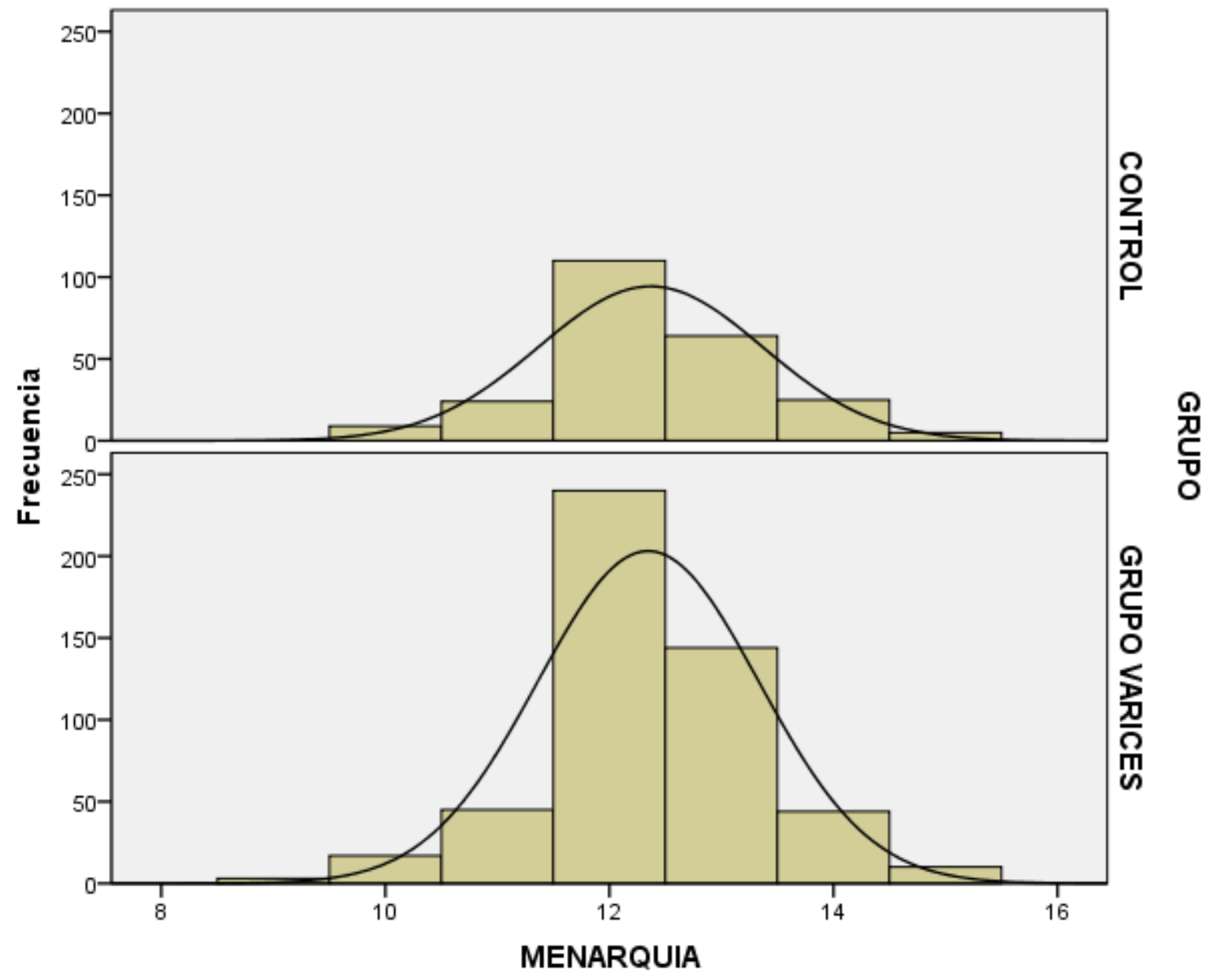

Figura 9. Distribución de la edad media de la menarquía en el grupo con patología varicosa y el grupo control. 


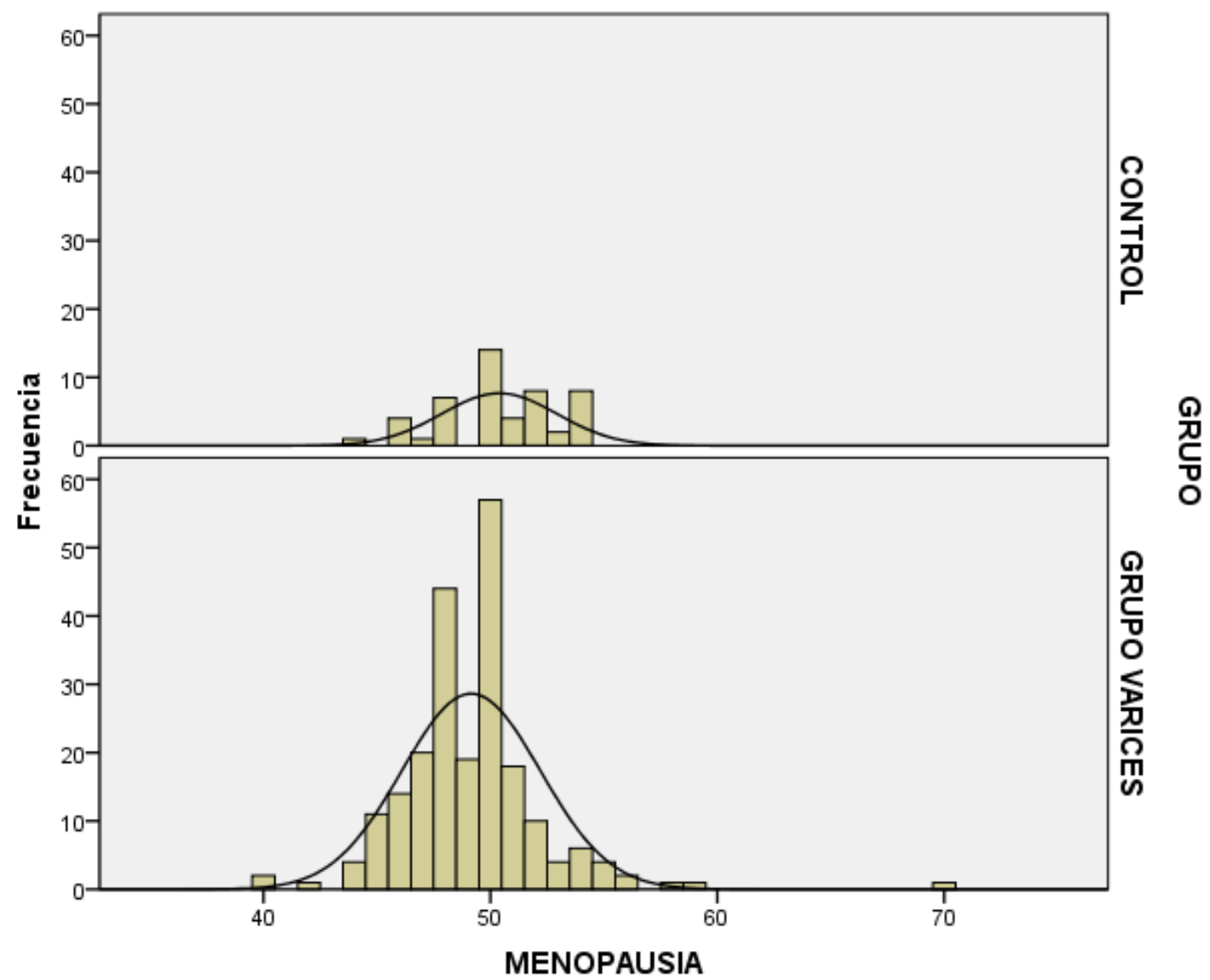

Figura 10. Distribución de la edad media de la menopausia en el grupo con patología varicosa y el grupo control. 


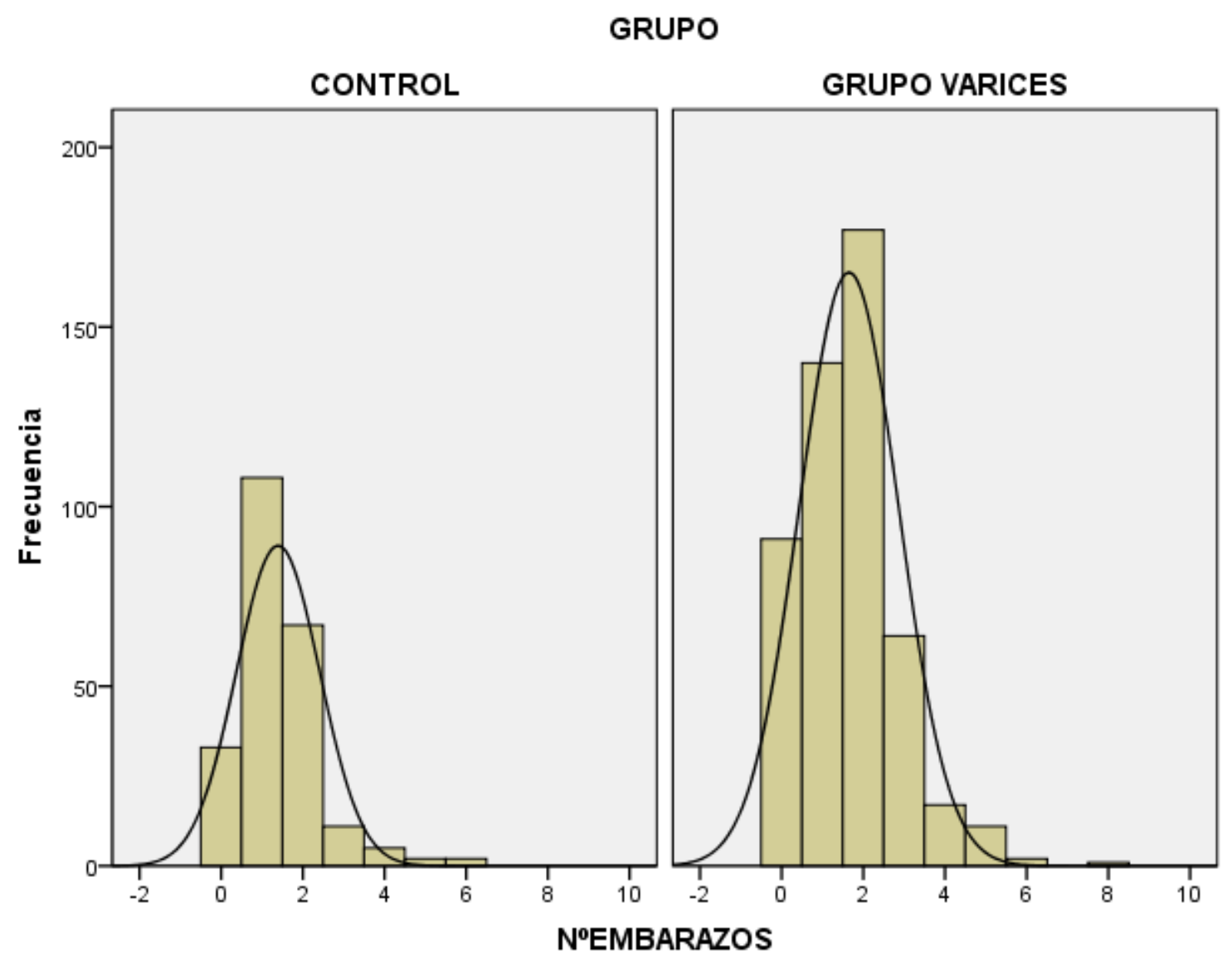

Figura 11. Distribución de la media del número de gestaciones en el grupo con patología varicosa y el grupo control. 


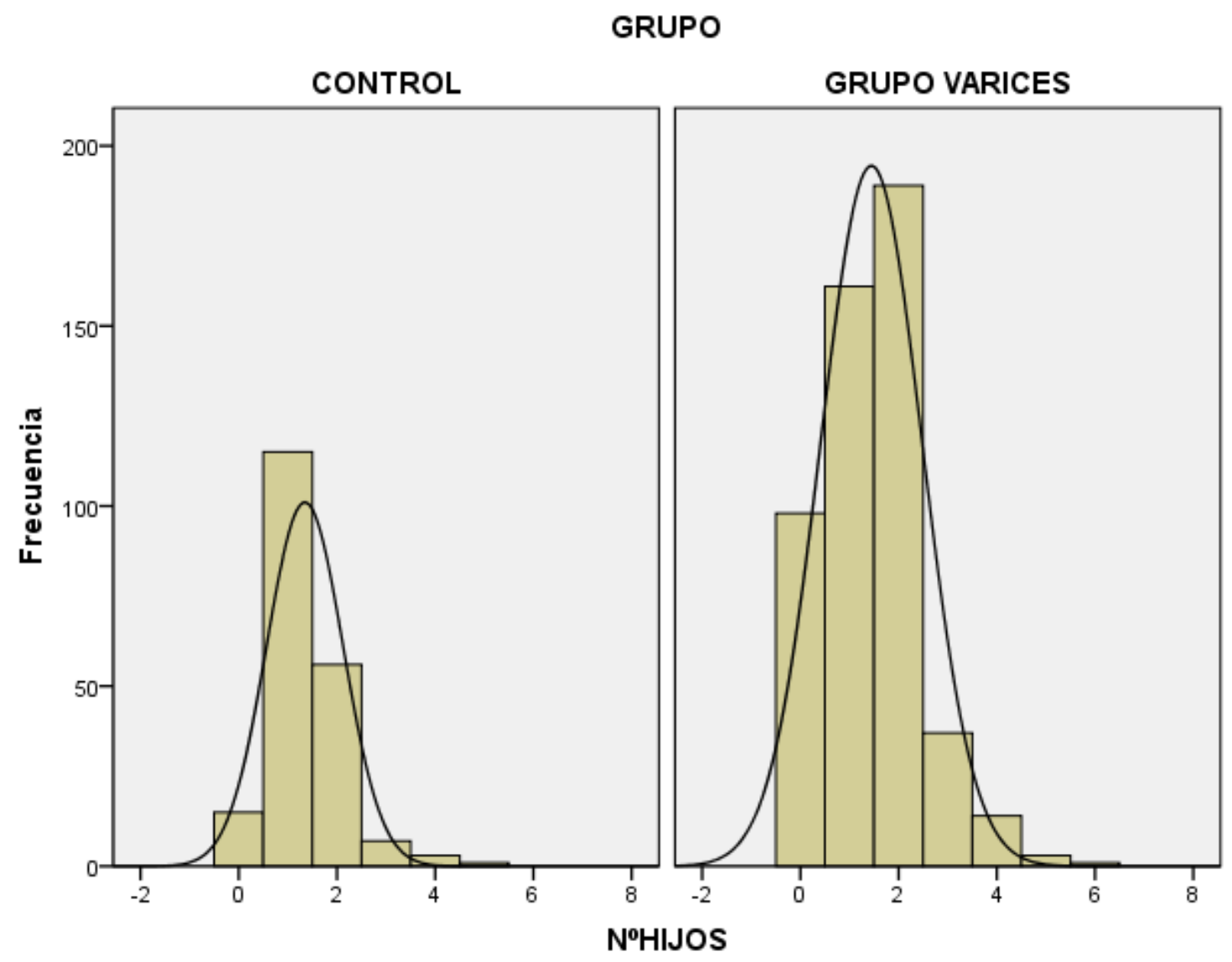

Figura 12. Distribución de la media del número de hijos en el grupo con patología varicosa y el grupo control. 
7. DISCUSIÓN 

El síndrome varicoso presenta gran incidencia y prevalencia, y muy especialmente en la mujer en una serie de circunstancias inherentes al sexo femenino que son factores predisponentes o desencadenantes de esta enfermedad como son el estado hormonal, el embarazo con sus implicaciones, los perfiles laborales más desarrollados por la mujer y otras circunstancias. Esto ha motivado al personal sanitario a valorar estos factores relacionando de una forma objetiva perfil femenino y síndrome varicoso, sin embargo, la documentación científica existente es muy escasa. Posiblemente esta situación sea derivada del perfil del personal sanitario que atiende la patología varicosa, más motivado por el aspecto clínico del enfermo, y muy especialmente en desarrollar una terapéutica quirúrgica, que por los aspectos epidemiológicos de la misma. Por otro lado, en muchas ocasiones al facultativo especialista en angiología y cirugía vascular le motivan más aspectos de la patología arterial, especialmente grandes intervenciones relacionados con vasos de gran tamaño o patología de transcendencia vital. El síndrome varicoso ha sido poco considerado y etiquetado como una patología de poca relevancia clínica, más relacionada con aspectos estéticos. Son las complicaciones las que inicialmente han incrementado la valoración de los facultativos por este tipo de patología, en especial las varicorragias por su presentación más o menos alarmista, la varicoflebitis por el temor de desarrollo de procesos trombóticos que pudieran derivar en situaciones vitales en casos extremos cómo la embolia pulmonar, y finalmente la úlcera post-flebítica que desencadena una situación de menoscabo de la calidad de vida por la pérdida de soporte cutáneo y la necesidad de cuidados hasta su cicatrización. 
Como ya se ha hecho referencia la incidencia y prevalencia del síndrome varicoso es altísima y raro es el ser humano que no lo sufre en mayor o menor grado a lo largo de su vida. En el caso de la mujer la incidencia es mayor considerando las circunstancias previamente comentadas. El análisis de los distintos factores del estudio nos aporta una información trascendental a la hora de considerar de una forma objetiva la relación de síndrome varicoso y sexo femenino. Relacionarlo con distintas situaciones desde el punto de vista hormonal como menarquia, menopausia y toma de hormonas aporta información soportada en una valoración contable y evidenciada por los hechos y por tanto objetiva. Otro aspecto relevante es el número de embarazos, por lo que la gestación supone en cambios hormonales en la mujer, junto con la considerada situación de compresión venosa abdomino-pélvica por parte del feto. Finalmente, se ha intentado ir más allá en un estudio analítico incluyendo la determinación de las hormonas sexuales más importantes, sin embargo, aunque se obtienen datos interesantes que pueden ser generadores de hipótesis, la evaluación de los resultados hormonales está limitada por la complejidad inherente del sexo femenino y el ciclo menstrual.

Las fortalezas del estudio se centran en el gran número de pacientes evaluadas e incluidas en el estudio con estimación de datos concretos donde no ha existido dispersión informativa al haber considerado los aspectos más objetivables y libres de apreciación subjetiva. El hecho de haber considerado numerosos aspectos hubiera chocado con la inconcreción, la dispersión informativa y la imprecisión en la adquisición del dato. Estas circunstancias hacen que los diseños con gran número de pacientes incluidos en los mismos deben de ser muy concretos, obteniendo datos relevantes. 
Presentamos un estudio de casos y controles sobre el perfil ginecológico de las pacientes con síndrome varicoso primario atenidas en nuestro medio. Se trata del primer trabajo que se ha focalizado en el estudio sistemático de los antecedentes ginecológicos en pacientes con insuficiencia venosa crónica atendidos en las consultas de Angiología y Cirugía Vascular.

A continuación exponemos los principales hallazgos del trabajo, para posteriormente realizar una discusión pormenorizada de los resultados.

- Las mujeres con insuficiencia venosa crónica atendidas en nuestro medio presentan una edad media de 47.7 años, con una baja tasa de obesidad (8.7\%) y una alta frecuencia de antecedentes familiares de síndrome varicoso primario (32\%). La situación laboral se relacionó con bipedestación prolongada en el $19.2 \%$ de los casos.

- La mayoría de pacientes con insuficiencia venosa crónica presentan datos analíticos dentro de la normalidad. Destacamos una tasa de glucemia basal alterada en el $8.8 \%$ de los pacientes y un $26.5 \%$ con valores de creatinina iguales o superiores a $1.2 \mathrm{mg} / \mathrm{dL}$.

- Entre las mujeres con síndrome varicoso primario existe una tasa de menopausia del $43.5 \%$, a una edad media de $49.2 \pm 3.1$ años. Además, el porcentaje de pacientes con gestación en algún momento de su vida es del $82 \%$, con una media de gestaciones de $2.1 \pm 1.03$. El $49.1 \%$ de las pacientes se encuentran bajo tratamiento hormonal. 


\section{Discusión}

- En comparación con el grupo control, las pacientes con síndrome varicoso primario presentan más antecedentes familiares de varices. Respecto a los parámetros analíticos, las pacientes con varices presentan valores más elevados tanto de glucemia en ayunas como de creatinina, y valores inferiores de hemoglobina. Destaca también mayor porcentaje de pacientes menopaúsicas y un mayor número de embarazos.

- El síndrome varicoso primario de las pacientes atendidas en nuestro medio se caracteriza por presentar en el $\mathbf{9 7 . 4 \%}$ de los casos unos estadios precoces de enfermedad (C1-C2), con frecuente afectación bilateral (88.9\%). La forma de manifestación más frecuente es la pesadez de piernas (70.6\%), pero hasta en un $14.7 \%$ de los casos la enfermedad es silente y el motivo de consulta es únicamente estético. Destaca una baja tasa de uso de medidas preventivas con compresión elástica (33.4\%), mientras que la tasa de cirugía varicosa previa fue del $20.3 \%$.

Hemos realizado una revisión sistemática de la literatura publicada en español e inglés y referenciada en buscadores como PubMed, BioMed Central y Google Scholar. Las palabras claves utilizadas en la búsqueda han sido "varices", "insuficiencia venosa crónica", "varices y gestación", varices y anticonceptivos". Además, otros estudios han sido revisados a partir de fuentes secundarias, incluyendo referencias de los primeros estudios encontrados. 


\subsection{PERFIL GENERAL DE LAS PACIENTES CON INSUFICIENCIA VENOSA CRÓNICA.}

A continuación vamos a discutir una a una las variables de carácter general estudiadas en la población con insuficiencia venosa crónica y su comparación con el grupo control. De estas variables, solamente los antecedentes familiares de insuficiencia venosa crónica se han relacionado en el análisis univariado con el desarrollo de la patología venosa.

\subsubsection{La edad}

La edad media de nuestras pacientes fue de 47.7 años, que es ligeramente inferior a la publicada por las encuestas nacionales DETECT-IVC 2000 y DETECT-IVC 2006 que situaban la edad media de la enfermedad en 51.4 y 52.3 años respectivamente. ${ }^{30,31}$ Esto puede ser debido a cambios culturales progresivos; en el momento actual las mujeres consultan con más frecuencia por este tipo de patología probablemente por motivos estéticos sin limitación de su calidad de vida, como se confirma con la alta frecuencia de pacientes asintomáticas (14.7\%) y con estadios precoces de la enfermedad (97.4\%).

Como ya hemos comentado previamente, la edad es un factor de riesgo primario y secundario para el desarrollo de EVC, sin embargo, dada su relación directa con el grado de reflujo venoso, su principal valor podría radicar en la aceleración del desarrollo de la enfermedad, favoreciendo la aparición de complicaciones. Factores relacionados como la pérdida de masa y tono muscular, la disminución de la actividad física o el aumento del tejido conectivo de la pared vascular podrían explicar la influencia de la edad en la evolución de la enfermedad, como ya ha sido señalado previamente. ${ }^{34,36}$ 


\section{Discusión}

\subsubsection{La obesidad}

No hemos encontrado diferencias en la prevalencia de obesidad entre grupos., siendo además el porcentaje de pacientes obesos (IMC $>30 \mathrm{Kg} / \mathrm{m}^{2}$ ) muy similar en ambos.

Probablemente esto suceda por las limitaciones de nuestro estudio respecto al tamaño muestral y las características de la población control. Al utilizar un grupo control con pacientes derivadas de consulta de Angiología y Cirugía Vascular, introducimos un sesgo de selección, ya que muy posiblemente estas pacientes presenten un perfil de riesgo cardiovascular muy diferente al de la población sana global.

De hecho, existen diversos artículos que apoyan la consideración de la obesidad como factor de riesgo para el desarrollo de insuficiencia venosa crónica, no solo a nivel de las piernas sino también en otras localizaciones, si bien, su influencia podría estar más relacionada con la progresión de la enfermedad a estadios clínicos más avanzados que con el desarrollo de la misma. ${ }^{34}$

En muchos casos la presencia de obesidad influye en la decisión terapéutica al considerarse factor predisponente $\mathrm{y}$ eliminable antes de realizar un tratamiento quirúrgico. Esta circunstancia condiciona que este perfil de mujer obesa permanezca en muchos casos con las varices al no eliminarse la causa predisponente por lo que interfiere en muchas ocasiones la claridad de los datos.

El tejido adiposo es un tejido con actividad endocrina, y como parte de esta actividad interviene en la producción de hormonas esteroideas. De hecho, se describe una situación de hiperandrogenismo en mujeres obesas. ${ }^{105,106,107}$ 
Por otro lado, existe una estrecha relación entre obesidad y menopausia, la cual se ha probado como factor aislado e independiente para el desarrollo de EVC, por lo que valorar la influencia independiente del peso en esta patología puede resultar complicado. Sin embargo, un estudio con tal propósito relacionó la asociación entre el índice de masa corporal, la capacitancia venosa y la evidencia clínica de varices después del ajuste para hormonas sexuales en mujeres posmenopáusicas, demostrando que la asociación entre obesidad y desarrollo de varices es independiente del estado hormonal. $^{42}$

\subsubsection{Antecedentes personales}

Nos hemos limitado a estudiar los antecedentes personales más relevantes en el grupo de pacientes con insuficiencia venosa crónica. La comparación con el grupo control carecía de interés y valor científico debido al bajo número de pacientes con patología, y a la imposibilidad de agrupamiento de las mismas.

Entre los antecedentes personales, los más frecuentes en el grupo de pacientes afectas de insuficiencia venosa crónica son: hipertensión arterial, la diabetes mellitus, el cáncer de mama, la enfermedad tiroidea y el síndrome depresivo. Es importante resaltar que si bien el número de pacientes con patología es bajo, la presencia de la comorbilidad asociada puede tener mucho valor clínico en el desarrollo de la enfermedad en cada caso como se expondrá a continuación. Según los estudios revisados, se he demostrado que las principales comorbilidades asociadas al desarrollo de varices y progresión de las mismas son: diabetes mellitus, hipertensión arterial, insuficiencia renal y EPOC o enfisema pulmonar. ${ }^{108}$ 
A continuación vamos a discutir uno a uno las principales patologías que hemos encontrad en el grupo de pacientes con insuficiencia venosa crónica:

\subsubsection{Cáncer de mama:}

Si bien no existen estudios que apoyen una relación directa entre cáncer de mama y desarrollo de varices, el uso de Tamoxifeno sí se ha relacionado con un riesgo incrementado de patología venosa, fundamentalmente trombosis venosa profunda en pacientes con coagulopatía de base. ${ }^{109,} 110$ La trombosis venosa profunda favorece el desarrollo de varices por sobrecarga de volumen del sistema venoso superficial, y por tanto, podría justificar la relación entre cáncer de mama y EVC. Si bien, la trombosis venosa profunda fue un criterio de exclusión en nuestro estudio, conviene recordar que en numerosas ocasiones esta situación clínica cursa de forma asintomática. ${ }^{111,112}$

\subsubsection{Hipertensión arterial}

La hipertensión arterial es una enfermedad sistémica, que no afecta únicamente al lecho vascular arterial, si no que revela la existencia de una disfunción endotelial global.

Clínicamente, esta afectación produce consecuencias más importantes a nivel arterial, con el desarrollo de ateroesclerosis y enfermedad cardiovascular, sin embargo, esto no quiere decir que en estas situaciones el funcionamiento del sistema venoso esté preservado. De hecho, la hipertensión arterial afectaría al sistema venoso tanto de forma anterógrada, como retrógrada por insuficiencia cardiaca, sobrecargando de presión al sistema venoso. 
A esto habría que añadir la disfunción endotelial y los efectos proinflamatorios derivados de la misma, que también tienen un efecto deletéreo. ${ }^{113}$ La hipertensión arterial actuaría como un factor primaria, favoreciendo la aparición de varices por disfunción endotelial y de las válvulas venosas, y como factor modificador de la enfermedad, provocando su evolución hacia estadios clínicos más avanzados.

Aunque la hipertensión venosa no es el único factor en el desarrollo de la insuficiencia venosa crónica, y en realidad la fisiopatología de la misma no está claramente establecida, muchas de las nuevas terapias que se están desarrollando para el tratamiento de las varices tienen como diana u objetivo principal disminuir la hipertensión venosa. ${ }^{114,115}$

\subsubsection{Diabetes Mellitus}

En los resultados de nuestro estudio vemos como la diabetes es una de las comorbilidades más frecuentes en el grupo de pacientes con varices. Aunque no hemos profundizado en la diferenciación entre los tipos de diabetes o el estadio clínico de la misma, si hemos realizado una determinación basal de glucemia en un subgrupo importante de pacientes que muestran un mayor nivel medio de glucemia y un mayor porcentaje de glucemia basal alterada entre las pacientes con insuficiencia venosa crónica.

El pie diabético es una de las principales complicaciones de la diabetes mellitus, y es responsable de una gran parte de la morbilidad y mortalidad derivada de la enfermedad. ${ }^{116,117,118}$ 
Se trata de úlceras tróficas que en su gran mayoría presentan un origen venoso, generalmente como evolución de una variz, y solamente en un $4 \%$ de los casos el origen de la lesión vascular es arterial. ${ }^{119,} 120$

La coexistencia de lesiones ulcerosas y venas varicosas, debe hacer pensar en el origen venoso de las mimas, estableciéndose un círculo vicioso entre diabetes mellitus, insuficiencia venosa crónica y úlcera vascular. ${ }^{121}$ Además sabemos que la insulina tiene un efecto vasodilatador, y que existen receptores de la misma a nivel endotelial, que podrían justificar la disfunción vascular en caso de resistencia insulínica. ${ }^{122}$

\subsubsection{Antecedentes familiares}

Existen estudios que muestran una asociación estadísticamente significativa entre los antecedentes familiares de la enfermedad y el desarrollo y progresión de la misma. ${ }^{55,123}$ En trombofilias hereditarias se ha determinado agregación familiar de la trombosis venosa profunda en pacientes con insuficiencia venosa crónica. ${ }^{124}$

A favor de estos estudios, que consideran la existencia de factores genéticos que influyan en el desarrollo de varices, se encuentran nuestros resultados. Un $32 \%$ de las pacientes con varices refería la existencia de esta misma patología en otros miembros de la familia. Un factor que puede influir en estos resultados podría ser que los pacientes con una enfermedad son más conscientes de la presencia de la misma en otros miembros de la familia, ya que en la mayoría de los estudios, la agregación familiar no es comprobada clínicamente. ${ }^{40}$ 
Otros estudios sugiere que si bien podría haber una cierta asociación familiar con influencia de factores genéticos, ${ }^{12,22,41}$ ésta asociación presenta una influencia poco significativa, y su efecto podría estar siendo magnificado por una agregación de otros factores ambientales modificables. ${ }^{125}$ Además los hábitos son diferentes según las familias, de tal forma que las costumbre también podrían influir en el desarrollo de la patología y no solo aspectos genéticos, del mismo modo que sucede con otras enfermedades como la obesidad.

\subsubsection{Bipedestación laboral}

Si bien la bipedestación laboral es más frecuente en el grupo de pacientes con insuficiencia venosa crónica, la diferencia con el grupo control no es estadísticamente significativa, por lo que los resultados podrían deberse al azar.

Si bien se trata de una variable ampliamente analizada en los diferentes estudios, no existe una conclusión claramente establecida al respecto. Es cierto que la situación laboral es importante desde el punto de vista clínico por el tiempo que supone, sin embargo, se trata de una variable difícil de cuantificar. Algunos estudios comparan diferentes ocupaciones laborales en las que es fundamental el periodo en bipedestación prolongada en comparación con la población general sin obtenerse resultados significativos. ${ }^{126}$ Sin embargo, otros estudios encuentran asociación directa con el número de horas de trabajo, siendo la prevalencia de EVC más frecuente en pacientes más antiguos en su puesto laboral o con mayor número de horas laborales. ${ }^{127}$ Estos datos hay que interpretarlos con cautela, ya que la posibilidad de sesgos es amplia, y no es únicamente la postura laboral la que determina el riesgo, sino el grado de movilidad del trabajador, ya que como hemos explicado previamente, la actividad física sería un factor protector. ${ }^{128}$ 
La mujer, a diferencia del varón suele ser más propensa a la utilización de medios de compresión elástica, asumiendo su utilización de forma más generalizada. En muchos casos y en determinadas profesiones en especial en los medios hospitalarios se utilizan de forma preventiva, por lo que modifica el perfil de la paciente. Por otro lado este medio terapéutico de contención elástica no es tolerado por algunas pacientes en algunos casos con un incipiente rechazo por la incomodidad de su uso o lo inapropiado de la selección del medio.

\subsection{PERFIL ANALÍTICO Y HORMONAL DE LAS PACIENTES CON ISUFICIENCIA VENOSA CRÓNICA.}

Se ha realizado un estudio analítico de un subgrupo de pacientes y controles para evaluar su relación con el desarrollo de insuficiencia venosa crónica. Aunque encontramos diferencias estadísticamente significativas en algunos de los parámetros evaluados, los resultados no son clínicamente relevantes ya que las diferencias son pequeñas variaciones. Discutimos a continuación cada uno de los resultados obtenidos.

\subsubsection{Bioquímica:}

De los datos obtenidos en el estudio de la analítica bioquímica de ambos grupos los hallazgos más importantes han sido las diferencias entre ambos grupos en los valores de glucosa basal, creatinina, proteínas totales y albúmina.

Como hemos comentado previamente no hemos realizado una comparación entre ambos grupos de las comorbilidades, sin embargo hemos podido comprobar que la media del valor de glucemia basal es superior en el grupo de varices respecto al grupo control de forma estadísticamente significativa, fundamentalmente a expensas de un mayor grupo de pacientes con valores de glucemia basal alterada en ayunas. 
Mati et al en su estudio sobre la insuficiencia venosa crónica y comorbilidades demostraron que la diabetes aparece como una de las comorbilidades más frecuentes en la IVC en mujeres, algo que no ocurre en varones, aumentando hasta 17 veces el riesgo de presentar estadios clínicos avanzados de la enfermedad. ${ }^{129}$

Los resultados respecto a los valores de creatinina, han mostrado diferencias estadísticamente significativas entre ambos grupos, observándose niveles superiores en el grupo de pacientes con IVC. Además en este grupo un $26.5 \%$ de las pacientes han presentado un valor mayor o igual a $1.2 \mathrm{mg} / 100 \mathrm{~mL}$. Si bien sabemos que el valor de creatinina sanguínea puede estar afectado por diferentes variables como el estado de hidratación, la diferencia entre grupos es llamativa. Claramente existe relación entre insuficiencia renal y formas avanzadas de la insuficiencia venosa crónica, sin embargo, existe la posibilidad de que la insuficiencia venosa crónica fuera un marcador de daño endotelial incipiente que justifique la diferencia de función renal entre pacientes. ${ }^{130}$

La hipoproteinemia podría justificar el edema por disminución de la presión oncótica intravascular con aumento del volumen de tejido intersiticial, sin embargo, y aunque el nivel de proteínas y albúmina es inferior en el grupo de pacientes con insuficiencia venosa crónica, no existen pacientes con valores en rangos patológicos que justificaran una influencia directa de las proteínas en los resultados del estudio. Por tanto, si bien el hallazgo puede ser generador de hipótesis, creemos poco probable que las proteínas plasmáticas hayan artefactado los resultados del estudio. ${ }^{131,132}$ 


\section{Discusión}

7.2.2. Citología sanguínea

Entre los valores de la citología sanguínea destaca un nivel más bajo de plaquetas y hemoglobina en las pacientes con insuficiencia venosa crónica. Estos resultados son difíciles de evaluar, ya que no hemos encontrado estudios que relacionen el síndrome de insuficiencia venosa crónica ni con la plaquetopenia ni con la anemia. Obviamente la plaquetopenia puede favorecer la varicorragia, así en casos de plaquetopenia disfuncional también podrían estar favorecidos los fenómenos trombóticos que tan importantes son en la evolución de la enfermedad. ${ }^{133}$ Sin embargo, dado el perfil de nuestra población con insuficiencia venosa crónica es poco probable que exista una relación causa-efecto entre el nivel de plaquetas y el desarrollo de varices. Algo similar ocurre con la anemia, si bien puede actuar como un factor modificador de la enfermedad exacerbando síntomas como cansancio o debilidad, o incluso empeorando la situación clínica de la variz por la hipoxia relativa y la taquicardia reactiva, parece poco probable que en nuestro estudio se establezca una relación causa-efecto ya que los niveles de anemia son límites en todos los casos. ${ }^{134}$

\subsubsection{Coagulación:}

En relación con los parámetros de coagulación no hemos encontrado grandes diferencias en nuestro estudio entre los pacientes con IVC y la población control. Si bien existen diferencias estadísticamente significativas en INR y tiempo de protrombina, estas diferencias no son clínicamente relevantes ya que no suponen valores fuera de los rangos normales de laboratorio. Evidentemente las coagulopatías pueden interferir en el desarrollo de la patología venosa, tanto por fenómenos trombóticos como hemorrágicos, sin embargo, igual que ha sucedido con otros hallazgos analíticos, parece poco probable que diferencias tan pequeñas entre grupos justifiquen los resultados de nuestro estudio. ${ }^{135}$ 


\subsubsection{Analítica hormonal:}

Si bien no hemos encontrado diferencias en los valores de hormonas sexuales entre ambos grupos, es necesario asumir una limitación importante en este sentido; los valores normales de las hormonas sexuales (FSH, LH, Estradiol y Progesterona) varían a lo largo del ciclo menstrual y según la edad de la paciente, y dado el carácter retrospectivo de la inclusión de estas variables, no hemos podido tener en cuenta estos factores. En este sentido serían necesarios estudios ajustados por los factores de corrección para sacar conclusiones contundentes, sin embargo, dada la normalidad e igualdad de los resultados entre grupos parece poco probable que se encontraran diferencias relevantes entre grupos. ${ }^{136}$

Los valores de prolactina son superiores en la mujer que en el varón, pero no se modifican a lo largo del ciclo menstrual. Si pueden influir otros factores como el estrés emocional o físico, comidas con alto contenido proteico y situaciones como el embarazo o la lactancia. De hecho, se recomienda confirmar un valor alterado de prolactina, por la alta tasa de falsos positivos. Sin embargo, en nuestro estudio ninguna paciente ha presentado alteraciones en el nivel de prolactina, ni se han encontrado diferencias significativas entre grupos. ${ }^{137}$

El nivel de AMH refleja el tamaño del conjunto de folículos primordiales y puede utilizarse como marcador bioquímico de la función ovárica. En las mujeres adultas, los niveles de $\mathrm{AMH}$ disminuyen con la edad; de tal forma que podría ser indetectable durante la menopausia. ${ }^{138,139,140}$ No hemos encontrado diferencias en la media del valor de $\mathrm{AMH}$ entre ambos grupos, y si bien existen pacientes con valores inferiores al límite de laboratorio en ambos grupos, sorprende un nivel medio estrictamente normal a pesar de una edad media avanzada en ambos grupos que justificaría niveles menores para ambos grupos. 
Respecto a los valores de TSH, aunque en ambos grupos todas las pacientes han presentado valores de hormona estimulante del tiroides normales, sí que hemos observado diferencias en la media entre ambos grupos, siendo ligeramente superior el valor medio de hormona en el grupo de pacientes con IVC. No existe información objetiva en la literatura que investigue esta relación causal, y si bien alteraciones del nivel tiroideo, tanto por exceso como por defecto, podrían incrementar al menos los síntomas de la enfermedad, se trata sólo de una hipótesis que requeriría estudios específicos al respecto para darla valor.

\subsection{PERFIL GINECOLÓGICO DE LAS PACIENTES CON INSUFICIENCIA VENOSA CRÓNICA}

Las mujeres con insuficiencia venosa crónica presentan un perfil ginecológico determinado, diferente de la población control. En el análisis univariado hemos podido comprobar que las pacientes con IVC presentaban con más frecuencia menopausia, referían un mayor número de gestaciones y de hijos y un mayor uso de terapia hormonal.

Se puede apreciar que esas situaciones representan estados hormonales muy contrapuestos lo que refleja la importancia y al mismo tiempo la dificultada de evaluación del factor hormonal en el desarrollo de la enfermedad. ${ }^{41,42,43} \mathrm{El}$ mecanismo por el cual los estrógenos intervienen en la génesis y desarrollo de la enfermedad venosa crónica es difícil de establecer, pero como ya hemos comentado previamente, existen diferentes mecanismos que varían en cada momento del ciclo vital de la mujer. ${ }^{45}$ A continuación vamos a discutir los factores ginecológicos más relevantes. 


\subsubsection{Terapia hormonal}

La mayoría de estudios refieren que no existe asociación entre el uso de anticoncepción hormonal combinada y la aparición de varices. ${ }^{141}$ Sin embargo, en nuestro estudio el $\mathbf{4 9 . 1 \%}$ de pacientes con varices refiere la toma de tratamientos hormonales frente al $25.3 \%$ de los controles, una diferencia que no sólo es estadísticamente significativa $(p<0.001)$, si no también clínicamente relevante.

Sí que existe más evidencia sobre un teórico riesgo tromboembólico aumentado en pacientes con insuficiencia venosa crónica de base presentaban un riesgo aumentado de desarrollar trombosis venosa profunda en contexto de toma de anticonceptivos combinados. ${ }^{142}$ Estos estudios presentan sesgos de selección importantes, y la extracción de conclusiones debe realizarse con cautela. De hecho, la Sociedad Española de Contracepción permite el uso de anticonceptivos hormonales combinados sin limitaciones en contexto de EVC o flebitis superficial, ya que su uso en este contexto no ha demostrado un riesgo incrementado de trombosis venosa profunda. ${ }^{143}$

No podemos obviar la relación que existe entre trombosis venosa profunda y uso de anticonceptivos hormonales combinados. Este riesgo es máximo al inicio del tratamiento y disminuye posteriormente, manteniéndose ligeramente por encima de la población control, siendo situaciones concretas y factores de riesgo adicionales (coagulopatía, tabaquismo, obesidad...) los que justifiquen generalmente esta diferencia de riesgo. ${ }^{144,145}$ 
Inicialmente se pensaba que el factor hormonal que realmente influía en el desarrollo de trombosis venosa profunda eran los estrógenos. Sin embargo, en 1995 en Reino Unido se evidenció un mayor riesgo en pacientes consumidoras de anticonceptivos combinados con gestágenos de tercera generación (gestodeno y desogestrel) frente a los de segunda generación, como el levonogestrel o la noretisterona. ${ }^{146}$ Por otro lado, compuestos exclusivamente de gestágenos parecen no influir en el desarrollo de trombosis venosa profunda, por lo que probablemente el factor determinante sea la dosis de estrógeno, y el tipo de gestágeno acompañante sea un factor secundario. ${ }^{147,148}$

\subsubsection{Menarquia}

En nuestro trabajo, no se han encontrado diferencias significativas en la edad de la menarquia entre pacientes con EVC y la población control.

Si bien no existen en la literatura trabajos que hayan estudiado la relación entre la edad de aparición de la menarquía y el desarrollo de varices de forma específica, sí que existen estudios que la asocian a la patología cardiovascular en general. Además, existe un estudio que sugiere una posible asociación entre la presencia de menarquia dolorosa y el desarrollo de insuficiencia venosa crónica más sintomática, sin embargo, los datos no son concluyentes, y no se puede obviar que el estudio podría estar sesgado por tratarse de pacientes que demandan más asistencia sanitaria en general. ${ }^{149}$

La relación entre la edad de la menarquia y las enfermedades de tipo vascular tendría una relación epidemiológica en forma de U. De esta forma, edades extremas de menarquia se asocian a mayor enfermedad vascular, fundamentalmente enfermedad coronaria, y en menor medida cerebrovascular e hipertensión arterial, lo que podría condicionar una mayor mortalidad en estas pacientes. ${ }^{150}$ 
Además, no podemos obviar la estrecha relación que existe entre menarquia precoz e índice de masa corporal. Una menarquia de aparición precoz se asocia a un índice de masa corporal más elevado, también durante la edad adulta, y un riesgo aumentado de desarrollar síndrome metabólico. ${ }^{151}$

\subsubsection{Menopausia}

A pesar de que no existen diferencias significativas en la edad de inicio de la menopausia entre de ambos grupos si hemos observado que un mayor número de pacientes con insuficiencia venosa crónica han alcanzado la menopausia (43.5\% vs 39\%, $p<0.001)$.

Los estrógenos tienen efectos beneficiosos sobre el sistema cardiovascular. Este es uno de los motivos por los que las enfermedades cardiovasculares afectan de forma diferente a hombres y mujeres, de tal modo que las mujeres tienen una cierta protección frente a este tipo de enfermedades hasta la menopausia. De esta forma, los hombres tienen la presión arterial más elevada que las mujeres de la misma edad, y además más incidencia de enfermedad cardiovascular, lo que justifica un papel protector cardiovascular de los estrógenos en las mujeres que disminuiría a partir de la menopausia. ${ }^{152}$

Los estrógenos actúan a nivel endotelial, sin afectar a la vasorreactividad independiente del endotelio. Entre los principales efectos fisiológicos de los estrógenos encontramos los siguientes ${ }^{149,153}$ :

- Efecto vasodilatador mediante el aumento de la actividad de la sintetasa de óxido nítrico (NOS). 
- Aumento de los factores de crecimiento endotelial y de los receptores de los mismos.

- Protección de las células endoteliales de la inflamación y la lesión.

- Inhibición de la proliferación de musculo liso vascular y la formación de placas.

- Disminución de la actividad del enzima convertidora de angiotensina, lo que conduce a una disminución de la angiotensina II.

No debemos olvidar que los estrógenos producen un aumento de la distensión a nivel venoso por activación de vasodilatadores derivados del endotelio y disminución de la contracción venosa. Este es uno de los mecanismos que justifica la mayor incidencia de varices en mujeres, y más aún durante la gestación. 154,155

En definitiva, es difícil evaluar el efecto de la menopausia sobre la génesis y el desarrollo de la insuficiencia venosa crónica. Por un lado los estrógenos suponen una protección cardiovascular, evitando la lesión endotelial y los procesos de inflamación, pero al mismo tiempo condicionan un aumento de distensión de la pared venosa. Probablemente el efecto de la menopausia sobre el desarrollo de insuficiencia venosa crónica sea el resultado de un cúmulo de situaciones en las que se incluyen factores asociados a la menopausia como la edad y el sobrepeso. Además, se ha descrito un aumento de los síntomas de la enfermedad durante la menopausia, algo que se pone en relación con otros factores adicionales como la disminución de la actividad física, y enfermedades osteo-musculares asociadas como la artritis y la artrosis. ${ }^{156}$

También podemos mencionar que hay estudios que describen un ligero aumento del riesgo de tromboembolismo venosos en pacientes postmenospausicas con venas varicosas que toman terapia hormonal sustitutiva. ${ }^{157}$ 


\subsubsection{Embarazo}

Existen estudios en los que se demuestra que no existe diferencia en la prevalencia de síndrome varicoso primario entre mujeres nulíparas y hombres, pero sí entre hombres y mujeres multíparas, lo que nos hace pensar que el factor gestación sería el factor determinante. ${ }^{33}$ Los resultados de nuestro estudio están en consonancia con estos datos, de tal forma que las pacientes con insuficiencia venosa crónica habían tenido un mayor número de gestaciones en general y a término. No solo existen diferencias entre ambos grupos en el número medio de gestaciones e hijos sino también en el número de pacientes que han tenido alguna gestación a lo largo de su vida como ya hemos comentado previamente.

Nuestros datos coinciden con los de otros muchos estudios que apoyan esta situación. Un meta-análisis sugiere que las probabilidades de que las mujeres con antecedentes de embarazo desarrollen venas varicosas aumentan significativamente en un $82 \%$ en comparación con las mujeres sin antecedentes de gestación. ${ }^{158}$ La gestación supone un estado en el que se producen una serie de cambios fisiológicos tanto estructurales como funcionales que influyen en el sistema venoso, favoreciendo el desarrollo de varices como ya hemos comentado. Entre estos cambios encontramos: un aumento del volumen circulante, el crecimiento uterino exponencial a lo largo de toda la gestación, un aumento de peso respecto a la situación basal, una disminución de la actividad física y cambios a nivel hormonal. ${ }^{159}$

Durante muchos años se pensó que el útero gestante, aumentado de tamaño respecto a la situación basal seria el principal determinante del desarrollo de varices durante la gestación por compresión de los vasos iliacos y la vena cava inferior. Sin embargo, el desarrollo de las varices en un gran número de gestantes se produce durante el primer trimestre de gestación momento en el que el útero aún no ha aumentado de tamaño lo suficiente como para producir esta compresión. 
Además, úteros con tamaños incluso superiores al de un útero en el primer trimestre de gestación, como un útero polimiomatoso no se asocian al desarrollo de varices. Todo esto ha llevado a la búsqueda de nuevos factores determinantes del desarrollo de varices durante la gestación. ${ }^{160}$

- El incremento ponderal asociado, con un peso promedio de hasta $12,5 \mathrm{~kg}$ es un factor determinante. Como ya hemos señalado anteriormente existe evidencia que relaciona el peso corporal con el desarrollo de varices, pero además hay que tener en cuenta que durante el embarazo no sólo aumenta el depósito de grasa, sino también el volumen sanguíneo circulante y el líquido extracelular. ${ }^{34}$

- Durante la gestación se producen evidentemente cambios hormonales. El aumento de estrógenos y progesterona lleva asociado cambios en el sistema cardiovascular que ya hemos comentado. Los estrógenos producen relajación a nivel del músculo liso y disminución de la adhesión entre las fibras de colágeno, y afectan a la síntesis de moléculas vasodilatadoras como la progesterona y el óxido nítrico. ${ }^{161}$

- Se describen además cambios anatómicos, fundamentalmente a nivel del sistema venoso superficial. Existe un aumento del diámetro de las venas de los miembros inferiores que comienza durante el primer trimestre de gestación, y aumenta de forma gradual a medida que avanza la misma. ${ }^{45,162}$ La presencia de edema en miembros inferiores, no siempre supone un indicativo de gravedad de insuficiencia venosa, pero sí está en relación con los procesos fisiopatológicos asociados a ella. 


\section{Discusión}

Muchas de estas alteraciones descritas serán reversibles tras la gestación, aunque no de manera inmediata. Se necesitarán más de seis semanas postparto para normalizar el estado funcional del sistema venoso, de tal forma que la valoración de la situación residual precisa de un período de al menos 8 a 12 semanas tras el parto. ${ }^{159,163}$

Las gestaciones sucesivas parecen tener un efecto incremental del daño. Dependiente del intervalo entre gestaciones el efecto puede ser mayor o menor, pero lo cierto es que aumentan las posibilidades de desarrollo de insuficiencia venosa crónica o su progresión de tamaño o gravedad. ${ }^{164,165}$ De esta forma, es evidente la indicación de medidas preventivas con medias de compresión, inmersión de extremidades en agua fría y ejercicios para evitar o tratar el desarrollo de insuficiencia venosa crónica, no estando indicado realizar intervenciones quirúrgicas sobre las varices hasta que el deseo genésico esté cumplido y se pueda realizar una evaluación completa de la situación. ${ }^{164,}$ $166,167,168$

Existen estudios que demuestran que la multiparidad no solo afecta a la patología de tipo venosos como las varices sino que también puede producir un aumento del riesgo de otras patologías vasculares como la aterosclerosis carotidea. Actuado la maternidad como un factor de riesgo aterosclerótico. ${ }^{169}$ 


\subsection{PERFIL CLÍNICO DE LA INSUFICIENCIA VENOSA CRÓNICA}

La sintomatología clínica es producto de una valoración por parte de la mujer que siente unas manifestaciones clínicas a veces no aprecias adecuadamente en lo que respecta a la patología varicosa. Por un lado la sintomatología no suele ser muy relevante, en especial si no hay complicaciones como son las mencionadas varicorragias, varicoflebitis y situaciones relacionadas con el desarrollo de la posible ulcera varicosa como son la pigmentación, induración y pérdida de sustancia cutánea. Muchos síntomas clínicos no son atribuibles a la variz sino a otra patología muy relacionada con el aparato locomotor como son las artrosis, lumbociáticas y en menor grado problemas isquémicos arteriales de los miembros. Mucha sintomatología dolorosa en presencia de alguna variz suele ser atribuible tanto por la enferma y en muchos casos por el médico de atención primaria al síndrome varicoso sin evidentemente estar claramente justificado. La sintomatología de pesadez, tirantez, prurito y piernas cansadas es lo típico y muy especialmente a un perfil de mujer que desarrolla un tipo de actividad muy específico.

Hemos realizado un estudio descriptivo de las principales características de la enfermedad venosa crónica entre las 503 pacientes incluidas en el estudio. El estadio clínico más frecuente ha sido la variz troncular ( $n=382,75.9 \%)$. Respecto al grado de evolución de la enfermedad, clasificado según la CEAP, Ilama la atención que la mayor parte de las pacientes (97.4\%, 490 pacientes) se encontraban en grado C1-C2 de la CEAP, y sólo un $2.6 \%$ mostraba grados de afectación superior.

Como hemos explicado previamente, los estadios C1 y C2 son los grados más leves de afectación y suponen la presencia de telangiectasias, venas reticulares o corona maleolar para el estadio C1 y varices para el estadio C2. Es lógico que el grado de afectación sea leve en la mayor parte de las pacientes, ya que en la mayoría de los casos 
la razón de la demanda de atención sanitaria es un problema estético, aunque hemos de destacar que en muchas ocasiones los estadios iniciales de la EVC presentan numerosos síntomas asociados. ${ }^{170,171}$

El tipo de varices sí que es un hecho diferencial. No tienen el mismo perfil las telangiectasias, mas relacionadas con aspectos hormonales y en especial estrogénicos, y las varículas, varices de menor entidad, que presentan un irrelevante sintomatología clínica, que las tronculares más relacionadas con los ejes venosos de la safena mayor y menor que presentan un perfil más típico de distribución anárquica con un perfil de formaciones venosas con dilatación y alteración estructural más típicas de cuadros postflebíticos como vía de drenaje sanguíneo tras obstrucciones del sistema venoso profundo o las que forman parte de los complejos patológicos de las malformaciones de los vasos sanguíneo. La aparición de varices de menor entidad es más frecuente que las de mayor soporte ya que se pueden considerar casi de afectación generalizada en la mujer a lo largo de su vida.

El 88.9\% (447) de las pacientes presentaban síndrome varicoso bilateral mientras que el $11.1 \%$ restante (56 pacientes) sólo presentaron varices en la extremidad inferior consultada.

Como ya sabemos, las varices pueden ser primarias, aquellas que se desarrollan como consecuencia de diferentes factores de riesgo como antecedentes familiares, obesidad, embarazos o determinadas factores no conocidos o secundarias, que aparecen como consecuencia de un traumatismo, alguna tumoración pélvica o tromboflebitis. Mientras que las primarias suelen presentar una afectación predominantemente bilateral, las secundarias generalmente se manifiestan de forma unilateral, y con una proporción similar entre hombres y mujeres. 
En nuestro estudio los factores secundarios eran un criterio de exclusión por lo que es fácil de entender la diferencia de resultado en bilateralidad, sin embargo, 47 pacientes (9.3\%) referían antecedentes de flebitis en la extremidad inferior predominantemente afectada por el síndrome varicoso. La bilateralidad no afecta a la funcionalidad y evolución de la insuficiencia venosa crónica, ni tampoco a la respuesta a los tratamientos. La intervención quirúrgica puede realizarse de forma bilateral de inicio, sin que ello suponga un incremento de la tasa de complicaciones por miembro, ni de la estancia hospitalaria ni el período de recuperación. 172,173,174

Las mujeres solicitan asistencia sanitaria de forma más precoz que los varones, probablemente porque la estética supone también una parte importante de las visitas médicas. Del total de las mujeres de nuestro estudio, 74 de ellas (14.7\%) consultaron por motivos estéticos, siendo el síndrome varicoso propiamente dicho asintomático. El resto de las pacientes presentaban alguna manifestación clínica; fundamentalmente pesadez de extremidades inferiores (72.2\%), pero también prurito (5.2\%), dolor (4.4\%) y edema (3.6\%).

La presentación clínica de las varices tiene una amplia gama de manifestaciones. Como ocurre en nuestro estudio, la forma más frecuente de manifestación es la pesadez y cansancio de piernas, seguido por el dolor y el edema de la extremidad. ${ }^{175,176} \mathrm{El}$ picor en las piernas también puede ser un síntoma presente en pacientes con EVC independiente de la presencia de ulceración o no. De hecho es más frecuente en estadios leves o moderados, pero afecta en gran medida a la calidad de vida. ${ }^{177,}{ }^{178} \mathrm{El}$ edema de piernas es una manifestación clínica frecuente y a menudo muy molesta que se relaciona con estadios evolutivos avanzados (grado de la CEAP igual o superior a 3). Empeora cuando los pacientes permanecen mucho tiempo en la misma postura y mejora en gran medida al caminar o elevar las piernas. El dolor que en nuestro estudio 


\section{Discusión}

ha supuesto un 3,8\% de las manifestaciones clínicas también se asocia con estadios avanzados de la enfermedad, en los que existe compromiso cutáneo y especialmente en la úlcera (grado de la CEAP igual o superior a 4). Suele ser un dolor localizado, no irradiado y a veces es difícil de diferenciar de manifestaciones generadas por otras patologías diferentes. ${ }^{179}$ Las ulceras de tipo venoso, son lesiones más recurrentes que las de tipo no venoso, y esta recurrencia suele ser mayor en pacientes con patología de base como la obesidad, diabetes o HTA. ${ }^{180,181}$

\subsection{FORTALEZAS DEL ESTUDIO}

El estudio de soporta en un proyecto desarrollado sobre bases reales informativas, cuyos datos se han obtenido de la práctica real cotidiana asistencial. Los posibles sesgos recogidos son los innerentes al estudio y el tipo de trabajo desarrollado. Se ajusta estrictamente a criterios éticos, que si en algún momento pudieran debilitar las aportaciones del estudio es incuestionable asumirles al ser prioritarios los mismos frente a otros factores que pudieran aportar una mayor precisión de la información obtenida. La fortaleza del estudio se basa fundamentalmente en el número de pacientes evaluados, en un servicio de angiología y cirugía vascular con gran volumen de atención de enfermos siendo por circunstancias demográficas, administrativas, organizativas y de recursos humanos y materiales disponibles el de mayor volumen del país.

Otra de las fortalezas lo representa el haber sido evaluado los pacientes por un equipo único con criterios uniformes en base a guías elaboradas en el ámbito de referencia del propio servicio asistencial y enmarados en los protocolos seguidos en la 
unidad asistencial flebológica, con experiencia en la valoración de los pacientes, recogiendo los datos en base a una amplia experiencia en la atención sanitaria del paciente varicoso.

El grupo control está constituido por pacientes valorados en consultas del Servicio de Angiología y Cirugía Vascular remitidas como actividades preventivas y que fueron consideradas con patología banal tanto del perfil vascular como de otra etiología tras la atención sanitaria y la valoración pertinente pudiéndose considerar como un colectivo sin patología.

Por otro lado, sólo hemos considerado pacientes con EVC de sexo femenino, ya que el objetivo principal ha sido relacionar el desarrollo de varices con diferentes antecedentes obstétrico-ginecológicos.

En relación a los datos analíticos, se han valorado aquellos disponibles en ambos grupos tanto de estudio por presentar patología de varices como el control sin patología significativa, no habiendo considerado realizar estudios analíticos a todas las pacientes incluidas en el trabajo por motivos éticos

Con respecto al estudio hormonal, como se ha comentado previamente, se ve influenciado por el momento del ciclo menstrual y la edad, algo que no se ha podido tener en cuenta en el análisis de los resultados de este subapartado por la imposibilidad técnica de realizar las extracciones con total precisión en relación con la situación de la paciente con respecto al ciclo menstrual. Por otro lado, gracias a la metodología empleada, este estudio ha sido factible dentro de una práctica asistencial normal, sin exploraciones complementarias a veces irrelevantes para las enfermas y que pudieran desarrollarse en el límite de los aspectos éticos previamente comentados. El estudio es un claro aprovechamiento de recursos al ser realizado con las herramientas empleadas 
en la práctica asistencial normal de las enfermas pero con un enfoque científico con objeto de rentabilizar los datos ofertados con un criterio investigador.

La solvencia científica del estudio lo avala la experiencia previa del equipo investigador con aportaciones a nivel nacional e internacional, tanto en la elaboración de guías y protocolos, como de publicaciones científicas de difusión nacional e internacional con índices indudables de calidad.

Las limitaciones del trabajo, siempre existentes en cualquier estudio, se pueden considerar inferiores a las aportadas por otros grupos en este campo de trabajo y reflejadas en sus publicaciones. El servicio es referencia nacional en el campo de la flebología y también internacional por sus publicaciones y aportaciones algunas de ellas en Cochrane, Database of Systematic Reviews,y concretamente en el área venosa. 


\section{CONCLUSIONES}





\section{Conclusiones}

1. Después de la revisión bibliográfica realizada para el estudio, se ha podido comprobar la limitada información disponible soportada en publicaciones científicas que relaciona el síndrome varicoso con el perfil ginecológico de la mujer. En la mayor parte de las aportaciones se relaciona ambos perfiles sin un soporte científico sólido.

2. El perfil ginecológico de las pacientes con síndrome varicoso primario es un determinante principal del desarrollo de insuficiencia venosa crónica, siendo más importante que otros factores previamente considerados como la obesidad o la bipedestación prolongada.

3. La menopausia en la mujer es un factor de riesgo para el desarrollo de varices. Lo que pone en evidencia los estrógenos como un factor modificador de la enfermedad.

4. La gestación es un factor primordial en el desarrollo de insuficiencia venosa crónica. El desarrollo del embarazo es determinante y refleja la influencia de los factores hormonales y físicos mantenidos en el tiempo en el desarrollo de la insuficiencia venosa. 


\section{Conclusiones}

5. Las pacientes con insuficiencia venosa crónica consumen más terapia hormonal que la población control. La aportación de nuestro estudio debe de manejarse con cautela y considerándose además la extensa información recogida en la bibliografía que correlaciona el uso de anticonceptivos orales y terapia hormonal sustitutiva con aumento de la incidencia de insuficiencia venosa crónica.

6. Si bien la presencia de comorbilidades cardiovasculares favorece el desarrollo de insuficiencia venosa crónica, no parecen existir marcadores analíticos que identifiquen de forma precoz la relación entre enfermedad sistémica y síndrome varicoso.

7. Las características generales del síndrome varicoso de las pacientes estudiadas en nuestro medio corresponden a una afectación de grado ligero, frecuentemente bilateral. La forma de manifestación más frecuente es la pesadez de piernas pero no es infrecuente la consulta médica por motivos estéticos en pacientes asintomáticas. Estas circunstancias pueden estar relacionadas con la sensibilidad social sobre esta afección vascular, el desarrollo del sistema sanitario y la disponibilidad de atención sanitaria especializada.

8. La utilización de medidas preventivas tipo media elástica en nuestro medio es baja. Su implementación junto con otras medidas clásicas preventivas basadas en hábitos de vida y en evitar situaciones predisponentes de estasis sanguíneo son necesarios para reducir la incidencia de la enfermedad. 


\section{BIBLIOGRAFÍA}





\section{Bibliografía}

1. Estevez I, San Norberto E, Taylor J, Gastambide V, Fuente R, Vaquero C. Embolización de venas hipogástricas como tratamiento de síndrome de congestión pélvica. Angiologia. 2013; 65:231-3.

2. Hernández Rivero J, Llanes Barrios A, Quiñones Castro M. Caracterización de la insuficiencia venosa crónica en consultas del Instituto de Angiología y Cirugía Vascular. Rev Cubana Angiol y Cirugía Vasc. 2010; 11(1):1-9.

3. Canata EH. Manual Práctico de Patología Quirúrgica. EFACIM; 2001. 75: 785-792.

4. Moore KL, Dalley AF. Anatomía con orientación clínica. Médica Panamericana Ed. Madrid. 2007. p 1205.

5. Tretbar LL. Deep veins. Dermatol Surg. 1995; 21(1):47-51.

6. Tobinick E. El sistema venoso cerebroespinal: Anatomía, fisiología e implicaciones clínicas. Arch Med. 2017; 6(1):2-6

7. Kosinski C. Observations on the Superficial Venous System of the Lower Extremity. J Anat. 1926; 60 (Pt 2):131-42.

8. Sobotta J, Putz R, Pabst R. Atlas de anatomía humana. Médica Panamericana Madrid. Ed. 2006.

9. Netter FH. Atlas. Segunda Ed. Masson Editor. Barcelona. 1999. p 457-477.

10. Verberch AW. Sistema venoso soleo-gemelar: su rol en la insuficiencia venosa de miembros. 1997. Masson Ed. Barcelona. p 215.

11. Miguel H. Ramos. Várices del miembro inferior. Rev Posgrado la Cátedra VI Fac Med - UNNE. Buenos Aires. 2000

12. Browse NL, Burnand KG, Irvine AT WN. Physiology and functional anatomy. In: Diseases of Veins. New York Oxford Univ Press. 1999; 49-65. 


\section{Bibliografía}

13. Del Río Solá L, Del Blanco I, Gutiérrez V, González JA, Carrera S, Ibáñez MA, Cenizo N, San Norberto E, Brizuela JA, Vaquero C. Fisiopatología de la insuficiencia venosa. Rev Esp Inves Quir. 2004; 4:191-5.

14. Andrade Castillo J. Insuficiencia venosa de miembros inferiores (Revisión bibliográfica). Madrid. 1986.

15. Elsharawy MA, Naim MM, Abdelmaguid EM, Al-Mulhim AA. Role of saphenous vein wall in the pathogenesis of primary varicose veins. Interact Cardiovasc Thorac Surg. 2006; 6(2):219-24.

16. Yetkin E, lleri M. Dilating venous disease: Pathophysiology and a systematic aspect to different vascular territories. Med Hypotheses. 2016; 91:73-6.

17. Sánchez Beorlegui J, Beorlegui JS. Bases Anatómicas para la Disección Quirúrgica de los Cayados Safenos. 1. El Confluente Safenofemoral. An Fac Med. 2014,7; 62(2):115-6.

18. San Norberto García EM, Brizuela Sanz JA, Merino B, Vaquero C. Patología venosa y linfática. Medicine. 2013; 11(45):2691-9.

19. Perrin M. Clasificación clínica, etiológica, anatómica y fisiopatológica (CEAP) y escalas de gravedad de los trastornos venosos crónicos. EMC - Cirugía Gen. 2006; $6(1): 1-7$

20. Azpeitia M, Del Río L, Vaquero C. perfil ginecológico de las pacientes con síndrome varicoso primario. Estudio observacional. Rev Iberoam Cir Vasc 2017:5,4:162-166

21. Eklöf B, Rutherford RB, Bergan JJ, Carpentier PH, Gloviczki P, Kistner RL, et al. Revision of the CEAP classification for chronic venous disorders: Consensus statement. J Vasc Surg. 2004; 40(6):1248-52. 


\section{Bibliografía}

22. Carpentier PH, Cornu-Thénard A, Uhl JF, Partsch H, Antignani PL. Appraisal of the information content of the $\mathrm{C}$ classes of CEAP clinical classification of chronic venous disorders: A multicenter evaluation of 872 patients. J Vasc Surg. 2003; 37(4):827-33.

23. Casana R, Tolva VS, Odero A, Mallgi C, Parati G. Three-years follow-up and quality of life of endovenosus radiofrequency ablation of the great saphenous vein with the ClusureFast procedure: Influence of BMI and CEAP class. Vascular 2018; Jan 1:17085538118762066 doi 10.1177/1708538118762066.

24. Brizuela Sanz JA, San Norberto García EM, Merino Díaz B, Vaquero Puerta C. Protocolo diagnóstico y terapéutico de la insuficiencia venosa crónica de las extremidades inferiores. Medicine 2013; 11(45):2717-20.

25. Ducajú GM. Enfermedades de las venas. Varices y trombosis venosa profunda. In Libro de la salud cardiovascular del Hospital Clínico San Carlos y la Fundación BBVA.2009. 537-48.

26. Mallick R, Lal BK, Daugherty C. Relationship between patient-reported symptoms, limitations in daily activities, and psychological impact in varicose veins. J Vasc Surg Venous Lymphat Disord. 2017; 5(2):224-37.

27. Villar Álvarez F, Ramón J, Banegas B, De Mata J, Campos D, Artalejo FR. INFORME SEA 2007 Las enfermedades cardiovasculares y sus factores de riesgo en España: hechos y cifras. Madrid. 2017.

28. Rosas Flores A, Serrano Lozano A, Henestrosa Peña K, Zarraga Rodríguez L, Cal Mayor Turnbull I, Meza Vudoyra M, et al. Calidad de vida en pacientes con insuficiencia venosa crónica Quality of life in patients with chronic venous insufficiency. Cir Gen Hosp Reg Lic Adolfo López Mateos. 2006; 28:56-83. 


\section{Bibliografía}

29. Beebe-Dimmer JL, Pfeifer JR, Engle JS, Schottenfeld D. The epidemiology of chronic venous insufficiency and varicose veins. Ann Epidemiol. 2005; 15(3):17584.

30. Gesto-Castromil R, Grupo DETECT-IVC GJ. Encuesta epidemiológica realizada en España sobre la prevalencia asistencial de la insuficiencia venosa crónica en atención primaria. Estudio DETECT-IVC. Angiología. 2001; 53:249-60.

31. Álvarez-Fernández L, Lozano F, Marinello-Roura J, Masegosa-Medina JA. Encuesta epidemiológica sobre la insuficiencia venosa crónica en España: estudio DETECT-IVC 2006. Angiologia. 2008; 60(1):27-36.

32. Moreno-Carriles RM. Registro de la actividad de la Sociedad Española de Angiología y Cirugía Vascular, año 2001. Angiología. 2002; 54(5):414-30.

33. Ebrahimi H, Amanpour F, Bolbol N. Prevalence and risk factors of varicose veins among female hairdressers: a cross sectional study in north-east of Iran. J Res Health Sci. 2015; 15(2):119-23.

34. Musil D, Kaletova M, Jiri H. Age, body mass index and severity of primary chronic venous disease. Biomed Pap. 2011,21; 155(4):367-72.

35. Laurikka J, Sisto T, Auvinen O, Tarkka M, Läärä E, Hakama M. Varicose veins in a Finnish population aged 40-60. J Epidemiol Community Health. 1993;1, 47(5):355-7.

36. Felipe Salech M, Rafael Jara L, Luis Michea A. Cambios fisiológicos asociados al envejecimiento. Rev Médica Clínica Las Condes. 2012; 23(1):19-29.

37. Baena Díez JM, del Val García JL, Tomàs Pelegrina J, Martínez Martínez JL, Martín Peñacoba R, González Tejón I, et al. Epidemiología de las enfermedades cardiovasculares y factores de riesgo en atención primaria. Rev Esp Cardiol. 2005; 58(4):367-73. 


\section{Bibliografía}

38. Kühnl A, Söllner H, Eckstein HH. Epidemiology and inpatient treatment of vascular diseases in Germany. Gefässchirurgie (Abstract). 2016, 23; 21(S1):1423.

39. Robertson L, Evans C, Fowkes FGR. Epidemiology of chronic venous disease. Phlebol J Venous Dis. 2008,1; 23(3):103-11.

40. Criqui MH, Jamosmos M, Fronek A, Denenberg JO, Langer RD, Bergan J, et al. Chronic venous disease in an ethnically diverse population: the San Diego Population Study. Am J Epidemiol. 2003,1; 158(5):448-56.

41. Asbeutah AM, Al-Enezi M, Al-Sharifi NM, Almajran A, Cameron JD, McGrath BP, et al. Changes in the diameter and valve closure time of leg veins across the menstrual cycle. J Ultrasound Med. 2014; 33(5):803-9.

42. Ciardullo A V., Panico S, Bellati C, Rubba P, Rinaldi S, lannuzzi A, et al. High endogenous estradiol is associated with increased venous distensibility and clinical evidence of varicose veins in menopausal women. J Vasc Surg. 2000; 32(3):544-9.

43. Franco Y, Mendoza-Fernández V, Lemini C. Mecanismos de acción de los efectos protectores de los estrógenos sobre el sistema cardiovascular Revista de la Facultad de Medicina. Rev Fac Med UNAM. 2017; 46(3):46-7

44. Dindelli M, Parazzini F, Basellini A, Rabaiotti E, Corsi G, Ferrari A, et al. Risk Factors for Varicose Disease Before and During Pregnancy. Angiology. 1993; 44(5):361-7.

45. Asbeutah AM, Al-Azemi M, Al-Sarhan S, Almajran A, Asfar SK. Changes in the diameter and valve closure time of leg veins in primigravida women during pregnancy. J Vasc Surg Venous Lymphat Disord. 2015; 3(2):147-53. 


\section{Bibliografía}

46. Puricaza M. Modificaciones fisiológicas en el embarazo. Rev Per Ginecol Obs. 2010; 56:57-69.

47. Hall ME, George EM, Granger JP. El corazón durante el embarazo. Rev Esp Cardiol. 2011; m64 (11):1045-50.

48. Ismail L, Normahani P, Standfield NJ, Jaffer U. A systematic review and metaanalysis of the risk for development of varicose veins in women with a history of pregnancy. J Vasc surgery Venous Lymphat Disord. 2016; 4(4):518-524.e1.

49. Bánhidy F, Ács N, Puhó EH, Czeizel AE. Varicose veins of lower extremities in pregnant women and birth outcomes. Cent Eur J Public Heal. 2010; 18(3):161-8.

50. Oral contraceptives, venous thrombosis, and varicose veins. Royal College of General Practitioners' Oral Contraception Study. J R Coll Gen Pract. 1978; 28(192):393-9.

51. Jukkola TM, Mäkivaara LA, Luukkaala T, Hakama M, Laurikka J. The effects of parity, oral contraceptive use and hormone replacement therapy on the incidence of varicose veins. J Obstet Gynaecol. 2006,2; 26(5):448-51.

52. Sprague BL, Trentham-Dietz A, Cronin KA. A sustained decline in postmenopausal hormone use: results from the National Health and Nutrition Examination Survey, 1999-2010. Obstet Gynecol. 2012; 120(3):595-603.

53. Laurikka J, Läärä E, Sisto T, Tarkka M, Auvinen O, Hakama M. Misclassification in a questionnaire survey of varicose veins. J Clin Epidemiol. 1995; 48(9):1175-8.

54. Lee A. Lifestyle factors and the risk of varicose veins Edinburgh Vein Study. J Clin Epidemiol. 2003; 56(2):171-9.

55. Kohno K, Niihara H, Li X, Hamano T, Nabika T, Shiwaku K, et al. Familial Transmission of Hospital-Treated Varicose Veins in Adoptees: A Swedish Family Study. J Am Coll Surg. 2016; 223(3):452-60. 


\section{Bibliografía}

56. Fiebig A, Krusche $P$, Wolf A, Krawczak M, Timm B, Nikolaus S, et al. Heritability of chronic venous disease. Hum Genet. 2010; 127(6):669-74.

57. Kim OJ, Hong SP, Ahn JY, Hong SH, Hwang TS, Kim SO, et al. Influence of combined methionine synthase (MTR 2756A \&gt; G) and methylenetetrahydrofolate reductase (MTHFR 677C \&gt; T) polymorphisms to plasma homocysteine levels in Korean patients with ischemic stroke. Yonsei Med J. 2007,30; 48(2):201-9.

58. Fernández-Peralta AM, González-Aguilera JJ. MTHFR polymorphisms in primary varicose vein disorder. EBioMedicine. 2015; 2(2):104-5.

59. Shadrina AS, Smetanina MA, Sokolova EA, Shamovskaya D V, Sevost'ianova KS, Shevela Al, et al. Association of polymorphisms near the FOXC2 gene with the risk of varicose veins in ethnic Russians. Phlebology. 2016; 31,9:640-8

60. Sokolyan AV., Murashko AV, Krechetova L V., Ziganshina MM, Sukhikh GT. The significance of angiogenic growth factor in the pathogenesis of gestosis in pregnant women with varicose disease. Bull Exp Biol Med. 2008, 26; 145(4):4802.

61. Sokolova EA, Shadrina AS, Sevost'ianova KS, Shevela AI, Soldatsky EY, Seliverstov $\mathrm{El}$, et al. HFE p.C282Y gene variant is associated with varicose veins in Russian population. Clin Exp Med. 2016,28; 16(3):463-70.

62. Chan JCN, Malik V, Jia W, Kadowaki T, Yajnik CS, Yoon K-H, et al. Diabetes in Asia. JAMA. 2009, 27; 301(20):21-9.

63. Poirier P, Giles TD, Bray GA, Hong $Y$, Stern JS, Pi-Sunyer FX, et al. Obesity and Cardiovascular Disease: Pathophysiology, Evaluation, and Effect of Weight Loss. Circulation. 2006; 113(6):12-7 


\section{Bibliografía}

64. Davies HO, Popplewell M, Singhal R, Smith N, Bradbury AW. Obesity and lower limb venous disease. The epidemic of phlebesity. Phlebology. 2017; 32(4):22733.

65. Willenberg T, Schumacher A, Amann-Vesti B. Impact of obesity on venous hemodynamics of the lower limbs. J Vasc Surg. 2010 Sep; 52(3):664-8.

66. van Rij AM, De Alwis CS, Jiang P, Christie RA, Hill GB, Dutton SJ, et al. Obesity and Impaired Venous Function. Eur J Vasc Endovasc Surg. 2008; 35(6):739-44.

67. Ageno W, Becattini C, Brighton T, Selby R, Kamphuisen PW. Cardiovascular Risk Factors and Venous Thromboembolism. Circulation. 2008; 117(1):1-2

68. Christiansen S, Lijfering W, Naess I. The relationship between body mass index, activated protein C resistance and risk of venous thrombosis. J Thromb Haemost. 2012; 10(9):1761-7

69. Heinen $M$, Achterberg $T$, Kerkhof P. Venous leg ulcer patients: a review of the literature on lifestyle and pain-related interventions. J Clin Nurs. 2004; 13(3):355-66.

70. Padberg FT, Johnston M V, Sisto SA. Structured exercise improves calf muscle pump function in chronic venous insufficiency: a randomized trial. J Vasc Surg. 2004; 39(1):79-87.

71. Kan YM, Delis KT. Hemodynamic effects of supervised calf muscle exercise in patients with venous leg ulceration: a prospective controlled study. Arch Surg. 2001;136(12):1364-9

72. Levine BD, Baggish AL, Kovacs RJ, Link MS, Maron MS, Mitchell JH. Eligibility and Disqualification Recommendations for Competitive Athletes With Cardiovascular Abnormalities: Task Force 1: Classification of Sports: Dynamic, Static, and Impact. Circulation. 2015; 132(22):7-9. 


\section{Bibliografía}

73. Bérard A, Abenhaim L, Platt R, Kahn SR, Steinmetz O. Risk factors for the firsttime development of venous ulcers of the lower limbs: the influence of heredity and physical activity. Angiology. 2002; 53(6):647-57.

74. Steins A, Junger M. Physical therapy in patients with chronic venous insufficiency. Phlebologie-Stuttgart. 2000;5:13-7

75. Joseph N, B A, Faizan Thouseef M, Devi M U, Abna A, Juneja I. A multicenter review of epidemiology and management of varicose veins for national guidance. Ann Med Surg. 2016; 8:21-7.

76. Espinola CF, Bernal M, Aucejo M, Villalba JC. Prevalencia de várices en miembros inferiores en el personal del Hospital de Clínicas. Rev Chil Cirugía. 2007; 59(5):342-7.

77. García-Gimeno M, Rodríguez-Camarero S, Tagarro-Villalba S, Ramalle-Gomara E, Ajona García JA, González Arranz Arranz MA López García D, Gonzalez Gonzalez E, Vaquero Puerta C. Reflux patterns and risk factors of primary varicose veins' clinical severity. Phlebology 2013, 6; 28(3):153-61.

78. García-Gimeno M, Rodríguez-Camarero S, Tagarro-Villalba S, Ramalle-Gomara E, González-González E, Arranz MA, García DL, Vaquero-Puerta C. Duplex mapping of 2036 primary varicose veins. J Vasc Surg. 2009; 49(3):681-9.

79. Martínez Rodríguez E, Paz Jiménez J. Trastornos circulatorios en cirugia: contribuciones al IV Curso de Avances en Cirugia. Guiones. Oviedo. 1993

80. Labropoulos N, Leon LR. Duplex evaluation of venous insufficiency. Semin Vasc Surg. 2005; 18(1):5-9.

81. Obermayer A, Garzon K. Identifying the source of superficial reflux in venous leg ulcers using duplex ultrasound. J Vasc Surg. 2010; 52(5):1255-61. 


\section{Bibliografía}

82. Neglen P RS. A comparison between descending phlebography and duplex Doppler investigation in the evaluation of reflux in chronic venous insufficiency: a challenge to phlebography as the "gold standard". J Vasc Surg. 1992; 16:687-8.

83. Brizuela Sanz JA, San Norberto García EM, Merino Díaz B, Vaquero Puerta C. Protocolo diagnóstico y terapéutico de la insuficiencia venosa crónica de las extremidades inferiores. Medicine 2013; 11(45):2717-20.

84. Neglen P, Raju S. A comparison between descending phlebography and duplex Doppler investigation in the evaluation of reflux in chronic venous insufficiency: A challenge to phlebography as the "gold standard." J Vasc Surg. 1992; 16(5):687-93.

85. Chiesa R, Marone EM, Limoni C, Volontè M, Petrini O. Chronic venous disorders: Correlation between visible signs, symptoms, and presence of functional disease. J Vasc Surg. 2007; 46(2):322-30.

86. Abu-Own A, Scurr JH, Coleridge Smith PD. Effect of leg elevation on the skin microcirculation in chronic venous insufficiency. J Vasc Surg. 1994; 20(5):705-10.

87. Dix FP, Reilly B, David MC, Simon D, Dowding E, Ivers L, et al. Effect of leg elevation on healing, venous velocity and ambulatory venous pressure in venous ulceration. Phlebol J Venous Dis. 2005, 23; 20(2):87-94.

88. Vaquero C. Síndrome varicoso en Cuidados de enfermeria en cirugia vascular. Secretariado de Publicaciones. Universidad de Valladolid. 2000. p 117-26.

89. Lattimer CR, Kalodiki E, Kafeza M, Azzam M, Geroulakos G. Quantifying the degree graduated elastic compression stockings enhance venous emptying. Eur J Vasc Endovasc Surg. 2014 Jan; 47(1):75-80.

90. Partsch H. Compression therapy of the legs. A review. J Dermatol Surg Oncol. 1991; 17(10):799-805. 


\section{Bibliografía}

91. San Norberto García EM, Merino B, Taylor JH, Vizcaíno I, Vaquero C. LowMolecular-Weight Heparin for Prevention of Venous Thromboembolism After Varicose Vein Surgery in Moderate-Risk Patients: A Randomized, Controlled Trial. Ann Vasc Surg. 2013; 27(7):940-6.

92. Partsch H, Blättler W. Compression and walking versus bed rest in the treatment of proximal deep venous thrombosis with low molecular weight heparin. J Vasc Surg. 2000; 32(5):861-9.

93. San Norberto E, García-Sainz I, Fuente R, Flota C, Estévez I VC. Tratamiento farmacológico de la insuficiencia venosa crónica: revisión y puesta al día. Rev Iberoam Cir Vasc. 2015; 3,1:41-7.

94. Marinero A, Martinez R, De la Llana R, Vaquero C, Nassar I, Garrido P LA. Tratamiento de las varices mediante endolaser en los obesos. Rev Esp Inves Quir. $2006 ; 2: 91-3$.

95. Vaquero Puerta C, de Marino P, Revilla Á. La cirugia endovascular en el siglo XXI. Anales de la Real Academia de Medicina y Cirugía de Valladolid. 2014; 51:87-102

96. San Norberto E, García-Sainz I, Urien LM, Fuente R, Flota C, Vaquero C. Tratamiento de las varices mediante ablación térmica: endolaser y radiofrecuencia. Rev Iberoam Cir Vasc. 2014; 4:176-82.

97. Paravastu SCV, Dodd PDF. Endovenous ablation therapy (LASER or radiofrequency) or foam sclerotherapy versus conventional surgical repair for short saphenous varicose veins (Protocol). Cochrane Database of Systematic Reviews 2013, Issue 12. Art. No: CD010878.

98. Gibson K, Gunderson K. Liquid and Foam Sclerotherapy for Spider and Varicose Veins. Surg Clin North Am. 2018;98(2):415-42. 


\section{Bibliografía}

99. San Norberto EM, Merino B, Vaquero C. Utilidad de la Bemiparina en la Cirugía de las Varices. Springer Health Care Iberica SL. Madrid 2014.

100. Rojas E, Rusty Molina D, Rodríguez C. Capítulo II definición, clasificación y diagnóstico de la diabetes mellitus. Diabetes. 2017. p 1050

101. Farreras Valentin P. Medicina Interna. 16‥ Elvesier Ed. Barcelona, España; 2010. p 589.

102. Farreras Valentin P. Medicina Interna. 16‥ Elsevier Ed. Barcelona, España; 2010. p 2069-2073.

103. Farreras Valentin P. Medicina Interna. 16‥ Elsevier Ed. Barcelona, España; 2010. p 1596-7.

104. Usandizaga Beguiristáin J.A. Obstetricia y Ginecología. 4‥ Marbán Ed. Madrid. España; 2011. p 28-30

105. Frühbeck G, Gómez-Ambrosi J. The adipocyte: a model for integration of endocrine and metabolic signaling in energy metabolism regulation. Am J Physiol Endocrinol Metab. 2001; 280(6):E827-47.

106. Mohamed-Ali V, Pinkney J, Coppack S. Adipose tissue as an endocrine and paracrine organ. Int J Obes Relat Metab Disord. 1998; 22(12):1145-58.

107. Bizzarri C, Benevento D, Ravà L, Patera I. Ovarian hyperandrogenism in adolescents and young women with type I diabetes is primarily related to birth weight and body mass index. Fertil Steril. 2011; 96(6):1497-502.

108. Matic P, Jolic S, Tanaskovic S, Soldatovic I, Katsiki N, Isenovic E, et al. Chronic Venous Disease and Comorbidities. Angiology. 2015,8; 66(6):539-44.

109. Kovac M, Kovac Z, Tomasevic Z, Vucicevic S, Djordjevic V, Pruner I, et al. Factor V Leiden mutation and high FVIII are associated with an increased risk of VTE in women with breast cancer during adjuvant tamoxifen. Results from a 


\section{Bibliografía}

prospective, single center, case control study. Eur J Intern Med. 2015; 26(1):637.

110.Ceran C, Aksam E, Aksam B, Yenidünya S. Tamoxifen-Related Thrombosis: An Experimental Study in Rat Venous Microvascular Anastomosis Model. Ann Plast Surg. 2017; 78 (2): 213-6

111. Estébanez RV. Veiras del Río O. Problemas de salud Trombosis venosa profunda AMF. 2009.5,2:37-9

112. Kahn SR. The clinical diagnosis of deep venous thrombosis: integrating incidence, risk factors, and symptoms and signs. Arch Intern Med. 1998,23; 158(21):231523.

113. Castro-Ferreira R, Cardoso R, Leite-Moreira A, Mansilha A. The role of endothelial dysfunction and inflammation in chronic venous disease. Ann Vasc Surg. 2018;46:380-93

114.Crawford JM, Lal BK, Durán WN, Pappas PJ. Pathophysiology of venous ulceration. J Vasc Surg Venous Lymphat Disord. 2017; 5(4):596-605.

115.Jacobs BN, Andraska EA, Obi AT, Wakefield TW. Pathophysiology of varicose veins. J Vasc Surg Venous Lymphat Disord. 2017; 5(3):460-7.

116. Boulton A, Armstrong D, Albert S. Comprehensive foot examination and risk assessment. Diabetes Care. 2008; 31(8): 1679-85

117.Sonne DP, Hemmingsen B. Comment on American Diabetes Association. Standards of Medical Care in Diabetes-2017. Diabetes Care 2017; 40(Suppl. 1):S1-S135. Diabetes Care. 2017,21; 40(7):92-3.

118. Herman WH, Petersen M, Kalyani RR. Response to Comment on American Diabetes Association. Standards of Medical Care in Diabetes. Diabetes Care. 2017; 40(7): 94-5. 


\section{Bibliografía}

119. Kaspar S. Veins and diabetes. Vnitr Lek. 2010; 56(4):329-32.

120.Apollonio A, Antignani PL, Di Salvo M, Failla G, Guarnera G, Mosti G, et al. A large Italian observational multicentre study on vascular ulcers of the lower limb. Int Wound J. 2016; 13(1):27-34.

121.Pannier F, Rabe E. Differential diagnosis of leg ulcers. Phlebology. 2013; 28(1_suppl):55-60.

122. Abularrage CJ, Sidawy AN, Aidinian G, Singh N, Weiswasser JM, Arora S. Evaluation of the microcirculation in vascular disease. J Vasc Surg. 2005; 42(3):574-81.

123. Lee AJ, Robertson LA, Boghossian SM, Allan PL, Ruckley CV, Fowkes FGR, et al. Progression of varicose veins and chronic venous insufficiency in the general population in the Edinburgh Vein Study. J Vasc Surg Venous Lymphat Disord. $2015 ; 3(1): 18-26$.

124.Zoller B, Ji J, Sundquist J, Sundquist K. Venous Thromboembolism and Varicose Veins Share Familial Susceptibility: A Nationwide Family Study in Sweden. J Am Heart Assoc. 2014 26; 3(4):piie000850-doi 10.116/JAHA.114. e000850.

125. Ahti TM, Makivaara LA, Luukkaala T, Hakama M, Laurikka JO. Effect of Family History on the Incidence of Varicose Veins: A Population-Based Follow-Up Study in Finland. Angiology. 2009, 1; 60(4):487-91.

126. Huang H-K, Weng S-F, Su S-B, Wang J-J, Guo H-R, Hsu C-C, et al. Standing Posture at Work Does Not Increase the Risk of Varicose Veins among Health Care Providers in Taiwan. Med Princ Pract. 2017; 26(3):266-72.

127. Chen C-L, Guo H-R. Varicose veins in hairdressers and associated risk factors: a cross-sectional study. BMC Public Health. 2014 Dec 28; 14(1):885. 


\section{Bibliografía}

128. Tabatabaeifar S, Frost P, Andersen JH, Jensen LD, Thomsen JF, Svendsen SW. Varicose veins in the lower extremities in relation to occupational mechanical exposures: a longitudinal study. Occup Environ Med. 2015; 72(5):330-7.

129. Matic, P, Jolic S, Tanaskovic S, Soldatovic I, Katsiki N, Isenovic E, Radak D. Chronic Venous Disease and Comorbidities. Angiology. 2015; 66(6) 539-44.

130. Velciov S, Gluhovschi GH, Feier V, Trandafirescu V, Petrica L, Gluhovschi C, Bob F, Bozdog GH, Gadalean F, Florescu C, Bobu M, Chiliban A. Elements of renal injury in patients with varicose ulcer. Preliminary study. Rom J Intern Med. 2011; 49(3):202-6

131. Rondon-Berrios H. New insights into the pathophysiology of oedema in nephrotic syndrome. Nefrologia (Madr.). 2011;31:148-54.

132. Manning RD, Jr, Guyton AC. Effects of hypoproteinemia on fluid volumes and arterial pressure. Am J Physiol. 1983; 245: H284-93.

133. Saad RA, Arepally GM, Uriel TL. Heparin induced thrombocytopenia. N Engl J Med. 2006; 355: 2598-9.

134. Madrazo-González Z, García-Barrasa A, Rodríguez-Lorenzo L, Rafecas-Renau A, Alonso-Fernández G. Actualización en anemia y terapia transufsional. Med Intensiva. 2011; 35 (1):32-40.

135. Böhm G, Al-khaffaf H. Trombophilia and arterial disease. Int anglo 2003;22:2.

136. Adkisson EJ, Casey DP, Beck DT, Gurovich AN, Martin JS, Braith RW. Central, peripheral and resistance arterial reactivity: fluctuates during the phases of the menstrual cycle. Experimental Biology and Medicine (Maywood). 2010; 235 (1):111-8. 


\section{Bibliografía}

137. Melmed S, Casanueva FF, Hoffman AR, Kleinberg DL, Montori VM, Schlechte JA. Diagnosis and treatment of hyperprolactinemia: an Endocrine Society Clinical Practice Guideline. J Clin Endocrinol Metab. 2011:96; 273-88.

138. Dewailly D, Andersen CY, Balen A, et al. The physiology and clinical utility of antiMullerian hormone in women. Hum Reprod Update 2014; 20:370-1.

139. Seifer DB, Baker VL, Leader B. Age-specific serum anti-Müllerian hormone values for 17,120 women presenting to fertility centers within the United States. Fertil Steril 2011; 95:747-8.

140.de Vet A, Laven JS, de Jong $\mathrm{FH}$, et al. Antimüllerian hormone serum levels: a putative marker for ovarian aging. Fertil Steril 2002; 77:357-9.

141.Jukkola TM, Mäkivaara LA, Luukkaala T, Hakama M, Laurikka J. The effects of parity, oral contraceptive use and hormone replacement therapy on the incidence of varicose veins. J Obstet Gynaecol (Lahore). 2006; 26(5):448-51.

142. Tepper NK, Marchbanks PA, Curtis KM. Superficial venous disease and combined hormonal contraceptives: a systematic review. Contraception. 2016; 94(3):2759.

143. Eichinger S, Evers JLH, Glasier A, La Vecchia I, Martinelli L, Skouby S, Somigliana E, Baird DT, Benagiano G, Crosignani PG, Gianaroli L, Negri E, Volpe A, Glasier A, Crosignani PG. ESHRE Capri Workshop Group Venous thromboembolism in women: a specific reproductive health risk. Human Reproduction Update. 2013; 19 (5): 471-82

144.Lidegaard O, Lokkegaard E, Svendsen AL, Agger C. Hormonal contraception and risk of venous thromboembolism: national follow-up study. BMJ. 2009,13; 339(aug13 2):2890-b2890. 


\section{Bibliografía}

145.Del Río Solá ML, González Fajardo JA, Vaquero Puerta C. Identificación de factores de riesgo clínicos en la trombosis venosa profunda idiopática recurrente. Med Clin (Barc). 2016; 146(6):254-7.

146. Lidegaard O, Bygdeman M, Milsom I, Nesheim BI, Skjeldestad FE, Toivonen J. Oral contraceptives and thrombosis. From risk estimates to health impact. Acta Obstet Gynecol Scand. 1999; 78(2):142-9.

147. Mantha S, Karp R, Raghavan V, Terrin N, Bauer KA, Zwicker JI. Assessing the risk of venous thromboembolic events in women taking progestin-only contraception: a meta-analysis. BMJ. 2012 Aug 7; 345(aug 07 2):e4944-e4944.

148.Stachowiak G, Połać I, Stefańczyk L, Owczarek D, Jedrzejczyk S, Pertyński T. The impact of hormone replacement therapy applied in women with varicose vein on changes in coagulation and fibrinolysis. Pol Merkur Lekarski. 2003; 15(90):521-4.

149.Dalmasso C, Maranon R, Patil C, Bui E, Moulana M, Zhang H, Smith A, Yanes Cardozo LL, Reckelhoff JF. Cardiometabolic Effects of Chronic Hyperandrogenemia in a New Model of Postmenopausal Polycystic Ovary Syndrome. Endocrinology. 2016;157(7):2920-7

150.Mueller NT, Odegaard AO, Gross MD, Koh WP, Yuan J-M, Pereira MA. Age at menarche and cardiovascular disease mortality in Singaporean Chinese women: the Singapore Chinese Health Study. Ann Epidemiol. 2012; 22(10):717-22.

151. Kivimäki M, Lawlor DA, Smith GD, Elovainio M, Jokela M, Keltikangas-Järvinen L, et al. Association of age at menarche with cardiovascular risk factors, vascular structure, and function in adulthood: the Cardiovascular Risk in Young Finns study. Am J Clin Nutr. 2008; 87(6):1876-82. 


\section{Bibliografía}

152. Revilla A, Fernandez-Urbón A, San Norberto EM, Martín-Pedrosa M, Taylor J VC. Terapia de disfunción sexual en pacientes vasculares. Angiologia. 2014; 66:91-4.

153.Schunkert H, Danser AH, Hense HW, Derkx FH, Kürzinger S, Riegger GA. Effects of estrogen replacement therapy on the renin-angiotensin system in postmenopausal women. Circulation. 1997; 95(1):39-45.

154.Raffetto JD, Qiao X, Beauregard KG, Khalil RA. Estrogen receptor-mediated enhancement of venous relaxation in female rat: Implications in sex-related differences in varicose veins. J Vasc Surg. 2010; 51(4):972-81.

155. Iannuzzi A, Panico S, Ciardullo A V., Bellati C, Cioffi V, Iannuzzo G, et al. Varicose veins of the lower limbs and venous capacitance in postmenopausal women: Relationship with obesity. J Vasc Surg. 2002; 36(5):965-8.

156.Aguilar-Ferrándiz ME, Castro-Sánchez AM, Matarán-Peñarrocha GA, de Dios Luna J, Moreno-Lorenzo C, Del Pozo E. Evaluation of pain associated with chronic venous insufficiency in Spanish postmenopausal women. Menopause. 2015; 22(1):88-95.

157.Stachowiak G, Połać I, Stefańczyk L, Owczarek D, Jedrzejczyk S, Pertyński T. The impact of hormone replacement therapy applied in women with varicose vein on changes in coagulation and fibrinolysis. Pol Merkur Lekarski. 2003; 15(90):521-4.

158. Ismail L, Normahani P, Standfield NJ, Jaffer U. A systematic review and metaanalysis of the risk for development of varicose veins in women with a history of pregnancy. J Vasc Surg Venous Lymphat Disord. 2016; 4(4):518-24 


\section{Bibliografía}

159. Kasperczak J, Ropacka-Lesiak M, Musiał-Swider J, Breborowicz GH. Analysis of venous insufficiency risk factors and appearance of clinical symptoms during pregnancy and puerperium in a group of pregnant women with and without symptoms of venous insufficiency of the lower limbs. Ginekol Pol. 2012; 83(3):183-8.

160. Estevez I, Martín-Pedrosa M, Fuente R, Taylor J, Gastambide V, Gutierrez D, Vaquero C. Insuficiencia venosa pélvica. Rev Iberoam Cir Vasc. 2014; 2:41-8.

161.Ropacka-Lesiak M, Kasperczak J, Breborowicz GH. Risk factors for the development of venous insufficiency of the lower limbs during pregnancy--part 1. Ginekol Pol. 2012; 83(12):939-42.

162.Sparey C, Haddad N, Sissons G, Rosser S, de Cossart L. The Effect of Pregnancy on the Lower-limb Venous System of Women with Varicose Veins. Eur J Vasc Endovasc Surg. 1999; 18(4):294-9.

163. McCausland AM, Hyman C, Winsor T, Trotter AD. Venous distensibility during pregnancy. Am J Obstet Gynecol. 1961; 81(3):472-9.

164. Nabatoff RA. Varicose Veins of Pregnancy. JAMA. 1960, 26; 174(13):1712-6.

165.Jukkola TM, Mäkivaara LA, Luukkaala T, Hakama M, Laurikka J. The effects of parity, oral contraceptive use and hormone replacement therapy on the incidence of varicose veins. J Obstet Gynaecol (Lahore). 2006; 26(5):448-51.

166.Dijkstra ML, Khin NY, Coroneos JC, Hazelton S, Lane RJ. The effect of pregnancy on venous valve repair to the sapheno-femoral junction for varicose veins. Obstet Med Med Pregnancy. 2014; 7(2):84-9.

167. Bamigboye AA, Hofmeyr GJ. Interventions for leg edema and varicosities in pregnancy. Eur J Obstet Gynecol Reprod Biol. 2006 Nov; 129(1):3-8. 


\section{Bibliografía}

168.Smyth RMD, Aflaifel N, Bamigboye AA. Interventions for varicose veins and leg oedema in pregnancy. Cochrane Database of Systematic Reviews 2015, Issue 10. Art. No.: CD001066.

169.Estévez-Fernández I, San-Norberto-García EM, Brizuela-Sanz JA, Sánchez AF, Taylor JH, Vaquero-Puerta C. Relación entre la historia reproductiva femenina y la aterosclerosis carotídea. Angiología. 2014; 66(4):163-72.

170.Parra WG, Guillermo W. Calidad de vida en pacientes con insuficiencia venosa crónica en el servicio de angiología y cirugía vascular del Hospital Luis Vernaza. Ecuador. 2015.

171. Howlader MH, Coleridge Smith PD. Symptoms of chronic venous disease and association with systemic inflammatory markers. J Vasc Surg 2003; 38(5):950-4.

172. Shamiyeh A, Schrenk P, Wayand WU. Prospective trial comparing bilateral and unilateral varicose vein surgery. Langenbeck's Arch Surg. 2017; 387(11-12):4025.

173. Defty C, Eardley N, Taylor M, Jones DR, Mason PF. A Comparison of the Complication Rates Following Unilateral and Bilateral Varicose Vein Surgery. Eur J Vasc Endovasc Surg. 2008; 35(6):745-9.

174. Rivlin E, Haddad M, Landau O, Nudelman I, Zelikovski A. Bilateral versus unilateral high ligation and stripping of the greater saphenous vein for varicose veins. Vasa. 1991; 20(3):267-9.

175. Wrona M, Jöckel K-H, Pannier F, Bock E, Hoffmann B, Rabe E. Association of Venous Disorders with Leg Symptoms: Results from the Bonn Vein Study 1. Eur J Vasc Endovasc Surg. 2015; 50(3):360-7. 


\section{Bibliografía}

176.Amsler F, Rabe E, Blättler W. Leg Symptoms of Somatic, Psychic, and Unexplained Origin in the Population-based Bonn Vein Study. Eur J Vasc Endovasc Surg. 2013; 46(2):255-62.

177.Paul JC, Pieper B, Templin TN. Itch: association with chronic venous disease, pain, and quality of life. J Wound Ostomy Continence Nurs. 2011; 38(1):46-54.

178. Duque MI, Yosipovitch G, Chan YH, Smith R, Levy P. Itch, pain, and burning sensation are common symptoms in mild to moderate chronic venous insufficiency with an impact on quality of life. J Am Acad Dermatol. 2005; 53(3):503-7.

179. Van der Velden SK, Shadid NH, Nelemans PJ, Sommer A. How specific are venous symptoms for diagnosis of chronic venous disease? Phlebology. 2014, 3; 29(9):580-6.

180. Nelzen O, Bergqvist D. Venous and non-venous leg ulcers: Clinical history and appearance in a population study. Br J Surg. 1994; 81: 182-7.

181. Nelzen O, Bergqvist D, Lindhagen A. The prevalence of chronic lower-limb ulceration has been underestimated: results of a validated population questionnaire. Br J Surg. 1996; 83(2):255-8. 
10. ANEXO 



\subsection{LISTADO DE ACRÓNIMOS}

- $\mathbf{A M H}$ : Hormona Antimuleriana

- AOC: Anticonceptivos Orales Combinados

- CEAP: Clínica, Etiología, Estadio anatomopatologico, Patofisiología

- CSVS: Sistema Venoso Cerebro Espinal

- DE: Desviación Estándar

- DM: Diabetes Mellitus

- EPOC: Enfermedad Pulmonar Obstructiva Crónica

- EVC: Enfermedad Venosa Crónica

- EVLA: Ablación Endovenosa con Láser

- FSH: Hormona Estimuladora del Folículo

- Hb: Hemoglobina

- HFE: Hemocromatosis

- HTA: Hipertensión Arterial

- HTV: Hipertensión Venosa

- IQ: Intervención Quirúrgica

- INR: Ratio Internacional Normalizada

- IVC: Insuficiencia Venosa Crónica

- LH: Hormona Luteinizante

- MTHFR: Metilentetrahidrofolato Reductasa

- NOS: Óxido Nítrico

- PRL: Prolactina

- RFA: Ablación con Radiofrecuencia 
- ROC: Característica Operativa del Receptor

- SEACV: Sociedad Española de Angiología y Cirugía Vascular

- SEMFYC: Sociedad Española de Medicina Familiar y Comunitaria

- TA: Tensión Arterial

- THS: Terapia Hormonal Sustitutiva

- TSH: Hormona Estimulante de la Tiroides

- TTPA: Tiempo de Tromboplastina Parcial Activado

- TVP: Trombosis Venosa Profunda

- UGFS: Escleroterapia con Espuma Guiada por Ultrasonido

- VEGFA: Factor de Crecimiento del Endotelio Vascular 

